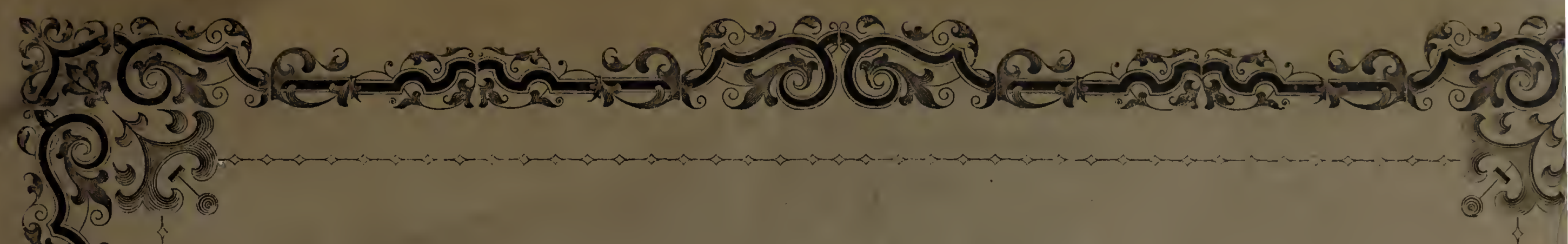

\title{
ELECTRISCHE ORGAN
}

DES

\section{ZITTER WELSES}

ANATOMISCH BESCHRIEBEN

VON

\section{THEODOR BILHARZ,}

\section{PROFESSOR DER ANATOMIE AN DER MEDICINISCHEN SCHULE IN TIAIRO.}

MIT 4 LITHOGRAPHIR'TEN TAFELN

\section{LEIPZIG,}

VERLAG VON WILHELM ENGELMANN

1857.

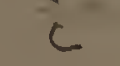


DAS

\title{
ELECTRISCHE ORGAN
}

\author{
D ES
}

\section{ZITTER WELSES}

\author{
ANATOMISCH BESCHRIEBEN
}

VON

$D^{R .}$ THEODOR BILHARZ,

PROFESSOR DER ANATOMIF AN DER MEDICINISCIHEN SCHULF IN KAIRO.

LEIPZIG,

VERLAG VON WILHELM ENGELMANN.

1857. 

SEINEM THEUERN LEHRER

\section{FRIEDRICH ARNOLD}

IN HOHER VEREHRCNG UNI) DANKBARKEIT

DER VERFASSER。 



\section{VORWORT.}

Indem ich vorliegende Schrift meinen Fachgenossen jenseits des Nocres übergebe, habe ich derselben nur weniges in's Wanderbüchlein zu schreiben. Sie enthält dic Ergebnisse einer im Norember 1852 begonnenen, und, mit Unterbrechungen durch Berufsgeschïfte und Mangel an Material, bis Mai 1856 fortgeführten Reihe von Untersuchungen. Uie Zahl der dazu rerwendeten Exemplare übersteigt 100, und es dürfte sich kaum eine Angrbe finden, dic nicht auf wicderholte Revision gestützt wäre. - Bei Beurtheilung der Mängel der Arbcit wird man billig in Anschlag bringen, dass die zu diesen zeitraubendon und mühsamen Untersuchungen erforderliche Musse vielen, und manchmal allzu vielartigen Berufsgeschäten abgewonnen werden musste; - dass dieselben zum grössten Theile unter den tausend Ärgerlichkeiten ägyptischer Sommermonate zu Stande kamen; - endlich dass der Verfasser seit bald 6 Jahren auf cinem Vorposten steht, wo der gewaltige Wellenschlag der heutigen doutschen Wissenschaft nur in gebrochenen und abgeschwiichten Schwingungen sich fühlbar macht.

Es ist mir eine angenehme Pflicht, einigen hochgeschïtrten Freunden, die auf die Lintwicklung meiner Arbeit fördernden Einfluss übten, meinen wïrmsten Dank auszusprechen : vor allen Herrn Professor Eckm in Freiburg, der mich durch Anregung, Rath und Mittheilung literarischer Hilfsmittel auf́s kräftigste unterstützte, ferner Her'n Dr. Marcuser in St. Petersburg, dem ich die unnittelbare Einführung in den Gegenstand zu rerdanken hatte, und Herrn Dr. Dianaxtr in Kairo, welcher mir die wichtigen Schriften I'Acrvis zur Verfügung 
stelltc. Ich kann nicht unterlassen, mein Bedaucrn darüber auszusprechen, dass letzterer (ein Schüler Matreuccr's) die Ergebnisse seiner, vor Jahren am Zitterwelse angestellten physiologischen Untersuchungen nicht veröffentlicht hat.

Endlich ergreife ich eine längst erschnte Gelegenheit, meinen tief gefühlten Dank dem Manne öffentlich darzubringen, welcher cinst, durch die grossartige Plastik seiner anatomischen Vorträge, wie durch dic anregende Einwirkung seincr Persönlichkeit im Präparirsaale und am Microscop-'Tische, das Grubenlicht der anatomischen Forschung mir angezündet hat.

Kairo im .Juni 1856.

Der Verfasser. 
I N H A L T.

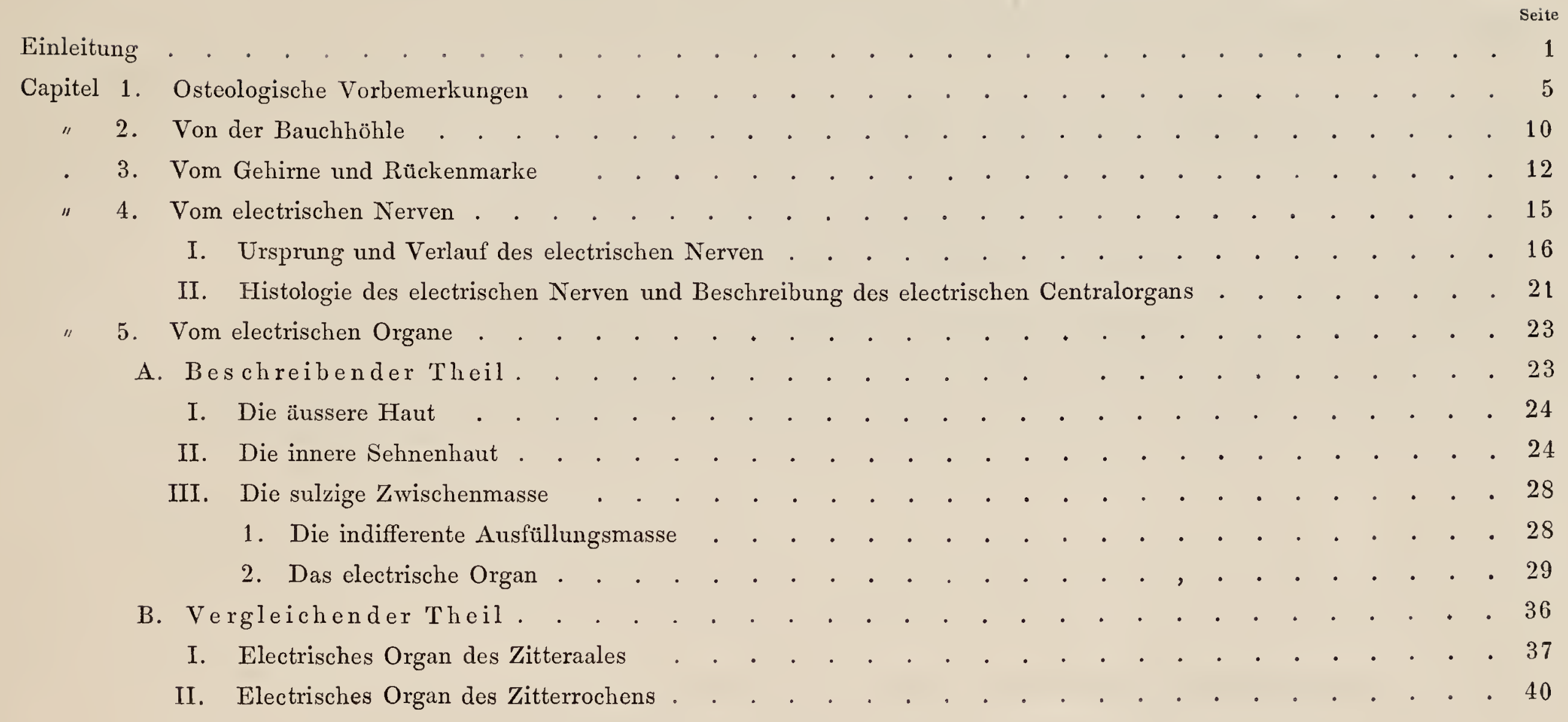





\section{EINLEITUNG.}

Der Zitterwels (Silurus electricus L. Malapterurus electricus Lacepède) scheint ein Bewohner aller Ströme, deren Quellengebiet dem tropischen Africa angehört, zu sein. Er wurde beobachtet: im Nil (von vielen Berichterstattern), im Senegal (von Adansox), im Zaire (von Tucker), endlich in einem Nebenflusse des Zambeze (von Peters).

Bei Kairo ist der Zitterwels einer der häufigeren Fische. Doch ist sein Erscheinen auf dem Fischmarkte nach den Jahreszeiten sehr verschieden, ein Umstand, dẻr hauptsächlich auf der grösseren oder geringeren Schwierigkeit seines Fanges beruhen dürfte. Am häufigsten ist er im November, also zu der Zeit, wo der in seine Ufer zurücktretende Strom eine Menge allmälig vertrocknender Pfützen und Lachen zurücklässst. Vom December bis März, wo das Strombett mit einer stattlichen Wassermasse gefüllt ist, erscheint er selten, und wird mit steigender Häufigkeit zwischen März und Juni, mit abnehmender zwischen Juni und August gefangen. Zur Zeit des höchsten Nilstandes (August, September, October) ist er wieder selten.

Seine Laichzeit fällt in den Monat Juli.

Die grössten von mir beobachteten Exemplare hatten eine Länge von $21-24$ 1/2" und ein Gewicht von 8-10 Pfunden.

Der Zitterwels gehört unter die schmackhafteren Nilfische, ist aber dessenungeachtet nicht sonderlich gesucht. Dagegen gilt er bei den Eingeborenen als Mittel gegen das Wechselfieber (similia similibus!). Es werden zu diesem Zwecke Stücke der Hautschwarte (electr. Organ) verspeist.

Sein arabischer Name ist raād, d. i. der "Zitterer ("), ein Name, der auch an der Küste des rothen und mittelländischen Meeres für den Zitterrochen in Gebrauch ist. FonsKå nennt ihn raāsch, was dieselbe Bedeutung hat, aber wenigstens in Kairo nicht üblich ist.

Da ich über die noch sehr wenig bekannte Naturgeschichte dieses Fisches nichts Neues beizubringen habe, und eine zoologische Beschreibung überflüssig wäre, so gehe ich ohne weiteres zur Darstellung unserer Kenntnisse über den Bau des electrischen Organes des Zitterwelses über.

Aus dem Alterthume werden uns fast keine Nachrichten über den Zitterwels überliefert. Alles beschränkt sich auf eine Stelle des Athenaeus ***), welcher angibt, dass unter den Nilfischen die "vé@ærn " der schmackhafteste sei.

*) Der Umstand, dass mit diesem Ausclrucke auch der Donner - der himmlische Zitterer - belegt wird, gibt GEoffRor ST. Hrldire Veranlassung, das Ahnungsvermögen des arabischen Volkes zu bewundern, welches die Entdeckung lirixkLrs's und Vouta's anticipirt habe!

i.) Deipnosophist. L. VII. c. 173. 
Bei den alten Aegyptern, welche doch auf Naturerscheinungen so aufmerksam waren, und unter ihren hieroglyphischen und heiligen Thieren manche Fische hatten, scheint der Zitterwels keine Rolle gespielt zu haben. Er findet sich auf den alten Denkmälern nur selten abgebildet bei Darstellungen des Fischfanges $*$ ).

Die erste Beschreibung der electrischen Wirkung des Zitterwelses gibt der arabische Arzt ABD-ELLATIF in seiner bekannten Beschreibung Aegyptens**). Dass er wirklich unseren Fisch und nicht etwa den mit demselben arabischen Namen bezeichneten Zitterrochen meint, geht daraus hervor, dass er sagt: " seine Haut ist fingerdick und lässt sich sehr leicht ablösen."

Adanson und ForskaiL, unter den neuern Naturforschern die ersten, welche die electrischen Eigenschaften unseres Fisches beschrieben haben, theiłen nichts Anatomisches mit.

Broussonet***) gibt nur eine kurze Notiz: "la peau qui recouvre cette partie "(sc. la queue), "nous a paru beancoup plus épaisse, que le reste du corps« (vielmehr: que celle d.r.d.c.), net nous y avons bien distingué un tissu particulier, blanchâtre et fibreux que nous avons pris pour les batteries du poisson."

Geoffroy St. Hilaire, welcher vor den meisten seiner Nachfolger den Vortheil voraus hatte, frische Exemplare untersuchen zu können, gibt eine ausführliche und, was das electrische Organ, seine allgemeine Anordnung und gröbern Structurverhältnisse betrifft, grösstentheils richtige Beschreibung †). Er sagt: „Ce n'est pas sur les côtés de la tête, comme dans la torpille, ni au dessous de la queue, comme dans le gymnote engourdissant, que se trouve l'organe electrique dans le silure trembleur: il est étendu tout autour du poisson. Il existe immédiatement au dessous de la peau et se trouve formé par un amas considérable de tissu cellulaire tellement serré et épais qu'au premier aspect on le prendrait pour une couche de lard: mais quand on y regarde de plus près, on s'aperçoit, que cet organe est composé de véritables fibres tendineuses et aponévrotiques qui s'entrelacent les unes dans les autres, et qui, par leurs différents entrecroisements, forment un réseau dont les mailles ne sont distinctément visibles qu’à la loupe. Les petites cellules ou alvéoles de ce réseau sont remplies d’une substance albumino-géla tineuse; elles ne peuvent communiquer à l'intérieur à cause d’une très-forte a ponévrose, qui s'étend sur tout le réseau électrique et qui y adhère au point qu'on ne peut le séparer sans le déchirer: d'ailleurs cette aponévrose tient seulement aux muscles par un tissu cellulaire rare et peu consistant."

Geoffroy St. Hilanre irrt darin, dass er die Hautschwarte des Zitterwelses in ihrer ganzen Ausdehnung für das electrische Organ in Anspruch nimmt und die Scheidung des Organes in zwei Hälften übersehen hat.

Den electrischen Nerven hält er für den $N$. lateralis vagi, was, wie unten gezeigt werden wird, nicht richtig ist.

Rudoupnt + ) berichtigt nach Untersuchungen an Weingeistexemplaren Georrroy's irrige Angabe über die Ausdehnung und Ungetheiltheit des electrischen Organes. Es sei nicht ein einziges Organ, welches

*) Dic ältcstc — sehr kenntliche! - bildliche Darstellung des Zitterwclses dürftc diejenige scin, welchc in den Basrclief's einer Grabkammer bei Saqāra (Gr. Nro. 15. bei LEsstus), unter andern, trefflich gczeichneten, Nilfischen, sich findct. (Vcrgl. Lepsius Denkmäler aus Aegypten und Aethiopien, II. Abthcilg. Blatt 46.)

**) Relation de l'Egypte par ÄBD-AritATrF, médecin arabe de Bagdad, traduit par Sylvestre de Sacy. Paris. 1810. pag. 145

***) Mémoircs de l'académie des sciences de Paris pour 1782.

t) Annales du Muséum d'histoire naturelle. Tom. I. 1802. p. 401, abgedruckt in der: Description de l'Egypte, edit. Panckoucke, Tom. 24.p. 304

†) Abhandlungen der K. Academie der Wissenschaften zu Bcrlin. 1821. pag. 139. 
den ganzen Fisch umhülle, sondern ein rechtes und ein linkes, die, sowol am Rücken, als am Bauche durch eine sehnige Scheidewand*) getrennt seien. Nach vorn erstrecke sich " die zellige Haut " (d. i. der das electrische Organ ausmachende Theil der Hautschwarte) "unten bis an die Kiemen, o ben aber mit einem rundlich auslaufenden Fortsatz über die Armflosse und den hintern obern Theil des Kopfes bis zum Auge hin." Nach hinten gehe die Haut freilich anscheinend bis zur Schwanzflosse, allein nur bis etwas hinter die Bauchflosse behalte sie ihr zelliges Wesen und daselbst sehe man blos eine sehnige Hant. Die Form der Zellen des Organes in Durchschnitten beschreibt er als eine länglich rhombische. Sonst fügt Rudolphr's ziemlich unklare Beschreibung der Georfror'schen nichts wesentlich Neues hinzu.

Die in der angegebenen Weise sich ergänzenden Angaben beider Schriftsteller geben ein gedrängtes. aber richtiges und ziemlich vollständiges Bild von der allgemeinen Anordnung und den gröberen Structurverhältnissen des electrischen Organes des Zitterwelses.

Dagegen brachte RudoLpH einige Verwirrung, indem er das zwischen dem electrischen Organe (resp. dessen sehnigem Ueberzuge) und der Musculatur des Rumpfes und Schwanzes gelegene Bindegewebe als eigene, von GEoffroy (der es mit den Worten: "tissu cellulaire rare et peu consistant " deutlich, aber als zu unbedeutend dargestellt hatte) angeblich übersehene Haut (»flockige Haut ") aufstellte und darin ein zweites, inneres electrisches Organ zu erkennen glaubte.

VALEnciennes ***) vermehrte diese Verwirrung, indem er die "flockige Haut "Rudolphi's durch "Laceration und Maceration " erst in zwei, dann in sechs und mehr Blätter zerlegte, was nach der histologischen Natur dieser angeblichen Haut nicht überraschend ist. Sonst enthält VaLenciennes' Beschreibung nichts Neues. Er hat ebenfalls nur Weingeistexemplare benutzt.

Peters ***) widerlegte nach Untersuchungen an frischen Exemplaren den Irrthum Rudolphi's und Valenciennes' und wies nach, dass die, zwischen dem electrischen Organe (resp. seiner Aponeurose) und den Muskeln gelegene Schicht nichts anderes sei, als ein laxes Zellgewebe. Dagegen bestreitet er mit Unrecht Rudot.PHI's Angaben über die Abgrenzung und bilaterale Scheidung des electrischen Organes und kehrt wieder zur Geofrroy'schen Ansicht von einem einzigen, über den ganzen Körper ausgebreiteten Organe zurück. Wemn ferner Peters im Widerspruche mit Geofrroy St. Hilarne zwischen Haut und electrischem Organe eine besondere Fascie annimmt und im Widerspruche mit Pacisi dem Organe am Bauche die grösste Dicke gibt: so muss ich mich auf Seite der letzteren Schriftsteller stellen. Peters gibt endlich die erste histologische Notiz über die feineren Bestandtheile des electrischen Organes. Man gewahre mit dem Microscop eine äusserst feine Haut, die sich leicht in feine Fältchen lege. welche man nicht mit Fasern verwechseln dürfe, und zweitens runde microscopische Körperchen, die eine gallertartige Masse zusammensetzen.

Cuvier-Duvernox $\dagger$ ) erwähnen einer, die Muskeln des Rumpfes und Schwanzes unmittelbar bedeckenden, dicken Fettschicht und schreiben derselben eine isolirende Bedeutung zu. Sie irren dabei

\footnotetext{
*) Diese Scheidewand dringt jedoch nicht, wie Rudolpmi angibt, bis zu den Muskeln hinein, sondern geht nur ron der Haut zur Aponeurose.

***) Arehives du Muséum d'histoire naturelle. Tom. II. 1\$41. pag. 59, und Annales des sciences naturelles. 2mme série.
} Tom. 14. 1840. pag. 243.

*****) Müller's Archiv f. Anat. u. Phys. 1\$45. p. 375.

†) Leçons d'anatomio eomparée. Tom. VIII. 1\$46. pag. 697. 
in sofern, dass sie diese Fettschicht unmittelbar unter der Aponeurose des electrischen Organes gelegen sein lassen und die zwischen beiden eingeschobene Bindegewebeschicht übersehen. Die Dicke des Organes beträgt nach ihnen im vorderen Theile seiner Ausbreitung $4-5 \mathrm{~mm}$, und nimmt nach hinten zu allmälig ab.

PACrNI $\left.{ }^{*}\right)$ gibt nach Untersuchungen an Weingeistexemplaren eine ausführlichere Beschreibung der electrischen Werkzeuge unseres Fisches, die durch Genauigkeit und Klarheit ausgezeichnet ist. Er schildert zuerst in sehr anschaulicher Weise die Lageverhältnisse und Verbindungen des electrischen Organes, welches er, mit dessen beiden Uberzügen zusammen, als: "sacco fibro-elettro-cutaneo " bezeichnet, dessen Grenzen er aber weniger genau, als Rudolphi, angibt. Ferner setzt er die beiden zwischen dem Organe und den Muskeln gelegenen Schichten: Bindegewebeschicht und Fettschicht zuerst in ihr richtiges Verhältniss. Was die Structur des Organes selbst betrifft, so findet er es aus kleinen Hohlräumen zusammengesetzt, deren Gestalt sich auf die eines Octa ëders zurückführen lasse und deren Weite ungefähr einen Cubikmillimeter betrage. Die Wände dieser Hohlräume bestehen nach ihm aus Zellgewebsfibrillen und innerhalb derselben sah er viele Kerne, die ihm das Vorhandensein eines Epitelium's wahrscheinlich machen.

Pacini widerlegt ferner die bisher allgemein angenommene Angabe Geoffroy St. Hiraire's, dass der electrische Nerv ein Ast des $N$. vagus, und zwar der Ramus lateralis $N$. vagi, sei. Er erklärt denselben für den ersten Rückenmarksnerven. Fr verlasse die Rückenmarkshöhle zwischen dem ersten Wirbel und dem Schädel und besitze daselbst ein grosses Intervertebralganglion, in welchem er das electrische Centralorgan vermuthet.

Marcusen **) berichtigte durch, an frischen Exemplaren angestellte Untersuchungen, Pacini's Angaben über den electrischen Nerven. Auch er betrachtet den electrischen Nerven als ersten Rückenmarks nerven und fand die Wurzeln, aus denen er zu entstehen schien, gleich nach dem Austritt aus dem Wirbelkanale zu einem Spinalganglion vereinigt. Er überzengte sich aber, dass der electrische Nerv isolirt durch das Ganglion trete, und dass letzteres von ihm abpräparirt werden könne. Murcusen hat ferner der Erste die histologischen Verhältnisse des Nerven untersucht. Er fand ihn mit einer Menge von Häuten umgeben, an und für sich sehr dünn, und mit der Eigenthümlichkeit, einen „Centralkanal « zu besitzen. (Dieser "Centralkanal " erwies sich in der Folge als eine einzige, sehr breite Primitivfaser). Endlich machte Marcusen auf das grobe Maschenwerk im Innern der Fettflosse und in der, den vorderen Theil des Kopfes überziehenden Schwarte aufmerksam.

Die Hauptresultate meiner, im November 1852 begonnenen Untersuchungen wurden vom Herrn Professor Ecker in Freiburg nach brieflichen Mittheilungen veröffentlicht****).

*) Sopra l'organo elettrico del Siluro elettrico del Nito, comparato a quello della Torpedine e del Gimnoto, e sull apparecchio di Webcr nel Siluro, comparato a quello dei Ciprini. Bologna 1846. (Annali delle scienze naturali; Luglio 1846.)

**) I. Nachrichten von der G. A. Universität und der Königl. Gesellschaft der Wissenschaften zu Göttingen. April 1853. p. 65.

II. Vorläufige Mittheilung aus einer Abhandlung übcr die Familie der Mormyren. (Aus den : Mélanges biologiques. Tom. II. pag. 46. St. Petersburg).

III. Mitthcilung über das electrische Organ des Zitterwelses (Bulletins de la classe phys. math. de l'Académie impériale de St. Pétersbourg. 1853).

***) Göttinger Nachrichten 1853. Nro. 9. Berichte über die Verhandlungen der Gesellschaft für Bcförderung der Naturwissenschaften zu Freiburg i/Br. Nr. 1. 2. 5. 11. 


\section{Capitel I.}

\section{Osteologische Vorbemerkungen.}

Auf eine Beschreibung des ganzen, durch manche Eigenthümlichkeiten ausgezeichneten Skeletes, welches durch Geoffroy St. Hilatre, Cuvier, Joh. Mülder und Pacini nur fragmentarisch bekannt geworden ist, werde ich mich hier nicht einlassen, um so weniger, als mein Freund Dr. Marcusen eine Arbeit über die vergleichende Osteologie der Siluriden mit besonderer Berücksichtigung des Zitterwelses vorbereitet hat. Ich beschränke mich auf diejenigen Theile des Skeletes, welche zum electrischen Nerven in näherer Beziehung stehen, nämlich: den vordersten Theil der Wirbelsäule.

Die Wirbelsäule des Zitterwelses besteht aus 42 Wirbeln, von welchen 23 dem Schwanze, 19 dem Rumpfe angehören. Von den ersteren sind 3 an der Bildung der die Schwanzflosse tragenden Platte betheiligt. Die Rumpfwirbel sind, mit Ausnahme der 3 ersten und der 3 letzten, rippentragend.

Die 4 vordersten Wirbel sind, wie bei vielen andern Siluriden, unter sich und mit dem Schädel (Os occipitale) sehr innig verbunden. Doch fand ich selbst bei den grössten Exemplaren niemals wahre, knöcherne Verwachsungen dieser Theile, wie sie bei manchen andern Welsen (z. B. Synodontis, wo die einzelnen Wirbel nicht mehr zu unterscheiden sind) vorkommen, sondern grosszahnige, fest in einander gekeilte Suturen.

Diese Nahtverbindungen bestehen besonders zwischen den Wirbelkörpern und zwar deren Rindensubstanz, während im Innern die Intervertebralhöhle vorhanden ist. Seltener erstreckt sich die Verwachsung auch auf die Bogentheile.

Die vorderen Wirbel zeigen in Bezug auf Form, Grösse und Bestandtheile beträchtliche Abweichungen von dem gewöhnlichen Baue und zwar um so mehr, je weiter nach vorn sie gelegen sind.

\section{Sechster Wirbel.}

Er unterscheidet sich von den weiter nach hinten gelegenen Rumpfwirbeln nur durch den höheren Ursprung der unteren Bogenschenkel. Dieselben entspringen nicht wie dort aus dem unteren Drittheile der Höhe des Wirbelkörpers, sondern aus deren Hälfte.

\section{Fünfter Wirbel. (Tab. I. Fig. 2. $W^{s}$.)}

Hier entspringt der untere Bogenșchenkel $\left(u^{5}\right)$ im oberen Drittheile der Höhe des Körpers. Ausserdem ist die Spitze des Dornfortsatzes $\left(d^{5}\right)$. mit dem Dornstücke des 2ten Wirbels $\left(D^{2}\right)$ durch Bandmasse verbunden. 
3. Vierter Wirbel. (Tab. I. Fig. 2. $W^{4}$.)

Beim vierten Wirbel ist die Ursprungsstelle des unteren Bogenschenkels $\left(u^{4}\right)$ noch höher gerückt. Derselbe entspringt aus der höchsten Stelle des Wirbelkörpers, nahe der Ursprungsstelle des oberen Bogenschenkels, mit dem er durch eine Knochenbrücke in Verbindung steht. Die Bauchfläche des Körpers zeigt nach vorn jederseits eine tiefe Grube zur Aufnahme eines entsprechenden Knochenfortsatzes des 3ten Wirbelkörpers, und nach hinten jederseits einen kurzen Fortsatz, der das vordere Ende des 5ten Wirbelkörpers bedeckt. Die Spitze des Dornfortsatzes $\left(d^{4}\right)$ ist ebenfalls mit dem Dornstücke des 2 ten Wirbels $\left(D^{2}\right)$ durch Bandmasse verbunden.

\section{Dritter Wirbel. (Tab. I. Fig. 1. 2. $W^{3}$.)}

Die Eigenthümlichkeiten des dritten Wirbels berwhen hauptsächlich auf seiner festen Vereinigung mit dem zweiten Wirbel. Diese Vereinigung durch grosszahnige Nähte findet an allen Punkten, wo die beiden Wirbel sich berühren, statt. In der That erkennt man erst nach genauerer Untersuchung, dass man es mit zwei vereinigten, nicht mit einem einzigen Wirbel zu thun hat. Die beide Körper trennende Intervertebralhöhle fehlt nie, ist aber gewöhnlich von den in einander gekeilten Zacken der Rindensubstanz so verdeckt, dass sie ohne Abtragung der letztern nicht oder nur an einer kleinen Stelle sichtbar ist (Fig. 2). Nach hinten und unten ist der Körper des dritten Wirbels jederseits in einen starken Zapfen ausgezogen, welcher in die entsprechende Grube des 4 ten Wirbels eingreift. Der Ursprung des unteren Bogenschenkels ist so weit in die Höhe gerückt, dass er mit der Wurzel des oberen Bogenschenkels verschmolzen ist und beide erst eine Strecke weit nach ihrem Ursprunge sich trennen. Der falsche Querfortsatz (untere Bogenschenkel) (Fig. 1. 2. $\left.u^{3}\right)$ trägt keine Rippe und ist an seiner Basis mit dem des 2 ten Wirbels $\left(u^{2}\right)$ durch Naht verbunden. Der Dornfortsatz $\left(d^{3}\right)$ ist klein und mit dem Dornstücke des 2 ten Wirbels $\left(D^{2}\right)$ verbunden. Vordere Gelenkfortsätze fehlen, entsprechend der Unbeweglichkeit des Wirbels nach dieser Seite.

\section{Zweiter Wirbel. (Tab. I. Fig. 1. 2. $W^{2}$, Fig. 3.)}

Der zweite Wirbel ist nicht allein durch Grösse und Form vor allen übrigen Wirbeln ausgezeichnet, sondern auch mit einem Gebilde versehen, welches nicht auf die wesentlichen Wirbelelemente zurückgeführt werden kann : - dem von Johandes MüLler so genannten Springfederfortsatz.

Der Körper des zweiten Wirbels ist merklich höher und doppelt so lang, als die übrigen Wirbelkörper des Rumpfes, dagegen weniger breit und seitlich zusammengedrückt. Seine untere Fläche enthält eine tiefe Rinne, welche nach vorn zu einer Grube wird, die in die Substanz des Wirbelkörpers eindringt, sich dort gabelig spaltet und jederseits im oberen Theile der Seitenfläche des Körpers ausmündet. Dieser gabelige Kanal und die ihn fortsetzende Rinne sind zur Aufnahme der Aorta bestimmt. - Die Verbindung des zweiten Wirbelkörpers mit dem dritten wurde oben beschrieben. Aehnlich, doch minder fest, ist seine Verbindung mit dem ersten Wirbelkörper. Dort hat die Verzahnung nur an der unteren Hälfte des Wirbelkörpers statt (Fig. 2, Fig. 3.z.), während nach oben hin die Ränder der beiden Wirbel sich einfach aneinanderlegen.

Die untern Bogenschenkel oder Querfortsätze $\left(u^{*}\right)$ entspringen aus der hintern Hälfte des Wirbelkörpers in dessen höchster Stelle, den oberen Bogenschenkeln so nahe, dass beide Gebilde dort verschmolzen sind und sich erst nachher trennen, indem die crsteren nach aussen, die letzteren nach innen treten. Der untere Bogenschenkel verwächst an seinem Hinterrande, wie oben beschrieben. eine Strecke 
weit mit dem vorderen Rande des entsprechenden Gebildes des 3ten Wirbels, trennt sich dann und endigt in einer horizontalen Ausbreitung von unregelmässiger Form (Fig. 1. 3. $\left.u^{2}\right)$.

Die oberen Bogenschenkel $\left(o^{2}\right)$ entspringen aus der höchsten Stelle des Wirbelkörpers, seiner ganzen Länge nach; hinten mit den untern Bogenschenkeln gemeinschaftlich, vorn für sich allein. Durch ihre baldige Vereinigung bilden sie über der Rückenmarkshöhle und dem Längsbande ein geschlossenes, horizontal von vorn nach hinten laufendes, vorne etwas nach aufwärts gebogenes Dach, welches zugleich durch zwei von seinen Seiten sich erhebende Längsleisten zum Boden einer Rinne wird (Frg. 1. v.). Das hintere und vordere Ende des Daches liegt in gleicher Linie mit dem hinteren und vorderen Ende des Wirbelkörpers. - Nach hinten ist der Bogentheil in ein Paar schief aufwärts laufender Spitzen ausgezogen (Fig. 1. 2. $o^{2}$ ), die sich aber nicht zum Dornfortsatze vereinigen, sondern getrennt endigen und deren Hinterrand mit dem vorderen Rande der oberen Bogenschenkel des 3ten Wirbels durch Naht verbunden ist. Gelenkfortsätze sind daran ebenfalls nicht zu unterscheiden. - Nach vorn ist der Bogentheil ebenfalls in zwei Spitzen $\left(g^{2}\right)$ ausgezogen, welche aber die hinteren an Grösse bedeutend übertreffen. Dieselben gehen aus dem Bogentheile mit breiter Basis und ohne deutliche Grenze hervor und erstrecken sich, aufwärts gekrümmt und schmäler werdend, bis zum $O s$ occipitale superius, dessen nach hinten gerichteten Dorn sie zwischen sich fassen. Ihr stumpfes Ende legt sich in zwei zu beiden Seiten des Dornes gelegene Vertiefungen dęs Os occipitale superius. Die Ränder des Fortsatzes sind mit den betreffenden Punkten des Os occipitale superius durch Bandmasse vereinigt. Was die morphologische Bedeutung dieses Fortsatzes betrifft, so scheint er nichts anderes zu sein, als ein bedeutend vergrösserter vorderer Gelenkfortsatz. Der durch den Dorn des Os occipitale superius nicht ausgefüllte Raum zwischen beiden Schenkeln des beschriebenen Fortsatzes wird von einem kleinen Knochenstücke eingenommen (Fig. 1., 2. $D^{1}$.), welches unten beschrieben werden soll.

Der Springfederforts atz war schon Georfroy St. Hilaire bekannt, der ihn in einer sehr mangelhaften Zeichnung dargestellt*), aber nicht beschrieben hat. Das Verdienst, diesen Fortsatz zuerst beschrieben, dessen physiologische Bedeutung und dessen Verbreitung in der Gruppe der Siluriden zuerst nachgewiesen zu haben, gebührt JoHannes MÜLLER***). Endlich gibt auch PACINI ${ }^{*} * * *$ ) eine kurze Beschreibung dieses Fortsatzes. Johannes MüLler erklärt den Springfederfortsatz für einen Theil des ersten Wirbels; nach PAcinı wird er von den Querfortsätzen der beiden ersten Wirbel gebildet. Beide Beobachter scheinen den unscheinbaren ersten Wirbel übersehen zu haben. - Es ist schwer, zu sagen, aus welchem Theile des zweiten Wirbels der Springfederfortsatz seinen Ursprung nimmt. Seine Basis ist eine breite dünne Lamelle $(f)$, welche schief von vorn und unten nach hinten und oben dem Wirbel aufsitzt, nach hinten mit der Basis des unteren Bogenschenkels verwachsen, nach vorn mit der Aussenfläche des (oberen) Wirbelbogens und Wirbelkörpers verschmolzen. Diese Basallamelle — F e d er, MüLL. — verengt sich nach aussen und theilt sich in zwei Fortsätze: einen grösseren, nach aussen gerichteten, verticalen - Platte, MüLl. - und einen kleineren, nach innen gerichteten, horizontalen : S tem mfortsatz, mihi. Die Platte (Fig. 1. 3.p.) ist'länglichrund, kreisrund oder lanzettförmig; ihre hintere Fläche meist concar, die vordere convex, seltener sind beide eben. Die hintere Fläche ist platt, die vordere besitzt nahe dem Innemrande

Description de l'Egypte Tab. XII. Fig. 3. l., und $a$ in den nummerlosen Abbildungen des Schädels.

**) Untersuchungen über die Fingeweide der Fische pag. 39. Tab. III. Fig. 1-6.

***) Sopra l'organo elettrico del siluro etc. pag. 17. 
einen kurzen knorrigen Fortsatz, welcher mit dem Schultergürtel (Os suprascapulare und Scapula) durch starke Bandmasse vereinigt ist. - Der Stemmfortsatz (Fig. 1. 3. st.) ist ein stabförmiger, ron oben nach unten abgeplatteter Fortsatz, welcher von der Verbindungsstelle der Platte mit der Feder entspringt und in horizontaler Richtung nach innen und etwas nach vorne zieht. Sein Ende ist quer abgestutzt. In dem gegenüber liegenden Basaltheile des Wirbelbogens findet sich eine Grube (Fig. 2.gr.), welche dem Ende des Stemmfortsatzes vollkommen entspricht und offenbar dazu bestimmt ist, dasselbe aufzunchmen. Zwischen beiden Theilen existirt aber nicht die geringste Verbindung, auch sind dieselben im gewöhnlichen Zustande durch einen kleinen Zwischenraum von einander getrennt und berühren sich nur dann, wenn die Platte nach vorn gedrückt wird. Hat das Ende des Fortsatzes sich in die Grube festgestemmt, so ist eine weitere Dislocation der Platte nach vorn, mithin auch eine allzu starke Spannung der Feder, nicht möglich. Ausser diesem Hauptzwecke dient der Stemmfortsatz dem Spannmuskel der Feder zum Ansatze.

\section{Dornstück des zweiten Wirbels.}

Als solches betrachte ich ein isolirtes Knöchelchen (Fig. 1, 2. $D^{2}$.) von länglicher Form, am hintern Ende breit, am vorderen zugespitzt oder gespalten, welches über den Dornfortsätzen des 3ten, 4ten und 5ten Wirbels liegt und mit deren Spitzen durch Bandmasse verbunden ist. Sein vorderes Ende schliesst sich an die nach hinten gerichteten Spitzen der oberen Bogenschenkel des 2ten Wirbels (Fig. 1. 2. $0^{\text {*. }}$ ) an und ist mit denselben durch Bandmasse im Zusammenhang.

6. Frster Wirbel. (Tab. I. Fig. 2. $W^{1}$. Fig. 4. 5.)

Der erste Wirbel scheint bisher übersehen worden zu sein, was nicht befremdet. da er nur geringe Ausdehnung besitzt und nur ein Körperstück ohne Fortsätze darstellt.

Der Durchnesser dieses Kör perstückes von vorn nach hinten (Längendurchmesser) beträgt ein Drittel bis die Hälfte eines gewöhnlichen Rumpfwirbelkörpers, ein Viertel des Körpers des zweiten Wirbels. Dem entsprechend sind seine Verbindungsflächen, die vordere sowol als die hintere, nur sehr wenig ausgehöhlt. Die untere Fläche ist nach hinten in mehre starke Knochenzähne (Fig. 5.z.) ausgezogen, welche in die entsprechenden Vertiefungen des zweiten Wirbelkörpers eingreifen; nach vorn besitzt sie selbst ähnliche Vertiefungen zur Aufnahme der Knochenzapfen des Os occipitale basilare (Fig. 4. z.). Die Seitenflächen sind glatt. Die obere Fläche zeigt nichts als einige kleine Knochenwärzchen (Fig. 4.w.), die einem rom Simus impar kommenden Sehnenbande zur Anheftung dienen.

\section{Dornstück des ersten Wirbels.}

Als solches betrachte ich einen kleinen, unpaaren Ínochen (Fig. 1. 2. 4. 5. $D^{1}$.), welcher zwischen dem Dorne des Os occipitale superius und der Spitze des vorderen Gelenkfortsatzes des zweiten Wirbels eingefügt ist (vergl. oben pag. 7). Er besteht aus einem dachförmigen Körper und zwei nach unten laufender Schenkeln. Seine vordere Fläche ist mit dem Dorne des Os occipitale superius durch Naht verbunden, die hintere ist frei. Sein oberer Rand ist nach hinten in eine Spitze ausgezogen. Der untere und vordere Theil seiner Seitenfläiche wird von den vorderen Gelenkfortsätzen des zweiten Wirbels umfasst, der obere und hintere 'Theil bleibt unbedeckt. Der Raum zwischen beiden Schenkeln dieses Dornstücks ist mit Knorpelmasse ausgefüllt. 


\section{Annexe Knochen der beiden ersten Wirbel.}

Zwischen dem zweiten Wirbel und dem Schädel finden sich 4 kleine Knochenpa are, welche ihrer Function nach dem Wirbelsysteme fremd sind, dagegen, in theils mittelbarer, theils unmittelbarer Weise die Verbindung zwischen der Schwimmblase und dem Gehörorgane zu vermitteln haben.

Um die Lage dieser Knöchelchen richtig zu bezeichnen, ist es nöthig, den Zwischenraum zwischen dem Schädel und dem zweiten Wirbel näher ins Auge zu fassen. Der von mir als vorderer Gelenkfortsatz des zweiten Wirbels bezeichnete Fortsatz $\left(g^{2}\right)$ läuft, wie oben beschrieben, nach oben und vorn, bis er auf die hintere Fläche des $O s$ occipitale superius trifft. dessen Dorn er zwischen sich schliesst. Dadurch bleibt zwischen dem zweiten Wirbel und dem Schädel eine L ü ck e in Form eines rechtwinkeligen, ungleichseitigen Dreiecks, dessen Hypotenuse von dem vordern Rande des Gelenkfortsatzes des zweiten Wirbels, dessen kurze Kathete von dem Körper des ersten Wirbels, dessen lange von dem, das Hinterhauptsloch nach aussen begrenzenden, freien Rande des Os occipitale laterale gebildet wird.

In diese dreieckige Lücke sind drei der genannten Knochenpaare eingelagert, so dass dieselbe, mit Ausnahme ihres hintern Winkels, vollkommen durch diese geschlossen wird. Die übrig bleibende Oeffnung im hintern Winkel (Fig, 2. e.) ist das erste Intervertebralloch, die Austrittsstelle des electrischen und mehrer anderer Nerven.

Von den erwähnten 4 Knochenpaaren bilden zwei die Kette zwischen der Schwimmblase und dem Gehörorgane, die zwei andern liegen abseits und scheinen den Zweck zu haben, das eine der vorigen in beweglicher Lage zu erhalten. Die beiden ersteren sind schon von Johanxes Müller und Pacini als Gehörknöchelchen erwähnt, die beiden letzteren, bisher unbeachtet gebliebenen, will ich Ausfüllungsknöchelchen nennen.

\section{a. Ausfüllungsknöchelchen.}

Das vordere Ausfüllungsknöchelchen (Fig. 2. 4.5. $A^{1}$.) ist ein längliches, an beiden Enden abgerundetes, aussen convexes, innen concaves Plättchen. Sein vorderer Rand hängt mit dem, das Hinterhauptsloch nach aussen begrenzenden Rande des $O s$ occipitale laterale durch Bandmasse zusammen. Sein oberes Ende füllt den oberen Winkel der genannten Lücke aus. Nach hinten und unten hängt es mit den zwei folgenden Knöchelchen zusammen.

Das hintere Ausfüllungsknöchelchen (Fig. 2.5. $A^{2}$.) hat die Gestalt eines kleinen dünnen Stäbchens. Sein oberes Ende ist spitzig, das untere quer abgestutzt mit einer Gelenkfläche. Sein vorderer Rand schliesst sich an den Hinterrand des vorigen an und ist mit demselben durch Bandmasse vereinigt. Die obere Hälfte seines Hinterrandes legt sich an den vordern Rand des vorderen Gelenkfortsatzes des zweiten Wirbels; die untere Hälfte bleibt frei und begrenzt das erste Intervertebralloch nach vorn. Das untere Ende articulirt mit dem ersten Gehörknöchelchen.

\section{b. Gehörknöchelchen.}

Das vordere, von PAcrini Steigbügel genannte Knöchelchen (Fig. 5. S.) schliesst sich unmittelbar an das untere Ende der beiden Ausfüllungsknöchelchen an, mit dem vorderen durch Bandmasse, mit dem hintern durch ein Gelenk verbunden. Es ist ein kleines, lanzettförıniges Plättchen, dessen Längendurchmesser in der Richtung von vorn nach hinten liegt. Es ist daher mit dem hinteren Ausfüllungsknöchelchen unter rechtem bis stumpfem Winkel verbunden. Die äussere Fläche des Knöchelchens ist 
convex und trägt nach hinten von der Mitte einen Fortsatz zur Anheftung des vorderen Endes des hinteren Gehörknöchelchens (Hammers). Die innere Fläche des Steigbügels ist concav und bedeckt mit ihrem vorderen Theile das Atrium des Sinus impar, dessen sehnige Wandung sich ringförmig an das Knöchelchen anheftet. Das hintere etwas verdünnte Ende des Steigbügels trägt eine Gelenkfläche zur Verbindung mit dem zweiten Ausfüllungsknöchelchen.

Das hintere Gehörknöchelchen (Fig. 1. 2. 3. H.) wurde von PAcint als Ham mer beschrieben*). Fs übertrifft das vordere bedeutend an Grösse und Stärke. Sein vorderer grösserer Theil ist länglich, von oben nach unten platt gedrückt und läuft in horizontaler Richtung zur Seite der beiden ersten Wirbelkörper lis zum Steigbügel, mit welchem das vordere Ende articulirt. Das hintere Ende ist sichelförmig abwärts gekrümmt. Die äussere Fläche der Sichel liegt dem vorderen Theile der Schwimmblase an. Etwa in der Mitte seiner Lünge geht rom Innenrande des Hammers ein dünner Knochenstiel ab, welcher sich an den Körper des zweiten Wirbels festheftet. Dieser Knochenstiel bildet die Axe für die Bewegungen des Hammers, welchen er, vermöge seiner Dünne und Biegsamkeit, kein Hinderniss in den Weg legt.

\section{Capitel II. Von der Bauchhöhle.}

(Tab. II.)

Die Bauchhöhle wird durch eine starke F a s cie (Tab. II. Fig. 1.2.3.T.) begrenzt, welche unmittelbar unter der Muskulatur (Seitenmuskel und geradem Bauchmuskel) gelegen ist und mit deren Innenfläche bald inniger, bald lockerer zusammenhängt. Das erstere ist besonder's der Fall im oberen Theile der Bauchhöhle, zu beiden Seiten der Wirbelsäıle. Dort ist die Fascie von den Muskeln nicht abzulösen und haftet nicht minder fest an der Beinhaut der in die Bauchhöhle hereinsehenden Knochen, nämlich: der Unterfläche der Wirbelsäule, der unteren Bogenfortsätze, der Rippenanfänge und des Springfederfortsatzes, dessen Platte auf beiden Flächen von ihr überzogen wird. Weniger innig hängt sie der hinteren Fläche des Zwerchfelles an; ziemlich locker endlich der hinteren Fläche des Rückwärtsziehers der Brustflosse, der Innenfläche des Seiten- und Bauchtheils des Seitenmuskels und der Innenfläche der geraden Bauchmuskeln. Doch sind die Sehnenstreifen (inscriptiones iendineae) genannter Muskeln ausgenommen, mit welchen sie fest verbunden ist.

Die Sehnenhaut bildet somit einen die Bauchhöhle umschliessenden Sack, der nur vorn von der Speiseröhre, hinten von dem Mastdarme durchbohrt wird. Dieser Sack hat im Allgemeinen die Form eines Kegels, dessen Basis auf dem Zwerchfelle ruht, dessen Spitze in die Gegend des Afters fällt.

Der hintere Theil der Bauchhöhle bietet nichts Bemerkenswerthes dar. In ihrem vorderen Theile dagegen zeigt sie verwickeltere Verhältnisse, welche hier eine nähere Berücksichtigung verdienen, weil der electrische Nerv auf seinem Laufe damit in Berührung kommt.

1. Der vordere Theil der Bauchhöhle besitzt nach oben jederseits von der Wirbelsäule eine Ausbuchtung, welche in der Gegend des Gten Wirbels beginnt, und, an Weite zunehmend, bis zum Schultergürtel reicht. Diese Ausbuchtung wird nach oben von den unteren Bogenschenkeln (Querfortsätzen) des

$$
\text { ') a. a. O. pag. 16. Fig I. } M \text {. }
$$


2-6ten Wirbels und dem Springfederfortsatze, nach vorn von dem Rückwärtszieher der Brustflosse begrenzt. Sic verdankt ihre Entstehung dem hohen Ursprunge der genannten unteren Bogenschenkel (rergl. pag. 5.). Sic wird durch die senkrecht hereinragende Platte des Springfederfortsatzes in \%wei Abtheilungen von ungleicher Grösse getheilt: eine hintere, grössere, und eine vordere, kleinere.

2. Der das Zwerchfell überzichende Theil der Fascie wird durch die Speiseröhre durchbohrt und in die Bauchhöhle eingestülpt, so dass er die Speiseröhre bis ungefähr zur Irälfte ihrer Länge als eng anschliessende Scheide begleitet (Tab. II. Fig. 2. $\beta$.). Die Speiseröhre steht mit dem parietalen Theile der Fascic durch zwei breite Bänder (Fig. 2. 3. $\varkappa_{\text {. }}$ ) in Verbindung, welche von der Seitenwand der Bauchhöhle entspringen, und sich, breiter werdend, an den seitlichen Theil der Speiseröhre festheften (Fig. 3. ú.), indem ihre Fasern mit denen der beschricbenen Scheide verschmelzen. Zwischen dem vorderen freien Rande des Bandes und dem Zwerchfelle bleibt eine halbmondförmige Lïcke (Fig. 2. $\gamma$.).

Der vordere Raum der Bauchhöhle wird durch die Speiseröhre und deren Flügelbänder in zwei über einander liegende Abtheilungen geschieden, welche ich, der Kürze wegen: "cavitas hypoesophagea" und "c. hyperoesophagea nennen will. Beide münden nach hinten in den ungetheilten Raum der Banchhöhle. — vor'n stehen sie jederseits durch die oben erwähnte Lücke (Fig. 2. $\gamma$.) unter sich in Verbindung.

Die cavitas lypoesophagea wird von der Hauptmasse der Leber erfüllt. - Die cavitas hyperoesophagea zeigt die unter Nro. 1. beschriebene Ausbuchtung nach oben. Sie wird, wie dort erwähnt wurde, durch die quer vorspringende Platte des Springfederfortsatzes in zwei Unterabtheilungen geschieden: eine hintere, grössere, und eine vordere, kleinere. Da der Rand der Platte des Springfederfortsatzes grösstentheils frei ist, so wïrde die Scheidung dieser beiden Unterabtheilungen eine unvollständige sein, wenn nicht jede durch eine besondere Tasche des Bauchfelles ausgekleidet wäre. (Siehe unten).

Die hintere Unterabtheilung der cavitas hyperoesophagea wird nach oben, ausserhalb des Bauchfells, von dem vorderen Theile der Schwimmblase (Fig. 1. 3. S.) erfüllt, — ihr unterer Theil bleibt ein lecrer, von einer Tasche des Bauchfelles ausgekleideter Raum. Die vordere Unterabtheilung der cavitas hyperoesophagea (Fig. 1. zwischen $\zeta$ und $\zeta$ ) wird durch den Seitenlappen der Leber $(\boldsymbol{F}$ ig. 3. U) ausgefüllt (bei u' punktirt angedeutet). Der Seitenlappen der Leber dringt zugleich mit einer Tasche des Bauchfells durch die genannte Lücke $(\gamma)$ aus der cavitas hypoesophagea herein. In diese vordere Unterabtheilung der cavitas hyperoesophagea ragen ausserdem zwei von vorn kommende Falten der die Bauchhöhle umhüllenden Sehnenhaut. Die eine, breitere (Fig.1.2.3. \&.), hält zwischen ihren Blättern zwei Nerven und eine Arterie. Ihrem freien Rande zunächst liegt der electrische Nerv $(N)$, weiter nach rorn hin der Nerv des Rückwärtsziehers der Brustflosse (8) und die Arterie des electrischen Organes (A). Die zweite, kleinere Falte liegt nach aussen und oben von der vorigen und enthält den Hantnerven der Brustflosse (7). Diese Falten legen sich in entsprechende Einschnitte der Leber.

Das Bauchfell bietet im hinteren Theile der Bauchhöhle und in der cavitas hypoesophagea nichts Bemerkenswerthes dar. Dagegen erhält jede Unterabtheilung der cavitas hyperoesophagea eine besondere 'Tasche des Bauchfelles, die vordere von unten her aus der cavitas hypoesophagea durch die Lücke $(\gamma)$, die hintere von hinten her aus dem ungeschiedenen Theile des Bauchfellsackes. Beide 'Taschen berühren sich am Rande der Platte des Springfederfortsatzes. Das so entstehende doppelte Pcritonäalblatt hebt die Communication zwischen beiden Unterabtheilungen der cavitas hyperoesophngea vollstindig auf. 


\section{Capitel III.}

\section{Vom Gehirne und Rückenmarke.}

(Tab. III. Fig. 1-5.)

Alles, was über die Centralorgane des Nervensystemes des Zitterwelses bekannt ist, beschränkt sich, meines Wissens, auf eine bildliche Darstellung von PACINI*), und auf eine kurze Beschreibung von R. WAGNER $\left.{ }^{* *}\right)$.

Pacrsi's Abbildung ist klein und undeutlich, und lässt daher eine vergrösserte und detaillirtere Darstellung als wünschenswerth erscheinen. R. WAGNer hebt besonders die starke Entwicklung des kleinen Gehirnes hervor, welches sehr viele Aehnlichkeit mit dem kleinen Gehirne des Zitteraales habe. Dies sei jedoch nicht mit der electrischen Eigenschaft in Beziehung zu setzen, da der gemeine Wels (Silurus Glanis) ganz ähnliche Verhältnisse zeige, dessen Gehirn überhaupt in der Anordnung seiner Theile und deren relativer Entwicklung mit dem des Zitterwelses auffallend übereinstimme, so dass kein wesentlicher Unterschied wahrzunehmen sei. Ueberdies sei der electrische Nerv durch PAcini als Rückenmarksnerv nachgewiesen worden. Auf dem Boden der vierten Hirnhöhle (Rautengrube) kommen ein paar kleine schwache Anschwellungen vor, die aber kaum entwickelter seien, als beim gemeinen Wels. Diese Angaben Wagners muss ich vollkommen bestätigen.

\section{Gehirn.}

Das Gehirn des Zitterwelses ist im Verhältnisse zum Körper sehr klein und erfüllt die Schädelhöhle nur sehr unvollständig.

\section{Vorderhirn (lobi olfactorii).}

Die lobi olfactorii ('Tab. III. Fig. 1-5. A.) sind ziemlich gross, der Länge nach durch eine Spalte von einander getrennt, nur hinten in der Tiefe durch eine kleine commissura interlobularis (Fig. 4. $i$.) verbunden. Sie sind zwei länglich runde Massen, deren vorderes Ende verdickt, stumpf abgerundet, nach unten gebogen ist; deren hinteres Ende nach innen mit den Hirnstielen (Pyramidensträngen) zusammenhängt, nach aussen sich zwischen die lobi optici und inferiores hineinschiebt. Die innere Fläche ist abgeplattet, die äussere und obere gewölbt, die untere vertieft. Der grössere Theil der Unterfläche wird von der frei zu Tage tretenden Verlängerung der Hirnstiele eingenommen. Sonst ist die weisse Substanz überall durch graue Rindenmasse überzogen, deren Oberfläche seichte Furchen und Andeutungen von Windungen zeigt. Diese graue Rindensubstanz endigt auf der Unterfläche der lobi olfactorii mit wulstigem, freiem Rande (vergl. Fig. 2. 3.). Aus dem vorderen Theile der Unterfläche, auf der Grenze zwischen weisser und grauer Substanz, entspringen die Geruchsnerven. Der hintere Theil der obern Fläche der lobi olfactorii ist ron der Spitze des Vorderlappens des kleinen Gehirnes bedeckt.

\footnotetext{
*) a. a. O. Fig. I. pag. 20.

Fortsetzung der Untersuchungen über elcetrische Fische, 9. December is 45 . (Neurologische Untersuchungen pag. 24).
} 


\section{Tubercula intermedia.}

Sie sitzen auf den Hirnstielen zwischen den lobi olfactorii und optici in Form von kleinen dreieckigen Körperchen (Fig. 4. 5.g.) Sie sind durch eine Spalte von einander getrennt, nur an ihrem hinteren Ende besteht zwischen ihnen eine feine Commissur (commissura tenuissima).

\section{Mittelhirn.}

Die Masse des Mittelhirns hängt mit den lobi olfactorii durch die Hirnstiele zusammen. Sie zeigt mehrere beträchtliche Hervorragungen : nach oben die lobi optici, nach unten die lobi inferiores mit dem trigonum fissum.

Lobi optici.

Die lobi optici $(B)$ des Zitterwelses sind durch ihre geringe Grösse ausgezeichnet, was mit der Kleinheit der Augen und der Dünne des Sehnerven in vollkommenem' Einklange steht. Ihr Volumen beträgt kaum ein Dritttel von demjenigen der lobi olfactorii.

Die lobi optici sind von oben her grösstentheils bedeckt durch den Vorderlappen des kleinen Gehirns (Fig. 1. 3. 4.). Erst nach Abtragung desselben ist ihre obere Fläche zu sehen. Nach unten stossen sie an die lobi inferiores, nach vorn an die lobi olfactorii, nach hinten an den Ursprung des $N$. trigeminus.

Die lobi optici haben eine nierenförmige Gestalt. Sie sind durch einen ziemlich breiten Zwischenraum von einander getrennt. Dieser Zwischenraum (3ter Ventrikel) bleibt nur nach vorn und unten hin leer. Sein hinterer und oberer Theil ist von einem, durch eine Medianfurche unvollkommen getheilten Lappen erfüllt, welcher dem als " Corpora quadrigemina " bezeichneten Gehirntheile zu entsprechen scheint, jedoch bei unserem Fische vollkommen im kleinen Gehirne wurzelt (Fig. 4. 5. C.).

In ihrer vorderen Hälfte sind die lobi optici durch ein queres Markblatt (Corpus callosum GotTsche) (Fig. 4.5 p.) untereinander verbunden, welches nach vorn und hinten mit freiem Rande endigt. Der hintere Rand ist sichelförmig ausgeschnitten und bedeckt das vordere Ende der als "corpora quadrigemina" erwähnten Erhabenheit. Trägt man diese Commissur ab, so gelangt man beiderseits durch eine horizontale Spalte in die Höhlen der lobi optici. Dieselben sind eng und von dem aus ihrem Boden heraufragenden thalamus opticus fast ausgefüllt. Beide thalami optici sind an ihrem vorderen Ende durch eine ziemlich dünne Commissur (commissura anterior) (Fig. 4. h.) verbunden. Diese Commissur grenzt nach vorne an die tubercula intermedia, dicht hinter ihr öffnet sich der aditus ad infundibuhum.

Aus dem vorderen und unteren Theile der lobi optici entspringen die Sehnerven. Sie laufen vor den lobi inferiores zur Unterfläche des Mittelhirns und kreuzen sich auf die gewöhnliche Weise. Hinter der Kreuzungsstelle gewahrt man die commissura transversa Halleri (Fig. 2.).

\section{Lobi inferiores und trigonum fissum.}

Auf der Unterfläche des Mittelhirns treten mehre Erhabenheiten hervor, welche an ihrer Basis theilweise verschmolzen sind: zwei parige, und eine unpare, zwischen jenen gelegene.

Die mittlere, unpaare (trigonum fissum) (Fig. 2. 3. 4.F.) liegt dicht hinter der Commissura transversa und enthält einen Medianspalt, durch welchen das Infundibulum heraustritt. An ihr ist die abgerundet 
kegelförmige Hypophysis befestigt (Fig. 3. 4. H.). Hinter und über dem trigonum fissum gewahrt man eine feine Doppelcommissur (commissura ansulata).

Zu beiden Seiten des trigonum fissum liegen bei unserem Fische zwei Hügelpaare, ein vorderes (lobi inferiores anteriores Fig. 2. 3. 7.) und ein hinteres (lobi inferiores posteriores Fig. 2. 3. 4. L.).

Das vordere Pa ar ist klein, nach hinten von dem hinteren Paare, nach oben von den lobi olfactorii durch eine tiefe Furche geschieden; nach vorn frei, nach innen mit dem trigonum fissum verwachsen.

Das hintere Paar ist ziemlich gross, länglichrund. Sein vorderes Ende grenzt an das vorige und an die lobi olfactorii, die obere Fläche an die lobi optici. Nach innen ist es in der vorderen Hälfte mit dem trigonum fissum verwachsen, während der hintere Theil frei endigt. Zwischen diese beiden hinteren Verlängerungen legt sich der saccus vasculosus.

\section{Cerebellum.}

Das kieine Gehirn ist, wie schon von R. WAGXER bemerkt wurde, durch seine Grösse ausgezeichnet. Dasselbe ist in einen unpaaren in der Mitte seicht gefurchten Lappen ausgezogen, welcher sich nach vorn umlegt und, wie oben beschrieben, den grössten Theil der lobi optici und einen Theil der lobi olfactorii bedeckt (Fig. 1. 3. 4. D.).

Ein zweiter mit ihm in Zusammenhang stehender und von ihm gänzlich bedeckter Lappen (Fig. 4. 5. C.), der den hinteren Theil des Ventriculus tertius erfullt, wurde oben als Analogon der "Corpora quadrigemina "Auctor. gedeutet.

Das Cerebellum enthält ein Höhle. welche aus dem vierten Ventrikel entspringt und im Hauptlappen nach vorne geht (Fig. 4.q.)

Seitlich geht das kleine Gehirn in die corpora restiformia über. Nach unten bedeckt es (resp. die "Corpora quadrigemina ") den aquaeductus Sylvii.

\section{Verlängertes Mark.}

Die medulla oblongatu $(O)$ entspringt aus dem Mittelhirne und Cerebellum als ein dicker, nach hinten allmälig sich verjüngender Strang. Aus den Seitenwänden der Rautengrube erheben sich zwci ziemlich starke paarige Wrhabenheiten (Fig. 1, 4.y.z.) Die vorderen berühren sich in der Mittellinie so nahe, dass dadurch der vordere Theil der Rautengrube nach oben geschlossen ist. Hinter dem hinteren Paare liegt die commissura spinalis (Fig. 1, 4.v.)

Aus der Seitenfläche des verlängerten Markes entspringen nach einander die Wurzeln des $N$. trigeminus (nebst facialis), des acusticus, glossopharyngeus und die vordere Wurzel des vagus; aus der oberen Fläche die hintere Wurzel des Vagus und die hintere Wurzel des gewöhnlich als $N$. hypoglossus, von Stannius als $N$. spinalis $I$. bezeichneten Nerven; letztere an der Grenze zwischen verlängertem Marke und Rückenmarke.

Die Unterfläche des verlïngerten Markes zeigt, dicht hinter der Commissura ansulata ein kleines Markkörperchen in die vordere Spalte eingekeilt (Fig. 2.). Nach hinten gewahrt man die decussatio partialis und auf der Grenze zwischen Medulla oblongate und spinalis zwei kleine Würzelchen, die sich zur vorderen Wurzel des Mypoglossus (N. spin. I. Strannius) vereinigen. 


\section{Rückenmark.}

Das Rückenmark $(\boldsymbol{S})$ des Zitterwelses nimmt die ganze Länge des Wirbelkanals ein. Es nimmt dabei allmälig an Dicke ab und zeigt nirgends Anschwellungen.

Im vordersten Theile des Rückenmarkes sind die vorderen Stränge sehr klein, so dass sie von den Seitensträngen eingeschlossen werden und die vorderen Wurzeln der ersten Rückenmarksnerven aus der vorderen Spalte zu kommen scheinen.

Der Ursprung der ersten Nervenpaare des Rückenmarks (N. spinalis I. II und N. electricus) wird im folgenden Capitel beschrieben werden.

\section{Capitel IV.}

\section{Vom electrischen Nerven.}

(Tab. I. Fig. 6, Tab. II. III.)

Die vorliegenden Angaben über den electrischen Nerven des Zitterwelses stehen in nicht geringem Widerspruch unter einander. Während er von Geoffroy St. Hilaire. Rudolphi, Valenciennes, CuvierDuvernoy als Hirnnerve betrachtet wird, erklären ihn Pacini, R. WAgner und Marcusen für einen Rückenmarksnerven.

Geoffroy Str. Hilaire*) behauptet, der electrische Nerv des Zitterwelses sei nichts anderes, als der Ramus lateralis Nervi vagi, welcher aber beim Zitterwelse einen abweichenden Verlauf nehme, indem die beiderseitigen Nerven beim Austritte aus der Schädelhöhle convergiren, den ersten Halswirbel, jeder für sich, durchbohren, auf dessen hinterer Seite durch eine gemeinschaftliche Oeffinung wieder hervortreten und sich dann plötzlich nach aussen schlagen, um sich unter die Seitenlinie zu begeben. wo sie zwischen den Muskeln und der Sehnenhaut des electrischen Organes nach hinten laufen, nach rechts und links Zwweige abgebend, welche die Sehnenhaut durchbohren und sich im electrischen Organe verlieren.

Nach PACini**) dagegen ist der electrische Nerv das erste Spinalnervenpaar, weil er aus dem Wirbelkanale zwischen dem Schädel und dem ersten Wirbel hervorkomme. Die Stelle des Rückenmarkes, aus welcher er entspringe, biete keine ausserordentliche Verhältnisse dar, ebensowenig das grosse und kleine Gehirn, mit welchen er übrigens in keiner directen, wenigstens keiner äusserlich sichtbaren Bezienung stehe. Der electrische Nerv sei, im Vergleiche mit den übrigen Rückenmarksnerven, ausserordentlich dick und mit einem sehr beträchtlichen Intervertebralganglion versehen, welches ihm das Hauptorgan zu sein scheint, in welchem der dynamische Einfluss auf das electrische Organ erzeugt werde - ein Analogou des electrischen Lappens des Zitterrochens.

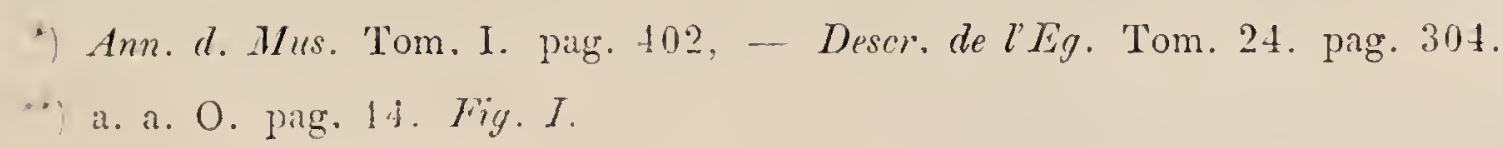


Marcusex*) fand, dass der electrische Nerv vom ersten Rückenmarksnerven entspringe, und zwar scheinbar aus dem recht starken Spinalganglion. Bei genauerer Untersuchung gelang es ihm aber, den electrischen Nerven von dem Ganglion ganz zu isoliren. Zwischen dem Ganglion und dem Rückenmarke fand er zwei Wurzeln. Aus welcher von diesen der electrische Nerv entspringe, blieb zweifelhaft. Endlich ist Marcuses der erste, welcher die histologischen Verhältnisse des Nerven untersucht hat, wovon weiter unten die Rede sein wird.

Ich muss die Angabe der letztgenannten Forscher, dass der electrische Nerv ein Rückenmarks nerve sei, bestätigen. Ich werde im Folgenden zuerst den Ursprung und Verlauf des Nerven angeben, dann zur Beschreibung seiner histologischen Verhältnisse und des electrischen Centralorganes, aus welchem er entstelıt, übergehen.

\section{Ursprung und Verlauf des electrischen Nerven.}

\section{Ursprung des electrischen Nerven und Verlauf innerhalb des Wirbelkanales.}

Der electrische Nerv verhält sich, was Ursprung und Verlauf im Wirbelkanale betrifft, vollkommen wie eine motorische (vordere) Wurzel. Man könnte ihn als dritten Rückenmarksnerven bezeichnen, welcher der sensitiven (hinteren) Wurzel entbehrte. Doch scheint es mir richtiger, ihn als ein neues, zwischen den zweiten und dritten Rückenmarksnerven eingeschobenes Element anzusehen.

Aus dem Anfangstheile des Rückenmarks, in der Gegend der Verbindungsstelle des ersten Wirbels nit dem Os occipitale basilare, entspringen mehrere feine Nervenwurzeln: nach oben, aus der oberen (hinteren) Seitenfurche des Rückenmarkes, dicht hinter einander zwei weisse, feinfaserige Wurzelpare, von welchen das hintere etwas stärker ist, als das vordere (Tab. III. Fig. 3. $s^{1} . s^{2}$.); nach unten, scheinbar aus der unteren (vorderen) Medianspalte, ein unpaares Bündel von graulicher Farbe (Fig. 2. 3. m.). Erstere laufen nach aussen und hinten und treten gemeinschaftlich durch die oberste Oeffnung der das erste Intervertebralloch verschliessenden Sehnenhaut in das unmittelbar nach aussen von derselben gelegene. von PACrNi entdeckte Intervertebralganglion. Sie sind als die sensitiven Wurzeln des ersten und zweiten R ückenmarksnerven (N. spin. $I I$. und $I I I$. nach Stannıus' Zählung) zu betrachten. - Das, scheinbar aus der unteren Medianspalte entspringende Bündel läuft erst gerade nach hinten, dann theilt es sich nach rechts und links, eine Sehnenmasse durchbohrend, welche vom Dache des Simus impar sich erhebt und sich an die Rückenmarkshäute anheftet. An der das erste Intervertebralloch verschliessenden Sehnenhaut angelangt, durchbohrt es dieselbe in ihrem unteren Theile und wendet sich ebenfalls zum Ganglion. Dieses Bündel besteht aus drei W urzelp a aren, welche dicht hinter einander entspringen und durch Bindegewebe so innig verbunden sind, dass sie nur mit Mühe isolirt werden könmen. sie entspringen aus der unteren (vorderen) Seitenfurche, welche aber wegen der Kleinheit der vorderen Sträinge des Rückenmarks (vergl. S. 15) in die Medianlinie gerückt ist. Diese drei Wurzelpaare sind die 
motorischen Wurzeln des ersten und zweiten (II. u. III. ST.) Rückenmarksnerven und der electrische Nerv (Tab.III. Fig. $4 . m^{1} . m^{2}$.e.) Die beiden letzteren werden von der ersten gedeckt.

Noch ist eines motorischen Nervenfädchens Erwähnung zu thun, welches, ohne Zweifel zur motorischen Wurzel des N. spin. I. zu rechnen, einen abweichenden Verlauf nimmt. Dasselbe ist sehr fein, entspringt dicht vor der motorischen Wurzel des N. spin. I. (Fig. 4. x.), tritt, mit derselben sich kreuzend, nach aussen, und verlässt den Wirbelkanal durch ein kleines, im Steigbügel befindliches Loch. Sein weiterer Verlauf wird unten angegeben werden.

Die erwähnten motorischen Wurzeln sind breitfaserig, von graulicher Farbe. (Die Histologie des electrischen Nerven siehe unten).

Die oben angeführte irrige Angabe Geoffroy St. Hitarre's. erklärt sich folgendermassen : Unter den, gegen den ersten Wirbel convergirenden und denselben durchbohrenden Ästen des $N$. vagus sind die nach hinten laufenden Aeste des Gehörnerven gemeint, welche sich zu dem im Os occipitale befindlichen Theile des Gehörorganes begeben und ganz in der von Geofrroy beschriebenen Weise unter den vorderen Rand der Knochenbrücke des Os occipitale (nicht des ersten Halswirbels!) eindringen. Am entgegengesetzten Rande der Knochenbrücke befindet sich gerade die Ursprungsstelle des Bündels, welches den electrischen Nerven enthält. Die Annahme, dass der paarige Nerv, welcher am vorderen Rande der Knochenbrücke in die Tiefe tritt, mit dem Nervenstrange, der am hinteren Rande derselben Brücke zum Vorschein kommt, eins und dasselbe sei, lag aber nahe genug. Hätte Geofrroy St. Hitarre die Knochenbrücke erbrochen, so hätte er allerdings leicht erkannt, dass der von vorn kommende Nerv dort endigt, indem er sich an den, dort versteckten, Gehörsteine enthaltenden Säckchen ausbreitet. -

Betrachten wir den electrischen Nerven als ein neues, zwischen N. spin. II. u. III. eingeschobenes Element, so stimmt das Verhalten der ersten Spinalnervenpaare vollkommen mit der bei den Siluriden und Cypriniden gewöhnlichen Anordnung (vergl. Stannius periph. Nervensyst. d. Fische, pag. 115) überein.

\section{Das Zwillingsganglion des ersten und zweiten Rückenmarksnerven und sein Verhältniss zum electrischen Nerven.}

Unmittelbar nach aussen von der das erste Intervertebralloch verschliessenden Sehnemmembran liegt der von PAcrisi als Intervertebralganglion des ersten Rückenmarksnerven, d. i. nach seiner Ansicht, des electrischen Nerven, bezeichnete Nervenknoten. Die Ansicht, dass dieser Knoten dem electrischen Nerven selbst angehöre, hatte vom theoretischen Standpunkte aus viele Schwierigkeiten. Die electrischen Nerven hatten bisher das Gepräge motorischer Nerven an sich getragen und peripherische Ganglien rein motorischer Nerven hatten seit Bell zu den unerhörten Dingen gezählt. PACini selbst suchte dieses paradoxe Phänomen durch die Annahme zu erklären, dass das Ganglion „das Hauptorgan, wo der dynamische Einfluss auf das electrische Organ sich erzeuge, sein möchte, und daher dem electrischen Lappen des Zitterrochens analog zu sein schiene." Wir hätten also ein ausserhalb des Wirbelkanales gelegenes, mit den Centralorganen des Nervensystemes nur mittelbar durch einige Nervenfädchen in Verbindung stehendes electrisches Centralorgan gehabt, - eine Deutung, welche ebenfalls des Anstössigen nicht wenig enthielt.

Fine befriedigende Lösung der Frage wurde durch Marcusen herbeigeführt, welcher fand, „dass man den electrischen Nerven von dem Ganglion ganz isoliren könne, und dass das Ganglion mit einem andern Nerren zusammenhänge." 
Das Ganglion ist nach aussen von einer Fascie bedeckt, über welcher der Springfedermuskel gelagert ist. Nach innen liegt es, wie oben bemerkt, der das erste Interverlebralloch verschliessenden Sehnenhaut an. Es ist rundlich, von aussen nach innen etwas plattgedrückt. Seine Grösse ist, wie schon PAcrni angibt, beträchtlich, aber ziemlich wechselnd, nicht immer der Grösse des Individuums entsprechend. Die Länge und Breite beträgt bei mittleren Exemplaren etwa 1"', die Dicke etwa $\frac{3^{\prime \prime \prime}}{4}$. Sein Umfang wird durch eine dicke Scheide von Bindegewebe fast ums Doppelte vermehrt; dieselbe geht aber in die Scheide der von dem Ganglion nach unten tretenden Nerven ohne Grenze über, so dass dann der Knoten nicht mehr als solcher zu unterscheiden ist (Tab. II. Fig. 1.g.).

Das Ganglion empfängt und entsendet scheinbar 5 Wurzeln und nicht weniger als 9 Nervenstämmchen (Tab. III. Fig. 6.g.). In Wirklichkeit aber gehören ihm nur 2 Wurzeln an. Bei genauer Untersuchung ergibt sich, dass das Ganglion aus z wei getrennten, aber aufs innigste durch Bindegewebe verwachsenen Knoten zusammengesetzt ist. Der eine gehört der sensitiven Wurzel des ersten, der andere der des zweiten Rückenmarksnerven an.

a. Ganglion spinale I. (Tab. III. Fig. 7.)

Dasselbe ist meist beträchtlich kleiner als das folgende. Es wird von letzterem, mit dessen innerer Fläche es verwachsen ist, fast ganz bedeckt. Es ist rundlich, von aussen nach innen plattgedrückt und misst etwa $\frac{1}{3}^{\prime \prime \prime}$ in Länge und Breite.

Die Eintrittsstelle der sensitiven Wurzel $(s)$ ist am oberen inneren Rande. Der austretenden Äste sind zwei, ein dorsaler und ein ventraler. Ersterer erscheint am oberen vorderen Rande, letzterer am unteren. Der ventrale Ast entsteht aus zwei abgesonderten Strängen $(\alpha . \beta$.$) , die sich bald vereinigen und$ so eine dreieckige Lücke zwischen sich lassen, welche zur Aufnahme der motorischen Wurzel bestimmt ist (vergl. unten). Hie und da ist der eine Strang nur durch ein dünnes Fädchen vertreten.

Ueber das Verhalten der Elemente im Innern des Ganglions weiss ich wenig zu bemerken, da die zähe und dicke Kapsel nicht geringe Schwierigkeiten macht. Doch wurde soviel klar, dass alle austretenden Fasern sich zuerst gegen den unteren Rand, der Eintrittsstelle der Wurzel gerade entgegengesetzt, begeben, und sich dort erst in beide Äste vertheilen, so dass die dem Ventralaste angehörigen gerade nach unten treten, während die des dorsalen innerhalb der Kapsel des Ganglions zurücklaufen und am oberen vorderen Rande zum Vorschein kommen.

Verhältniss der motorischen Wurzel des N. spin. I. zum Ganglion.

Die motorische Wurzel $(m)$ tritt von unten und hinten an das Ganglion heran und theilt sich dort in drei Äste: einen dorsalen, einen medianen und einen ventralen. Der erstere steigt an der innern (freien) Seite des Ganglions in die Höhe und legt sich dann an den aus dem Ganglion hervorkommenden sensitiven Dorsalast zur Bildung des Ramus dorsalis $N$. spin. I. (1.). - Der zweite und dritte gehen durch die beschriebene Lücke zwischen beiden Ursprungssträngen des sensitiven Ventralastes, worauf der Medianast gerade nach vorn läuft und sich im Springfedermuskel vertheilt (3.). Der stärkere Ventralast geht nach unten und bildet mit der starken aus dem Ganglion kommenden Portion den Ramus ventralis N. spin. I. (6.). 
b. Ganglion spinale II. ('Tab. III. Fig. 8.)

Es übertrifft das vorige gewöhnlich um das 3-5fache an Grösse, selten ist es kleiner. Es ist nach aussen und hinten von dem vorigen gelegen und bedeckt es meistens fast vollständig. Seine Form ist rundlich. Der Längen- und Breitendurchmesser beträgt etwa $1^{\prime \prime \prime}$. die Dicke ungefähr $\frac{1^{\prime \prime \prime}}{2}$.

Die Wurzel tritt ebenfalls im oberen hinteren Rande ein. Der austretenden Áste sind drei: ein dorsaler, ein ventraler und ein medianer. Die beiden ersteren verhalten sich den ihnen entsprechenden des vorigen Ganglions analog; nur sind sie beträchtlich stärker. Die zwischen beiden Ursprungssträngen $(\alpha$ und $\beta$ ) des ventralen Astes bestehende Lücke ist gross. - Der mediane Ast (5) kommt zwischen den beiden übrigen aus dem Vorderrande des Ganglions hervor und ist viel schwächer als diese.

Der Faserlauf stimmt ganz mit dem oben angegebenen Verhalten überein. Auch hier sammeln sich sämmtliche austretende Fasern an der dem Eintritte der Wurzel entgegengesetzten Stelle. Ein Theil derselben läuft dann innerhalb der Kapsel zurück und begibt sich in den dorsalen und medianen Ast.

\section{Verhältniss der motorischen Wurzel des $N$. spin. $I I$. und des electrischen Nerven zum Ganglion.}

Die motorische Wurzel des $N$. spin. $I I .(m)$ und der electrische Nerv $(e)$ treten von hinten und unten an das Ganglion heran. Dort theilt sich die erstere in drei Äste: einen dorsalen, medianen und ventralen, von denen der erstere nach vorn und oben geht, sich an die innere Seite des Ganglions anlegt und zum sensitiven Dorsalaste tritt, mit dem er als Ramus dorsalis (2) weiter geht. - Die beiden andern dringen mit dem electrischen Nerven durch die zwischen beiden Ursprungssträngen des sensitiven Ventralastes bestehendeLü̈cke. Dann geht der Medianast (4) gerade nach vorn in den Springfedermuskel, während der motorische Ventralast nach unten zieht und durch Theilung und Wiedervereinigung eine Schleife um den electrischen Nerven bildet (8). Die beiden letztern Äste der motorischen Wurzel scheinen

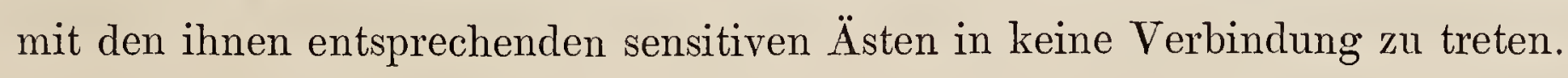

\section{Verlauf des electrischen Nerven vom Zwillingsganglion bis zum Wintritte in das electrische Organ.}

Die vom Zwillingsganglion ausstrahlenden Nerven sind also folgende 9 :

1. Dorsalast des N. spin. I., gemischt.

2. Dorsalast des $N$. spin. II., gemischt.

3. Medianast des N. spin. I., Muskelnerv.

4. Medianast des N. spin. II., Muskelnerv.

5. Medianast des N. spin. II., Hautnerv.

6. Ventralast des N. spin. I., gemischt.

7. Ventralast des N. spin. II., Hautnerv.

8. Ventralast des $N$. spin. II., Muskelnerv.

9. electrischer Nerv.

Diese Nerven lassen sich in Bezug auf ihren Verlauf in folgende Gruppen zusammenfassen:

Nro. 1 und 2. (Tab. II. Fig. 1., Tab. III. Fig. 6. 1. 2.) verlaufen ganz nach der Weise der Dorsaläste. Sie ziehen auf dem Bogen des 2ten Wirbels, gedeckt von dem Springfedermuskel, nach oben 
und gehen, nach Abgabe kleinerer Zweige, an die Muskulatur, besonders den zwischen Hinterhaupt und Dornstück des zweiten Wirbels ausgespannten $M$. interspinalis, in den $N$. lateralis trigemini über.

Nro. 3 und 4. (Tab. III. Fig. 6. 3.4.) verzweigen sich nach kurzem Verlaufe im Springfedermuskel.

Nro. 5. (Tab. III. Fig. 6. 5.) schlingt sich um den Springfedermuskel herum und durchbohrt das zwischen dem unteren Bogenschenkel des 2ten Wirbels und dem Schultergürtel ausgespannte Sehnenband, woselbst er einen, durch die Schädeldecke tretenden Ast des $N$. lateralis trigemini (k) aufnimmt. Dann zieht der vereinigte Strang (d) zur Brustflosse und vereinigt sich mit dem stärkeren Ventralaste (Nro. 7.) (Tab. II. Fig. 1., 'Tab. III. Fig. 6.).

Nro. 6. 7. 8. 9. verlaufen eine Strecke weit als gemeinsames Bündel von beträchtlicher Dicke. Dieses Bündel (Tab. II. Fig. 1.g.) zieht dem vorderen Rande des Stemmfortsatzes entlang zur Platte des Springfederfortsatzes. Am Innenrande der Platte trennt sich:

Nro. 6. (Tab. III. Fig. 6. 6.). Er zieht gegen den Innenrand der Clavicula, verbindet sich dort mit einem starken Aste des N. hypoglossus (N. spin. I. nach Stanvius), welcher schon früher das isolirte motorische Nervenfädchen $(x)$ aufgenommen hatte. Der Strang $(b)$ theilt sich sodann in zwei Äste, die durch eigene Löcher der Clavicula durchtreten und, der eine in den Vorwärtsziehern, der andere in den Rückwärtsziehern der Brustflosse, sich verzweigen.

Nro. 7. trennt sich bald nach Abgang des vorigen Nerven von dem gemeinsamen Bündel. (Tab. III. Fig. 6. 7.). Er zieht unter dem Knorren der Platte des Springfederfortsatzes nach aussen und durchsetzt in einer eigenen Falte eingeschlossen die Nebenkammer der Bauchhöhle (vordere Unterabtheilung der cavitas hyperoesophagea). (Tab. II. Fig. 1. 7.). Am Rückwärtszieher der Brustflosse angekommen verbindet er sich mit dem durch einen Ast des $N$. lateralis trigemini verstärkten medianen Hautnerven (Nro. 5.) (Tab. II. Fig. 1., Tab. III. Fig. 6. d l.). Der gemeinschaftliche Strang läuft dem Vorderrande des Muskels entlang und senkt sich an der Basis der Brustflosse, zwischen dem ersten und zweiten Strahl in die Tiefe. Er erfüllt den zwischen den Strahlenhälften befindlichen Kanal und sendet zwischen je zwei Strahlen einen Zweig gegen die Spitze der Flosse.

Nro. 8. An dem untersten Punkte des Innenrandes der Springfederplatte theilt sich das Bündel in seine letzten Bestandtheile, die in entgegengesetzten Richtungen aus einanderlaufen: der ventrale Muskelast des N. spin. II. nach vorn und unten, der electrische Nerv nach hinten und unten. Beide laufen, zugleich mit der Arterie des electrischen Organes, zwischen den Blättern der in die erwähnte Nebenkammer der Bauchhöhle hereinragenden grossen Falte (Tab. II. Fig. 1. $\delta$.) der tiefen Sehnenhaut. Nro. 8. (Tab. II. Fig. 1., 'Tab. III. Fig. 6. 8.) kreuzt sich mit der Arterie des electrischen Organes und endigt im Rückwärtszieher der Brustflosse.

Nro. 9., der electrische Nerv $(N$.$) . zieht in einem Bogen, dessen Concavität den freien Rand$ der genannten Falte (d) bildet, durch die Nebenkammer der Bauchhöhle (Tab. II. Fig. 1.). Am Innenrande des zum Schultergürtel gehenden Kopfes des Seitenmuskels (M. l'.) kommt er, zugleich mit der Arterie, aus der Falte hervor, geht, erst ron diesem Muskel gedeckt, dann zwischen ihm und dem geraden Bauchmuskel nach hinten und verläuft nun in der Schicht ̈̈usserst lockeren Bindegewebes, welche den '/wischenraum zwischen der Muskulatur und dem electrischen Organe ausfüllt, von der Arterie (in der Mitte) und der Vene (unten) des electrischen Organes begleitet, der Seitenlinie entlang bis gegen die hintere Grenze 
des electrischen Organes. Nach beiden Seiten gibt er zahlreiche Aeste (19-28) ab, die nach kurzem Verlauf und 1-2facher'Theilung plötzlich unter die innere Sehnenhaut des electrischen Organes hinabtauchen. ('Tab. I. Fig. 6.)

\section{Histologie des electrischen Nerven, und Beschreibung des electrischen Centralorganes.}

\section{Ilistologische Verhältnisse des electrischen Neren.}

Die histologischen Verhältnisse des Nerven sind zuerst von Marcusen einer näheren Prüfung unterworfen worden. Er fand*) denselben mit einer Menge von Häuten umgeben (gegen 10_15), an und für sich sehr dünn und mit der Eigenschaft, einen »Centralkanal « zu besitzen.

Ich ${ }^{*}$ ) wies sodann nach, dass dieser Centralkanal nichts anderes sei, als eine einzige, kolossale Primitivfaser, welche sich einerseits in das Rückenmark einsenke, andererseits in eben so viele Äste und Zweige theile, als Nervenäste und Zweige in das electrische Organ eindringen.

Bald darauf, und unabhängig von mir, kam MARCusen****) durch weitere, an Chromsäurepräparaten angestellte Untersuchungen zu demselben Resultate, welches ausserdem durch EckER und KöLLIKER bestätigt wurde.

Der electrische Nerv ist im mittleren Theile seines Verlaufes ein sehr ansehnlicher Strang, welcher bei grossen Exemplaren ungefähr eine Linie im Durchmesser hat. Davon fällt aber nur der kleinste 'Theil auf die im Centrum des Stranges gelegene Nervenfaser. Der bei weitem grösste Theil gehört einer bindegewebigen Hülle an, welche aus unzähligen, in einander gesteckten Scheiden oder Röhren besteht. Diese Hülle ist sehr scharf in zwei Lagen geschieden: eine äussere, gefässhaltige, und eine innere, gefässlose.

1. Die äussere, gefässhaltige Schicht nimmt etwa $\frac{9}{10}$ der Dicke des Stranges ein. Sie besteht aus zahlreichen, locker in einander gesteckten Scheiden. Diese Scheiden bestehen aus einem weitmaschigen Gewebe von in verschiedenen Richtungen verlaufenden Bindegewebefasern. Sie sind von zahlreichen Blutgefässen durchzogen. Nach aussen werden sie von circulär oder spiralig laufenden Faserzügen, ebenfalls aus Bindegewebefibrillen bestehend, umsponnen. - Diese äussere Schicht erhält der electrische Nerv erst nach seinem Austritte aus dem Wirbelkanale. Sie ist am dicksten im mittleren 'Theile seines Verlaufes, also vom Ganglion an bis zum Eintritte in das electrische Organ. Sie nimmt an allen Theilungen der Nervenfaser Antheil und begleitet diese bis nahe zu ihren Endigungen.

2. Die innere, gefässlose Hülle (Tab. III. Fig. 9. 11.s.) bildet einen Strang von etwa $\frac{1}{10}{ }^{\prime \prime}$ Dicke. Sie ist farblos, durchsichtig, der Länge nach durch parallellaufende, gewellte Fasern gestreifelt. Sie erinnert auf das Lebhafteste an die Scheide des Stiels eines Pucrer'schen Körperchen mol die Fasern

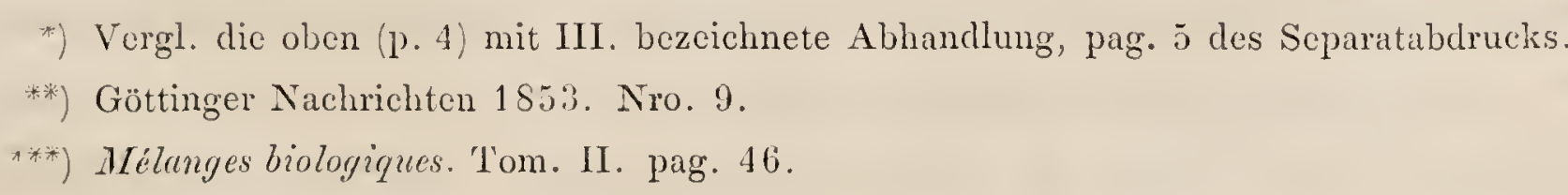


scheinen der Ausdruck vieler zarter, in einander gesteckter Röhrchen zu sein. Bei Zusatz von Essigsäure (Tab. III. Fig. 10.s.) wird der Strang dünner, blasser, die faserige Textur undeutlicher; und es treten viele kleine längliche Kerne ( $\boldsymbol{K}$ ) hervor. Die innere Hülle entspringt an der Unterfläche des Rückenmarkes und empfängt die aus letzterem hervorkommende electrische Nervenfaser (Fig. 11. s.), welche fortan deren C'entrum einnimmt. Sie macht alle Theilungen der Nervenfaser mit, und umhüllt sie bis nahe zu den Endigungen ihrer letzten Zweige.

3. Der durch die beiden beschriebenen Hüllen gebildete Strang enthält, wie oben bemerkt, nur eine Primtivfaser (Tab. III. Fig. 9. 10.11.e.). Dieselbe hat das ganze Organ ihrer Seite zu versorgen, und theilt sich daher schon ausserhalb des Organes (Tab. I. Fig. 6.), noch mehr aber in demselben (Tab. IV. Fig. 8.), in eine unzählige Menge von Aesten und Zweigen. Die Dicke der Faser beträgt von

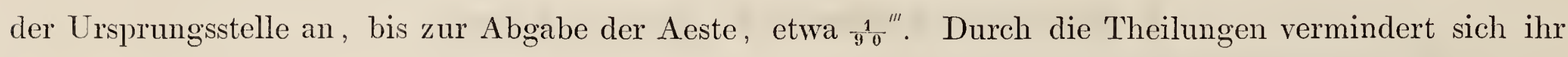
Durchmesser nur wenig, so dass erst nach vielen 'Theilungen ein beträchtlicher Unterschied erkennbar' ist. - Die Nervenfaser zeigt eine dicke Markschicht, welche einen Axencylinder von etwa Tí "umgibt. Letzterer tritt besonders deutlich bei Chromsäurepräparaten hervor (Tab. III. Fig. 11.f.).

\section{Mectrisches Centralorgan.}

'Theilt man den Anfangstheil des in Weingeist oder Chromsäure erhärteten Rückenmarkes durch einen von der unteren (vorderen) Längsfurche ausgehenden Schnitt in zwei gleiche Seitenhälften und trägt in der Gegend des Ursprunges des electrischen Nerven eine dünne Schicht von der Schnittfläche ab, so gewahrt man, schon mit freiem Auge, noch deutlicher mit der Lupe, einen kleinen rundlichen Fleck (Tab. III. Fig. 4. n.), welcher sich aus der umgebenden Masse des Rückenmarkes durch dunklere Färbung hervorhebt. Derselbe liegt ungefähr $\frac{1}{5}$ "' von der unteren (vorderen) Fläche des Rückenmarkes entfernt, etwas nach oben und aussen vom Centralkanale, der Ursprungsstelle des electrischen Nerven gerade gegenüber.

Trägt man durch einen weitern, parallel mit dem vorigen geführten Schnitt die den Fleck enthaltende Stelle sammt den Nervenursprüngen ab und bringt sie unter das Microscop, so ersclieint der Fleck als ein rundlicher, etwa $\frac{1^{\prime \prime}}{7}$ im Durchmesser haltender Körper (Tab. III. Fig. 11. n.), welcher die Charaktere eines Ganglienkörpers, und zwar eines multipolaren an sich trägt.

Es ist bei einiger Uebung nicht schwer, den genannten Körper in jedem Chromsäurepräparate doppelt je einen in jeder Rückenmarkshälfte) darzustellen. Dagegen ist die genauere Erforschung seiner Beschaffenheit mit grossen Schwierigkeiten verbunden. Derselbe ist nämlich durch seine zahlreichen Ausläufer mit der ihn umgebenden Masse des Rückenmarkes so sehr verfilzt, dass es nicht möglich ist. ihn vollständig zu isoliren. Indessen ist es mir durcli sehr zahlreiche Untersuchungen nach und nach gelungen, über die wesentlichen Punkte ins Klare zu kommen.

Der Körper enthält einen hellen, bald kugeligen, bald länglichrunden Kern von ungefähr $\frac{1}{30}{ }^{\prime \prime}$ Durchmesser, mit einem $\frac{1}{y_{0}}{ }^{\prime \prime}$ grossen Kernkörperchen. Die Oberfläche des Ganglienkörpers ist uneben, mit einer grossen Menge von Ausläufern, die sich meist bald nach dem Ursprunge theilen, besetzt: Sein Ansehen erinnert an die Igelkolbe oder noch mehr an das Ei von Hydra vulgaris. Diese Fortsätze sind dick, glasartig, homogen, mattglänzend und laufen nach verschiedenen Richtungen. Nur einer derselben konnte bis zu seinem Ziele verfolgt werden, und dieser ist nichts anderes, als der Ax encylinder der electrischen Nervenfaser $(t)$. Trentspringt mit sehr breiter $\left.s^{\frac{1}{\prime \prime \prime}}\right)$ Basis aus dem untern Theile des Ganglienkörpers, 
dringt, dünner $\left(\frac{1}{100}^{\prime \prime \prime}\right)$ werdend, in geradem Laufe nach unten, zwischen dem, hier sehr kleinen, und fast ganz in der unteren (vorderen) Rückenmarksspalte verborgenen unteren (vorderen) Strange $(\boldsymbol{B})$ und dem Seitenstrange zur unteren (vorderen) Seitenfurche und senkt sich dort in die gefässlose Scheide $\langle s$ ), welche letztere, mit den Ursprüngen der beiden motorischen Wurzeln (N. spin. I. und II.) sich kreuzend, von rorn kommt. Der beschriebene Fortsatz (Axencylinder der electrischen Nervenfaser) scheint sich erst bei seinem Eintritte in die gefässlose Scheide mit einer Schicht dunkelrandigen Nervenmarkes ( $g$ ) zu entkleiden.

\section{Capitel V. \\ Vom electrischen Organe.}

(Tab. I. Fig. 6., Tab. II. Tab. IV.)

\section{A. Feschreibender Theil.}

Der Zitterwels verdankt seine unförmliche Gestalt hauptsächlich einer Hautschwarte, welche in verschiedener, meist sehr beträchtlicher Dicke seinen ganzen Körper umhüllt (Tab. I. Fig. 6. H, 'Tab. II. Fig. 1. 2. 3. H, Tab. IV. Fig. 1.). Dieselbe erscheint zunächst aus drei verschiedenartigen Lagen zusammengesetzt:

1. Der Haut, als äusserem Überzuge $(c)$.

2. einer starken Sehnenhaut, als innerem Überzuge $(f)$.

3. einer sulzigen Zw ischenmasse $(0 . i$.). Sie ist es, welche die Dicke der Schwarte bedingt. Ihre Mächtigkeit ist nach den Körperstellen sehr verschieden. Sie fehlt nur an wenigen Stellen. Diese sulzige 'Zwischenmasse wurde bisher in ihrer ganzen Ausdehnung für das electrische Organ angesehen. Bei näherer Untersuchung aber ergibt sich, dass dieselbe in zw๋ei, nur dem äusseren Ansehen nach einander ähnliche, nach Bau und Function aber höchst verschíedenartige Substanzen (o und $i$ ) zerfällt. Beide Substanzen sind durch sehnige Scheidewände von einander getrennt (Tab. I. Fig. 6. x. y. Tab. IV. Fig. 1. $y-f$.) getrennt, welche in querer Richtung den Fisch umkreisen und die Hautschwarte in drei, hinter einander gelegene Abtheilungen scheiden. Nur die mittlere, grösste dieser Abtheilungen $(x-y)$ ist als electrisches Organ (o) zu betrachten. Sie zerfällt durch eine dorsale und ventrale I,ängsscheidewand (Tab. II. Fig. 1.w.w.) wieder in zwei seitliche Hälften.

Die genannten drei Bestandtheile der Hautschwarte - Haut, Sehnenhaut und Zwischenmasse sind durch zahlreiche Verbindlungsstränge und Scheidewände aufs innigste unter einander verbunden, so dass es, wie Georroy ST. Huame bemerkt, nicht möglich ist, einen der Überzüge ohne Kerreissung der ‘wischenmasse abzulösen.

Um so lockerer ist dagegen die Verbindung der Hautschwarte mit den tiefer liegenden 'Theilen. Sie ist nur am Kopfe und den Flossen festgeheftet, sonst hängt sie mit den tiefern Theilen nur durch ein äusserst lockeres, verschiebbares Bindegewebe zusammen, und umhüllt so den grössten 'Theil des Körpers in Form eines schlaffen, weiten, beweglichen Sackes, aus welchem derselbe mit der grössten Leichtigkeit herausgeschait werden kann: - PACñ's sacco fibro-elettro-cutaneo. 


\section{Die äussere Haut. (c).}

Die Haut des Zitterwelses ist, wie bekannt, vollkommen weich, auf der Bauchseite ungefärbt, seitlich, und besonders auf dem Rücken gleichförmig grau mit eingestreuten Flecken. Sie ist überall mit zahlreichen fadenförmigen Papillen (Tab. IV. Fig. 2.b.b.) besetzt, welche, je nach der Körperstelle, Pigmentflecken tragen, oder nicht.

Der Bau der Haut des Zitterwelses weicht von dem durch RAтнкE u. A. bei andern Fischen beobachteten nicht ab. Sie besteht aus über einander geschichteten, sich kreuzenden Lagen parallel laufender Bindegervebsbündel, welche Horizontalschichten in bestimmten Zwischenräumen von säulenartigen, senkrecht gegen die Epidermis laufenden Bündelchen durchbrochen werden.

Die Nerven des, das electrische Organ überziehenden Theiles der Haut zeigen einen eigenthüm-lichen Verlauf. Dieselben werden nicht, wie Marcusen*) vermuthet, von dem electrischen Nerven, in dessen Scheide versteckt, mitgenommen, noch dringen sie auf andere Weise durch die Masse des electrischen Organes: sondern sie erreichen die Haut, ohne mit dem letztern in Berührung zu kommen, durch die beiden sehnigen Längsscheidewände, welche das Organ in zwei seitliche Hälften abtheilen. Es sind dieses 10 dorsale und $4-5$ ventrale Nervenpaare, erste aus dem $N$. lateralis trigemini, letztere aus den ventralen Ästen der mittlern Wirbelnerven entspringend. Nachdem dieselben die Musculatur durchbohrt, durchlaufen sie in Gestalt langer geschlängelter Fäden das zwischen letzterer und der innern Sehnenhaut des electrischen Organes gelegene lockere Bindegewebe, und dringen dann in die genannte Scheidewand ein und in derselben bis zur Haut, in welche sie nach beiden Seiten hin ihre Zweige senden.

\section{Die innere Sehnenhaut. $(f)$.}

Durchschneidet man die Hautschwarte des Zitterwelses an irgend einer Stelle des Rumpfes oder Schwanzes und schlägt sie zurück, so fällt sogleich die, den inneren Überzug der Schwarte bildende derbe Aponeurose in die Augen. Sie wird von sämmtlichen Beobachtern erwähnt.

\section{Structur der inneren Selneuhaut.}

Die innere Sehnenhaut besteht aus einem groben Geflechte sich kreuzender, starker, silberglänzender Fasern. Dieselben liegen in zwei Schichten, welche in entgegengesetzter Richtung streichen und daher der Sehnenhaut das gekreuzte Ansehen geben. Die oberflächliche (d.i. dem electrischen Organe zugekehrte) Schichte streicht von oben und vorn nach unten und hinten, die tiefere von oben und hinten nach unten und vorn. Während an den Seitentheilen die Kreuzung nur eine scheinbare ist, findet in der Mittellinie des Bauches eine wirkliche Kreuzung der Fasern statt, wodurch die tiefere Schicht zur oberflächlichen wird, und umgekehrt. In der Mittellinie des Rückens dagegen gehen die beiderseitigen Fasern der tiefern Schicht in einander über, während die der oberflächlichen Schicht dort entspringen. - Jede Faser umschlingt somit den Körper des Fisches zweimal, in Form einer Achtertour.

In histologischer Beziehung bietet diese Aponeurose nichts eigenthümliches dar.

*) 1. c. 2. pag. 46 . 


\section{Verbindungen der inneren Selnenhaut.}

a. Mit den tiefer liegenden Theilen.

Die nach innen gewendete Fläche der Sehnenhaut erscheint glatt, eben, und wie freipräparirt. Dieselbe steht nämlich im grössten Theile ihrer Ausdehnung mit den tiefer liegenden Theilen vermittelst des oben erwähnten lockeren Bindegewebes in Zusammenhang. Ausgenommen sind nur der Vorderkopf, die Kehle mit Einschluss der Kiemenöffnungen, und die wahren Flossen. An diesen Stellen verwächst sie unmittelbar mit der Beinhaut oder den oberflächlichen Muskelfascien und ist nicht mehr isolirt darzustellen.

Genauer bezeichnet sind ihre Anheftungsstellen folgende:

1. am Kopfe und der Kehle: Sie geht über in die Beinhaut der von den Stimbeinen gebildeten Medianleiste, - in die Fascie des zwischen dieser Leiste und den Augen gelegenen Theiles des gemeinschaftlichen Kiefermuskels, - in die Beinhaut des Augenringes; - ferner in die Beinhaut der Brustflossenstrahlen, nahe über deren Basis, - in die Beinhaut des äusseren Randes der Clavicula, — des Randes des Kiemendeckels, und der Kiemenhautstrahlen - endlich in die Fascie des zwischen beiden Schenkeln des Zungenbeins ausgespannten Quermuskels.

2. an der Schwanzflosse, Afterflosse und den Bauchflossen geht sie über in die Beinhaut der Flossenstrahlen, nahe über deren Basis.

An allen übrigen 'Theilen des Körpers aber, also am ganzen Rumpfe und Schwanze, und dem hinteren Drittheile des Kopfes, wird die Verbindung der innern Fläche der Sehnenhaut mit den tiefer liegenden Theilen vermittelt durch das

$$
\text { subaponeurotische Bindegewebe. }
$$

Dasselbe hat die Aufmerksamkeit der Naturforscher,vielfach, verdienter und unverdienter Weise, auf sich gezogen.

Nachdem es von Geofrroy St. Hitalre*) nur mit wenigen Worten erwähnt worden war, wurde es von Rudolphi **) als eine, wie er glaubte, von Geoffroy übersehene, aus einem regellosen flockigen Gewebe bestehende Haut dargestellt. Nehme man etwas mit der Pincette weg, so bilde es lockere Büschel von unordentlich verlaufenden, sehr weichen Fasern. Rudotphr bezeichnet es mit dem Namen der »flockigen Haut« und vermuthet darin ein zweites, inneres electrisches Organ. Dasselbe wird nach ihm von sehr dünnen Zweigen der Wirbelnerven (rami intercostales) versehen.

Valenciennes ***** adoptirte Rudolphi's Ansicht und zerlegte dessen flockige Haut in 6 und mehr dünne aber feste Blätter, die auf ihrer äusseren Fläche Fäden aus dem grossen Nerven, der unter die Aponeurose geht $(N$. electricus $)$, auf der inneren Fläche aber Zweige der Intercostalnerven erhalten sollen. Unter starken Vergrösserungen betrachtet sei das Gewebe aller dieser Membranen identisch und bestehe aus Fasern, ähnlich denen der Aponeurosen; sie bilden aber ein laxeres Gewebe und lassen zwischen sich zahlreiche Zellen.

Peters + ) erkannte es in seiner wahren Natur als ein laxes Zellgewebe, welches durchaus nichts mit dem electrischen Organe gemein habe, sondern den eigenthümlichen Bau des Bindegewebes zeige. kir

i) a. a. O.

$$
\text { *) Siehe oben pag. 2. } \quad \text { **) a. a. O. pag. } 140 . \quad \text { ****) Ann. sc. nat. pag. 213. - Arch. d'hist. nat. pag. 59 }
$$


vermuthet, dass es die Bestimmung habe, die Muskeln von dem steifen electrischen Organe so zu trennen, dass die Bewegungen der ersteren nicht beeinträchtigt werden. Als Isolator könne es seiner feuchten Beschaffenheit wegen nicht gelten. Von Valenciennes' 6 Häuten finde' er nichts Analoges.

PACINI $*$ ) beschreibt es als ein lockeres, weiches und flockiges Zellgewebe, so dass es wie gallertig und halbflüssig erscheine. Es sei gleichsam auf embryonaler Stufe stehen geblieben, denn das Microscop zeige ausser vielen, aus Zellen und aus Kernen vollständig entwickelten Fasern, auch viele ovale Kerne, welche noch nicht, oder unvollkommen in Fasern umgewandelt seien. Die grosse Weichheit und Halbflüssigkeit dieses Gewebes rühre von dem ziemlich reichlich vorhandenen, noch nicht organisirten Blasteme her.

Ich finde das subaponeurotische Bindegewebe zusammengesetzt:

1. aus zahlreichen, sehr langen, gröbern und feineren, is olirt verlaufenden, in allen Richtungen sich kreuzenden Bindegewebefibrillen.

2. einer blassen, fein granulirten Grundmasse mit sparsamen, zerstreuten, blassen, länglichen Kernen, die mit blassen, äusserst feinen Fasern in Zusammenhang stehen.

Das Bindegewebe ist von sehr viel Flüssigkeit durchfeuchtet und reich an Blutgefässen. - Endlich wird es von den Hautnerven durchzogen, welche darin lange Strecken durchlaufen, ehe sie in die Sehnenscheidewände eindringen.

\section{Fet $\mathrm{tschicht}$.}

Zwischen der eben beschriebenen Bindegewebeschicht und der Muskulatur liegt noch eine ansehnliche Fettschicht, die von den meisten Beobachtern unbeachtet gelassen wurde. Nur Cuvier-Duvernor **) und PAcins haben ihrer Erwähnung gethan und ihr eine isolirende Bedeutung zugeschrieben.

Nach PACinI ****) ist der ganze Rumpf, soweit sich das electrische Organ erstreckt, von einer beträchtlichen Schichte Fettes bedeckt, welche eine Dicke von 1-5 mm. besitzt, Diese Schicht ist verhältnissmässig dicker an jenen Stellen, die der grösseren Dicke des electrischen Organes entsprechen. Er schliesst daraus, dass diese Fettschicht den Zweck habe, den Rumpf des Fisches gegen die electrischen Ströme zu isoliren.

Ich finde die Mächtigkeit dieser Fettschicht sehr wechselnd, sowol nach den Körperstellen, als nach den Individuen. Niemals sah ich Exemplare, wo eine über den ganzen Rumpf ausgebreitete, zusammenhängende vorhanden gewesen wäre. Eine solche existirt in der Regel nur um den Schwanz herum, wo sie 1-5" Dicke hat, ausserdem in der Mittellinie des Rückens; an den Seiten des Rumpfes aber, und auf der Bauchfläche ist die Fettablagerung meist nur auf die Furchen zwischen den Muskelbündeln beschränkt. Bei magern Exemplaren ist dies auch am Rücken und Schwanze der Fall.

Es dürfte daher auf die isolirende Eigenschaft dieser Schicht keine so hohe Bedeutung zu legen sein, als es durch Pacisi geschieht.

\section{b. Verbindung der inneren Sehnenhaut mit den oberflächlicheren Theilen.}

Die innere Sehnenhaut geht nur an einem Punkte in ihrer Totalität in die änssere Haut über, nämlich im Umkreise des Afters. Beide Membranen werden fast überall durch die sulzige Zwischenmasse aus-

$$
\text { ") a. a. O. pag. } \left.6 .{ }^{* *}\right) \text { Lerons d'unat. comp. T. VIII. p. 697. ***) a. a. O. pag. 12. Fig. 1. P. Fig. 2. G. }
$$


einandergehalten, stehen aber durch zahlreiche Fortsätze, welche in Form von Scheidewänden, Balkenund Fächernetzen die Zwwischenmasse durchsetzen, mit einander in Verbindung.

S c he i d e w än de.

Durchschneidet man die Hautschwarte des Zitterwelses in verschiedenen Richtungen, so trifft man auf vier dünne, aber dicht gewobene Scheidewände, welche, zwischen Aponeurose und Haut ausgespannt, die sulzige Zwischenmasse abtheilend: zwei Querscheidewände, eine vordere (Tab. I. Fig. 6. x.) und eine hintere (Tab. I. Fig. 6.y. Tab. IV. Fig. 1.y-f.), die eine zwischen Kopf- und Rumpftheil, die andere zwischen Rumpf- und Schwanztheil den Fisch umkreisend - und zwei Längsscheidewände, welche, die eine in der dorsalen (Tab. II. Fig. 1.w.w.), die andere in der ventralen Mittellinie laufend, die beiden Querscheidewände verbinden. Es bilden mithin diese vier Scheidewände eine z u sammenhängende Umfassungsmauer, die durch gabelige Theilung und Wiedervereinigung den Rumpftheil der Zwischenmasse einerseits nach vorn und hinten abgrenzt, andererseits in $z w e i$ symmetrische Seitenhälften theilt.

Genauer angegeben ist der Verlauf dieser Scheidewand folgender: In der Mittellinie des Rückens erstreckt sie sich nach vorn bis zum hinteren Drittheile des Kopfes, theilt sich dort gabelig und läuft beiderseits in einem nach vorne convexen Bogen bis zum oberen Winkel der Kiemenspalte, dann hinter der Insertion der Brustflosse herum, und endlich in einer, dem Zwischenraume zwischen Schultergürtel und Kiemenhaut folgenden Bogenlinie bis zur Vereinigung mit der ventralen Medianscheidewand. Nach hinten erstreckt sich die dorsale Medianscheidewand bis dicht vor den Anfang der Fettflosse, theilt sich dort gabelig, zieht dann in einem, nach hinten convexen Bogen zum Anfange der Afterflosse, wo die Vereinigung beider Seiten zur ventralen Längsscheidewand stattfindet. Dicht hinter der Afteröffnung spaltet sich diese noch einmal, zieht um die Basis der Bauchflossen herum, und vereinigt sich dicht vor den letzteren zur medianen Scheidewand.

Diese Scheidewand wird nur von Rudolphr und Pacins erwähnt, und zwar haben sie nur die beiden Längsscheidewände gekannt. RudotPH *) macht mit Recht darauf aufmerksam, dass dadurch das electrische Organ in zwei Organe, ein rechtes und ein linkes, abgetheilt werde, eine Bemerkung, die später in Vergessenheit gerieth. Irrig ist seine Behauptung, dass die sehnige Scheidewand von der Haut bis zu den Muskeln dringe.

Pacini ***) bemerkt richtig, dass die Scheidewand nur bis zur Aponeurose dringe: übrigens findet er sie äusserst dünn und unbedeutend.

B a l ken-und Fächernetz.

Die übrigen, von der Haut zur Sehnenhaut tretenden Fortsätze zeigen eine verschiedene Beschaffenheit, je nachdem sie in dem, durch die Scheidewand umfangenen Raume, oder ausser demselben gelegen sind.

Dieses tritt besonders deutlich auf einem, nach der Axe des Fisches geführten, lang en Schnitte durch die Hautschwarte hervor (Tab. IV. Fig. 1.).

${ }^{*}$ ) a. a. O. p. $141 . \quad$ **) a. a. O. pag. 7 . 
In dem a usserhalb des Umkreises der Scheidewand, aber im Kopf- und Schwanztheile, gelegenen Theile der sulzigen Zwischenmasse (i) gewahrt man ein unregelmässiges, weitmaschiges Netz, durch grobe oder feine Brücken und Balken gebildet, welche die sulzige Zwwischenmasse in den verschiedensten Richtungen durchsetzen und sich in regelloser Weise theils unter sich, theils mit der Haut und Sehnenhaut verbinden, - ein Balkennetz, analog dem der Milz und der corpora cavernosa penis et clitoridis der Sängethiere.

Marcuser $^{*}$ ) ist der einzige, welcher dieses groben Netzwerkes auf dem Kopfe und in der Fettflosse Erwähnung thut.

Der innerhalb des Umfanges der Scheidewand gelegene Theil (o) zeiǵt dagegen ein sehr zartes, nur bei näherer Betrachtung mit freiem Auge wahrnehmbares, sehr regelmässiges, aus unzähligen rautenförmigen Maschen bestehendes Netzwerk. Das Gewebe, dessen Ausdruck auf Längsschnitten das eben beschriebene Netzwerk ist, wird durch unzählige zarte Lamellen gebildet, welche, in geringer Entfernung von einander, unter sich parallel, mit der Axe des Fisches sich kreuzend, denselben umkreisen und durch zahlreiche Verwachsungen jeder Lamelle mit ihren beiden Nachbarn, eine unzählige Menge kleiner, gleichartiger, linsenförmiger, vollkommen geschlossener Hohlräume zwischen sich lassen. Ich nenne dieses Gewebe, wofür mir kein Analogon bekannt ist. ein Fä chernetz und verspare mir dessen nähere Darstellung bis zur Beschreibung des electrischen Organes. dessen Gerüste es bildet.

\section{Die sulzige Zwischenmasse.}

Der Zwischenraum zwischen der äusseren Haut und der inneren Sehnenhaut, oder den sie vertretenden Knochen- und Muskelüberzügen, ist fast durchweg von einer gallertähnlichen Substanz angefüllt, welche schon von Geoffroy St. Hilaire in Bezug auf ihr äusseres Ansehen (nicht aber auf Fettgehalt!) nicht unpassend mit Speck verglichen worden ist.

Die Mächtigkeit dieser Zwischenmasse und die dadurch bedingte Dicke der Schwarte wechselt sehr nach den Körperstellen. Sie ist am beträchtlichsten in der Mitte des Rumpfes und nimmt nach vorn und hinten ab. Im Umkreise der natürlichen Körperöffnungen fehlt sie vollkommen.

Die Zwischenmasse ist nicht, wie es nach der Beschreibung der meisten Schriftsteller scheinen könnte, in ihrer ganzen Ausdehnung gleichartiger Natur, sondern zerfällt in zwei, anatomisch und physiologisch höchst verschiedene Abtheilungen, welche durch die eben beschriebene Scheidewand von einander getrennt sind: 1. die indifferente Ausfüllungsmasse und 2. die Substanz des electrischen Organes.

\section{Die indifferente Ausfüllmugsmasse. $(i)$.}

Der ausserhalb des Umkreises der sehnigen Scheidewand - also um den Kopf und um den Schwanz - gelegene Theil der Hautschwarte wird ron dem oben beschriebenen Balkennetze durchzogen. Dessen Maschen sind durch eine farblose, durchsichtige, sulzige Masse ausgefüllt. Dieselbe ist besonders in der Fettflosse und auf dem Kopfe in beträchtlicher Masse angehäuft.

$$
\text { *) a. a. O. III. pag. } 5 \text {. }
$$


Die microscopische Untersuchung zeigt eine homogene, glasartige, farblose Grundmasse, die einerseits von zahlreichen, bald isolirten, bald zu Bündeln vereinigten Bindegewebefibrillen durchzogen ist, andererseits zahlreiche, längliche Kerne, welche mit äusserst feinen blassen Fasern in Verbindung stehen, eingebettet enthält.

Diese indifferente Ausfüllungsmasse scheint von der gallertigen Substanz, welche den Raum zwischen der Haut und den Kopfknochen mancher Fische (andere Siluren, Cyprinoiden, Esox, Lota etc.) ausfüllt*), nicht verschieden zu sein.

\section{Das electrische Organ.}

F or m.

Das electrische Organ (oder vielmehr Organenpaar) des Zitterwelses hat die Form einer, aus zwei symmetrischen Seitenhälften zusammengesetzten Röhre, deren Mündungsränder in die Ränder zweier Hohlkegel (der vorderen und hinteren Abtheilung der indifferenten Ausfüllungsmasse) übergehen. Die äussere Oberfläche dieser Röhre ist von der Haut, die innere von einer fibrösen Membran überzogen In dem Lumen der Röhre endlich steckt, locker mit ihr verbunden, der Körper des Fisches***).

\section{A u s d e hn ung.}

Die Ausdehnung des electrischen Organes ist eine sehr beträchtliche. Sein Gewich t beträgt (beide Überzüge eingerechnet), über $\frac{1}{4}$ des gesammten Körpergewichtes $\left.{ }^{*} * *\right)$.

Die Länge des Organes bleibt sich überall fast gleich, man mag es in der Rückenlinie, Bauchoder Seitenlinie messen $\dagger$ ). Nach vorne reicht es seitlich bis hinter die Brustflosse, oben mit lappenartiger Verlängerung bis in die Zwischenaugengegend, unten his zum Vorderrande des Schultergürtels. Nach hinten: oben bis zum Anfange der Fettflosse, unten bis zum Anfange der Afterflosse, seitlich bildet es eine lappenartige Verlängerung nach hinten.

Die Dicke ist am beträchtlichsten in der Mitte des Rumpfes und etwas nach vorn davon, und nimmt gegen das vordere und hintere Ende des Körpers allmälig ab. In querer Richtung liegt die grösste Dicke des electrischen Organs in der Gegend der Seitenlinie, und nimmt gegen den Rücken, und noch mehr gegen den Bauch hin ab + t) $+\cdots)$.

*) Vergl. Leydig, über die Haut einiger Süsswasserfische, Zeitschr. f. wiss. Zool. Bd. III. p. 4 .

**) s. Pscini, a. a. O. Fig. 2.

***) Gew, eines Exemplars von 22 Zoll $=8 \not \ell$.

Gew. des Körpers ohne Organ $=5 \frac{3}{4} \not \ell$.

Gew. des electrischen Organs $=2 \frac{1}{4} \mathscr{\ell}$

†) Länge des obigen Exemplares von $\delta \mathscr{\ell}$

von der Schnauze zum Ende der Schwanzflosse 22 ".

von der Schnauze zum Anfang der Schwanzflosse 19".

Länge des Kopftheiles der Hautschwarte . . . . oben 2 $\frac{1}{2} "$, unten $2 \frac{1}{2}$ ", seitlich $3 \frac{1}{2}$.

Länge des Schwanztheils der Hautschwarte . . . oben $4 \frac{1}{2} "$, unten 5 , seitlich $3 \frac{1}{2}$ ".

Länge des (electrischen) Rumpftheils der Hautschwarte oben 12", unten 11:", seitlich 12".

†t) s. Pucris's Durchschnitt a. a. O. Fig. 2.

计市) Dicke des electrischen Organes bei obigem Exemplare:

in der Mitte des Rumpfs, etwas über der Seitenlinie $=\delta^{\prime \prime \prime}$

in der Mittellinie des Rückens . . . . . . 2 $2 \frac{1}{2}$.

in der Mittelinie des Bauches . . . . . . 2". 


\section{Structur des electrischen Organes.}

Der das electrische Organ enthaltende Theil der Hautschwarte zeigt ein von dem der analogen Organe der übrigen Zitterfische so verschiedenes Ansehen, dass man kaum erwarten möchte, seinen Bau mit der bei letzteren bestehenden Anordnung in Einklang bringen zu können. Während nämlich die Elemente der letzteren deutlich als kleine Plättchen zu erkennen sind, welche, in regelmässigen, von Flüssigkeit erfüllten '/wischenräumen an einander gereiht, Säulen bilden, deren Ähnlichkeit mit der Volta'schen Säule den meisten Beobachtern sich aufdrängte: stellt das electrische Organ des Zitterwelses eine continuirliche, speckähnliche, gallertartige Masse dar, welche in, nach gewissen Richtungen geführten Durchschnitten fast homogen, in andern von einem zarten Netzwerke durchzogen erscheint. Bei genanerer Untersuchung ergibt sich indessen, wie unten bewiesen werden soll, dass diese, scheinbar so bedeutende Verschiedenheit im Bau physiologisch entsprechender Organe keine fundamentale ist, sondern nur auf einer abweichenden Gruppirung wesentlich analoger Elemente beruht.

Die vorliegenden Beschreibungen des electrischen Organes beschränken sich fast gänzlich auf die gröberen Structurverhältnisse.

Geoffroy St. Hilaire*) sagt, dass das electrische Organ aus wahren Sehnenfasern zusammengesetzt sei, welche durch Kreuzung ein Netz bilden, dessen Maschen deutlich nur mit der Lupe zu erkennen seien. Die einzelnen Hohlräume dieses Netzes seien mit einer eiweissig-gallertigen Substanz gefüllt.

Nach Rudolphi*****) besteht es aus kleinen rautenförmigen Zellen, deren Wände blättchenartig an einander liegen. -

VaLEncrennes ${ }^{* * *}$ ) beschreibt es als ein zelliges, gleichsam schwammiges Gewebe, zusammengesetzt aus dünnen, sich kreuzenden Blättchen, wodurch Maschen gebildet werden, die von gallertiger Flüssigkeit durchdrungen sind. -

Nach Peters †) hat das electrische Organ, mit blossem Auge betrachtet, ein faserig-zelliges Ansehen. Diese Zellen erscheinen, mit der Lupe betrachtet, rhomboidal; schneide man ein Stückchen heraus. so finde man bald rhomboidale, bald mehrseitige Zellen. Zuweilen scheine es, als wenn diese Zellen (von aussen nach imnen gehend) eine Art Perlenschnur bildeten. Bei der Untersuchung mit dem zusammengesetzten Microscope bestehe das electrische Organ aus einer äusserst feinen Haut, die sich leicht in feine Fältchen lege, welche man nicht mit Fasern verwechseln dürfe und zweitens aus runden, microscopischen Körperchen, die eine gallertartige Masse zusammensetzen. -

Pacror $+t)$ findet die Hohlräume des electrischen Organes gross genug, um, wenn die Wände ausgedehnt sind, mit freiem Auge gesehen zu werden. Sie haben ungefähr die Weite eines Kubikmillimeters (in einem Individuum von 30 Centim. Länge). Diese Hohlräume sind nach allen Sciten hin geschlossen und stehen nicht unter einander in Verbindung, wie man aus den Worten Georrnor's: me peuvent pas communiquer à l'intérieur à canse« etc. schliessen könnte. - Die Wandungen dieser Hohlräume bestehen aus Zellstofffasern, geflochten wie in den feinen serösen Häuten. Vielleicht besitze deren freie Fläche ein Pflasterepitelium, an dessen näherer Untersuchung ihn die durch den Alcohol bewirkte Veränderung verhindert habe. Wenigstens habe er viele Kerne dort gesehen. die ihm das Vorhandensein eines Epiteliums

\footnotetext{
Siche pag. 2.

*a) a. a. O. pag. 139. +†) a. a. O. pag. 10. Fig. 3. C. 
wahrscheinlich machen. Die vieleckige Form der Hohlräume könne im Allgemeinen auf die eines Octaëders zurückgeführt werden, denn, in welcher Richtung man das electrische Organ durchschneide, so erscheine der Durchschnitt der Hohlräume meist in Form eines Rechtecks, oder Trapezes oder Quadrates. Führe man den Schnitt durch das electrische Organ in einer, senkrecht auf die Oberfläche der Haut fallenden Ebene, so erscheine der Durchschnitt in Form einer Raute. Eine der sechs Ecken des Octaëders sei stets gegen die Haut gekehrt, die entgegengesetzte gegen die Sehnenhaut. Die 8eckige Form der Hohlräume bewirke, dass die 8 Wände, aus welchen jeder gebildet sei. zu einander schief stehen, und daher sei es nicht möglich, zu bestimmen, in welcher Ordnung sie als electromotorische Flemente gestellt seien. -

Das electrische Organ des Zitterwelses gehört unter die schwierigsten Gegenstände für die anatomische Untersuchung. Es erinnert vielfach an den Glaskörper des Auges. Seine Zusammensetzung aus kleinen, mit farbloser Flüssigkeit gefüllten Hohlräumen, abwechselnd mit feinen und durchsichtigen, aber zähen Häutchen und zarten, hinfälligen Gebilden, macht reine Schnitte zur Unmöglichkeit und gewährt daher dem Microscope nur verworrene Bilder; während die ineinandergeschobene Anordnung der Elemente, die Durchsichtigkeit und Zartheit derselben, der Untersuchung mit freiem Auge oder mit der Lupe eben so grosse Schwierigkeiten entgegensetzt. Eine klare Einsicht in den Bau des electrischen Organes ist nur durch gelungene Chromsäurepräparate zu erlangen. Erst nach erfolgter Orientirung durch diese, ist die Untersuchung frischer Präparate von Nutzen.

$$
\text { Frische Präparate. }
$$

Durchschneidet man das electrische Organ an irgend einer Stelle, von der Haut zur Sehnenhaut dringend, so fliessen einige Tropfen klarer Flüssigkeit ab; die Schnittflächen erscheinen vorgewölbt, halbdurchsichtig, von graulich gelbweisser Farbe. Die Consistenz ist der des Glaskörpers oder der Wharton'schen Sulze zu vergleichen. Bei genauerer Betrachtung mit freiem Ange oder mit der Lupe erkennt man an den meisten Durchschnitten das von Geofrroy St. Hilaire u. A. erwähnte Netzwerk, gebildet von feinen, weissen, von der Haut zur Sehnenhaut ziehenden, unter spitzem Winkel sich kreuzenden Fasern (Tab. IV. Fig. 1. o.) Die Maschenräume dieses Netzes sind graulich, halbdurchsichtig, rautenförmig, ihr kurzer Durchmesser der Axe des Fisches parallel, ihr langer, etwa $\frac{1}{2}{ }^{\prime \prime \prime}$ messend. - Das erwähnte Netzwerk ist aber nur auf solchen Durchschnitten zu sehen, welche entweder der Axe des Fisches parallel gehen oder dieselbe in schicfe Winkel schneiden, oder auf solchen, welche der Hautoberfläche parallel laufen. Dagegen zeigen Durchschnitte, welche die Axe des Fisches in rechtem Winkel schneiden, gleichförmige, gelbweisse Schnittflächen, auf denen, ausser den unregelmässig verlaufenden Nerven und Gefässen, keine weitere Faserzüge zu erkennen sind*). - Die microscopische Untersuchung frischer Präparate gibt, wie gesagt, erst dann brauchbare Resultate, wenn man sich über die allgemeine Anordnung schon anderweitig orientirt hat.

Weing e istpräparate.

sie lassen die eben geschilderten Structurverhältnisse in manchen Punkten noch deutlicher erkennen. Die Śchnittfläche ist undurchsichtig, gelbweiss, eingesunken. Auf Durchschnitten, die mit der Axe

*) PAcru's Fiy. 2. ist daher, was das Netzwerk betrifft, nicht richtig, wol aber Fig. 1. 
des Fisches parallel sind, oder sie in schiefem Winkel schneiden, oder der Hautoberfläche parallel gehen, hat die Schnittfläche ein schwammiges Ansehen, das Netzwerk tritt deutlicher hervor und dessen Maschenräume sind leer. Durchschnitte, welche die Axe des Fisches in rechtem Winkel schneiden, zeigen höchst undeutlich runde, flach vertiefte Grübchen. - Weingeistpräparate eignen sich, ihrer Undurchsichtigkeit wegen, ebenfalls nicht für microscopische Untersuchung.

Chromsäurepräparate.

Dieselben verhalten sich, mit blossem Auge oder der Lupe untersucht, ganz wie die Weingeistpräparate.

Die microscopische Untersuchung gibt folgende Resultate:

Wir haben zunächst zwei Bestandtheile zu unterscheiden :

1. das fibröse Gerüste des Organes, welches schon oben unter dem Namen des Fächernetzes erwälnt wurde.

2. die in demselben enthaltenen Theile.

a. Fasergerüste (Fächernetz) (Tab. IV. Fig. 2, c.)

Schon aus der Untersuchung frischer Präparate mit freiem Auge oder der Lupe geht deutlich hervor, dass das electrische Organ unseres Fisches ein blättriges Gefüge hat, und dass der Zug dieser Blätter eine, die Axe des Fisches in rechtem Winkel schneidende Richtung nimmt. Diese Blätter sind nichts anderes, als die Elemente des Fächernetzes.

Man hat sich die Anordnung des Fächernetzes in folgender Weise vorzustellen: es wird gebildet aus einer unzähligen Menge zarter bandförmiger Membranen, die, durch kleine Zwischenräume von einander getrennt, neben einander laufen. Mit dem einen Rande sind sie an der Innenfläche der Haut, mit dem andern an der Aussenfläche der Sehnenhaut festgeheftet; ihr eines Ende ist an die dorsale, ihr anderes an die ventrale Medianscheidewand befestigt. Auf diese Weise ist das Organ von unzähligen, sichelförmigen, unter sich parallelen, sämmtlich quer auf die Axe des Fisches gestellten Scheidewänden durchzogen. Die zwischen diesen Scheidewänden befindlichen Zwischenräume werden nun dadurch, dass die einander zugewendeten Flächen der Scheidewände unter sich zahlreiche kreisförmige Verwachsungen eingehen, in in viele kleine, mit einander nicht communicirende Hohlräume - Fächer — abgetheilt.

Diese Fächer sind unter einander an Form und Grösse sehr übereinstimmend. Die Grundforn derselben ist die Linse, welche aber durch wechselseitigen Druck zur niedrigen polygonen Doppelpyramide wird, gerade so, wie die Kugelform der freien Pflanzenzelle im Parenchym zum Polyeder sich abflacht. Die Axen dieser linsen- (oder doppelpyramiden-) förmigen Fächer liegen sämmtlich parallel der Axe des Fisches; ihre Äquatorialebenen stehen rechtwinklig auf derselben; die eine Wand ist dem vorderen, die andere dem hinteren Ende des Fisches zugewendet.

Die Grösse dieser Fächer ist sehr unbedeutend. Der lange (Äquatorial-) Durchmesser beträgt etwa $1^{\prime \prime \prime}$, der kurze bietet sich auf Durchschnitten niemals in seinen natürlichen Verhältnissen dar.

Eine Berechnung der Zahl dieser Fücher, wie sie von Valentix und R. WAGNer für die analogen Gebilde des Zitterrochens und Zitteraales versucht wurde, ist, ihrer Anordnung wegen, nicht möglich.

Histologisch bestehen die das Füchernetz bildenden Membranen aus einer homogenen, wasserklaren 
Gruudmasse und zahlreichen, in verschiedenen Richtungen durch einander geflochtenen, bald isolirten, bald in Bündeln vereinigten Bindegewebefibrillen.

Die Membranen des Fächernetzes werden von zahlreichen Gefässen und Nerven durchzogen. Erstere lösen sich darin in reiche Endnetze auf. Letztere - die Äste und Zweige des electrischen Nerven - durchlaufen sie, ohne in ihnen zu endigen.

Der Verlauf des electrischen Nerven von seinem Ursprunge bis zum Eintritte in das electrische Organ ist oben beschrieben worden. Die Äste des Nerven durchbohren die innere Sehnenhaut und versenken sich in die Substanz des electrischen Organes. Jeder Ast ist in seine beiden Scheiden, die gefässhaltige und die gefässlose, eingehüllt und wird noch überdies eine Strecke weit von einem scheidenartigen Fortsatze der innern Sehnenhaut begleitet. Innerhalb des electrischen Organes verläuft er, den Membranen des Fasernetzes folgend, und erleidet daselbst unzählige Theilungen (Tab. IV. Fig. 8.). Alle drei Bestandtheile des Astes (Primitivfaser, innere und äussere Scheide) nehmen daran Theil. Die äussere Scheide ist an den Theilungsstellen etwas verdickt. Die Theilung ist bald 2-, bald 3-, bald 4 fach. In der Regel ist der Durchmesser jedes der Zweige nicht merklich geringer, als derjenige des Astes, aus welchem sie entspringen. Allmälig aber, nach wiederholten Theilungen, werden die '/weige dünner und dünner, endlich zu Endzweigen von etwa $-\frac{1}{7}$ "' Durchmesser, während die in denselben enthaltene Nervenfaser zu einem feinen, $\frac{1}{80}-\frac{1}{600}$ "' messenden Fädchen geworden ist, welches aber durch Glanz und doppelte Contur deutlich erkennbar bleibt. An einer gewissen Stelle aber hört die stark lichtbrechende und dunkelrandige Markschicht auf und das Innere des Nervenfädchens wird durch eine feinkörnige, schwach lichtbrechende Masse (Axencylinder) erfüllt. Bald nach dieser Umwandlung seines Inhaltes verlässt das Endzweiglein das Fasernetz, indem es die hintere Wand eines Faches in ihrem Mittelpunkte durchbohrt, und sich an die, im Folgenden zu beschreibende »electrische Platte« festsetzt. Es erleidet dabei selber weitere Veränderungeu, die an ihrem Orte beschrieben werden sollen.

\section{b. Inhalt der Fächer des Fasergerüstes.}

Die Fächer des electrischen Organes sind an frischen Präparaten stets prall gefüllt. Bei Durchschnitten entleeren sich nur die durch den Schnitt getroffenen, die tiefern nicht.

Jedes Fach enthält zweierlei Bestandtheile: 1. eine klare Flüssigkeit und 2. eine membranartige Ausbreitung von höchst eigenthümlicher Beschaffenheit.

$$
\text { «. Flüssigkeit. }
$$

Über die chemischen und morphologischen Eigenschaften dieser Flüssigkeit weiss ich wenig anzugeben, da es kaum möglich sein dürfte, auch nur eine kleine Menge rein zu erhalten. Wahrscheinlich ist, dass diese Flüssigkeit viel Eiweiss enthält. Die aus grösseren Schnittflächen ausgedrückte Flüssigkeit ist fadenziehend und trübt sich sehr stark bei Zusatz von Salpetersäure; die blanke Messerklinge erhält kurze 'Zeit nach dem 'Tode des 'Thieres beim Durchschneiden schwarzen Beschlag und das Organ fault mit starkem Schwefelwasserstoffgeruch. Übrigens kömnen alle diese Frscheinungen durch die im Folgenden zu beschreibende Substanz bedingt sein.

$$
\text { P. Dic membranöse Ausbreilung. (Tab. IV. Fig. 2. d., Fig. 3. 4. 5. 6. 7.) }
$$

Jedes Fach enthält eine eigenthümliche, scheibenförmige, hautartige Ausbreitung, welche ich als das wahre electromotorische Element und als die Endausbreitung eines Nervenzweigleins erkennen muss 
und daher electrische Platte oder Nerven-Endplatte (lamina terminalis s. electrica) nenne.

Die genannte Platte überzieht die ganze hintere Wand des Faches. Ihr R and liegt in dem Falze des linsenförmigen Hohlraumes; ihre vordere (freie) Fläche sieht gegen das Kopfende des Fisches; ihre hintere Fläche liegt der Vorderfläche der hintern Wand des Faches an, ist aber mit Ausnahme des Mittelpunktes nur locker mit derselben verbunden und ziemlich leicht davon abzulösen. Im Mittelpunkte steht sie durch einen Stiel (Tab. IV. Fig. 2. 4. 5. 6. n.), welcher ein feines Nervenzweiglein enthält, mit der Hinterwand des Faches in fester, organischer Verbindung.

Im Innern des electrischen Organs besitzen die electrischen Platten die Gestalt einer kreisförmigen in der Mitte dickern, gegen die Peripherie hin zugeschärften, mit einem verdickten Rande versehenen Scheibe (Fig. 2. d., Fig. 3.). Da, wo der Hohlraum seine regelmässige Gestalt verliert, wie in der Nähe der Überzüge Fig. 2. $d^{\prime}$.), nimmt auch die Nervenendplatte eine unregelmässige Gestalt an. - Der Rand der Scheibe ist ziemlich regelmässig kreisrund, sanft wellenförmig, etwas verdickt. - Die hintere Fläche der Scheibe ist, mit Aúsnahme des Centrums, vollständig glatt. Im Mittelpunkte bildet sie eine Einsenkung oder Höhle (Fig. 4.6.h.), deren Mündung durch unregelmässige, warzenförmige Hervorragungen ringförmig verengt wird (Fig. 4. 6. r.). Das Centrum dieses Ringes und die Axe der Höhle wird durch den oben erwähnten, das Nervenzweiglein enthaltenden Stiel $(n)$ eingenommen. Das Ende des Stielchens $(k)$ ist auf dem Boden der Höhle eingepflanzt. - Die vordere Fläche der Scheibe zeigt dagegen zahlreiche Unebenheiten. Der Mittelpunkt wird von einer platten Hervorragung (Fig. 4. 5. e.) von länglich rundem Umkreise eingenommen, welche der auf die hintern Fläche der Platte befindlichen Einsenkung entspricht. Die Oberfläche dieser Hervorragung zeigt zahlreiche warzenförmige Erhabenheiten $(w)$ und trägt in ihrer Mitte ein kleines schiefes, trichterförmiges Grübchen $(t)$, welches genau der Verwachsungsstelle des Nervenstielchens gegenüberliegt. - Von dieser centralen Hervorragung entspringen 9-10 strahlenförmige erhabene Falten $(f)$, welche, vielfach gewunden, sich theilend und verbindend, gegen die Peripherie hinziehen, allmälig niedriger werden und endlich in sanfte wellenförmige Unebenheiten sich auflösen. Diese Bildung erinnert lebhaft an eine centrale Hochebene mit strahlenförmig von ihr auslaufenden Gebirgsketten. -

Die Grösse der electrischen Platten scheint bei einem und demselben Individuum nur geringen Schwankungen unterworfen zu sein. Der Flächendurchmesser einer normal gebildeten Platte beträgt bei mittelgrossen Exemplaren etwa $\frac{1}{2}^{\prime \prime \prime}$, die Dicke in der Mitte $\frac{1}{40}-\frac{1}{50}$, an den Rändern $\frac{1}{\frac{1}{9}}-\frac{1}{90}{ }^{\prime \prime \prime}$.

Das histologische Verhalten der electrischen Platten ist ein sehr merkwürdiges. Im frischen Zustande erscheint die electrische Scheibe als eine ziemlich dicke, weiche, homogene, aus einer glasartig durchsichtigen Grundmasse, vielen äusserst kleinen Körnchen und grösseren, runden, in bestimmten Abständen zerstreuten Kernen bestehende Membran. - Bei beginnender Zersetzung aber, und an Chromsäurepräparaten erkennt man, dass die ganze Oberfäche der Scheibe von einem äusserst zarten, structurlosen Häutchen überzogen ist. Im ersteren Falle (bei beginnender Zersetung) verwandelt sich die Scheibe in ein Säckchen, dessen zarte Hülle unzählige feine Falten wirft, während die winzigen Körnchen des Inhaltes in lebhafter Molecularbewegung begriffen sind. Auf Querschnitten der Scheibe an Chromsäurepräparaten sieht man jederseits eine feine Linie als Ausdruck der zarten Hüllenmembran (Fig. 4. m. m'.).

Die ron der genannten Membran umschlossene Inhaltsmasse (Fig. 4. i. Fig. T.) der Platte ist 
aus drei Bestandtheilen zusammengesetzt: 1. einer zäh-weichen, homogenen, glashellen, farblosen, schwach lichtbrechenden Grundmasse. 2. aus sehr feinen, farblosen Körnchen, welche in grosser Menge in der Grundmasse eingebettet liegen. 3. aus kugelrunden Kernen von $\frac{1}{2} \frac{1}{20}-\frac{1}{3-1 "}$ Durchmesser; welche in Abständen von $\frac{1}{40}-\frac{1}{60}$ "' unregelmässig zerstreut sind. Jeder Kern besitzt ein helles, rundes, wandständiges Kernkörperchen von etwa $\frac{1}{4000} "$ Grösse.

Die genannten Bestandtheile der Inhaltsmasse finden sich in allen Theilen der Scheibe. Doch bestehen in Bezug auf deren Gruppirung manche Verschiedenheiten. Im periplierischen Theile der Scheibe liegen die Kerne der vorderen (freien) Fläche der Scheibe genähert, während die Molecularkörperchen hauptsächlich gegen die hintere Fläche der Scheibe angehäuft sind. Im centralen Theile der Scheibe dagegen häufen sich die Körnchen hauptsächlich um die Kerne herum, wodurch kugelige Massen entstehn, die ganz das Aussehen kleiner Ganglienkörper haben. Dieselben liegen meist der (vorderen oder hinteren) Oberfläche der Scheibe nale und bilden dann warzenförmige, nach aussen von der Hüllmembran der Scheibe überzogene Erhabenheiten, während deren nach innen gewandter Theil mit der Inhaltsmasse in unmittelbarer Continuität zu stehen scheint. Solche warzenförmige Erhabenheiten finden sich, wie oben angegeben wurde, sowol auf der Oberfläche der platten Hervorragung der Vorderfläche (Fig.4.w.), als auch auf dem Boden der ihr entsprechenden Höhle der Hinterfläche und auf dem Mündungsringe dieser Höhle (Fig. 4. r.). Ähnliche kugelige Körperchen finden sich endlich in dem kolbig angeschwollenen Ende des Nervenstielchens $(k)$.

Dieses Nervenstielchen ist die unmittelbare Fortsetzung eines Endzweigleins des electrischen Nerven. Es wurde oben (pag. 33) bis zu der Stelle', wo es die hintere Wand des Faches durchbohrt, verfolgt. Dort (Fig. 4. n.) besteht es 1. aus einem blassen feingranulirten Centralcylinder (Axencylinder), 2. einem dünnen innern Hüllencylinder als Fortsetzung der gefässlosen Scheide und 3. sparsamen Bindegewebefasern, als Rest der äussern Scheide. - An der Stelle, wo das Endzweiglein die Rückwand des Faches durchbohrt $(d)$, verliert es die äusseren Bindegerwebefasern, welche ohne Zweifel in das Gewebe dieser Wand übergehen. Die innere Scheide dagegen verdünnt sich zu einem zarten Häutchen. Trotzdem nimmt der Durchmesser des Nervenstielchen nicht ab, sondern schwillt im Gegentheile kolbenförmig an (Fig. 4. 6. k.). Denn zu gleicher Zeit ist eine bedeutende Veränderung seines Inhaltes vor sich gegangen. An der Stelle des Axencylinders, und mit demselben in unmittelbarem Zusammenhang stehend, erfüllen das Innere des Nervenzweigleins zellenartige Körperchen von kugeliger Form und etwa $\frac{1}{10} \overline{0}$ "Grösse, welche vollkommen das Ansehen von Ganglienkörperchen haben. Dieselben stimmen mit den das Centrum der electrischen Platte $(w . r$.$) erfüllenden Körperchen in Bezug auf Form, Grösse und Zusammenhang vollkommen überein,$ und schliessen sich auch räımlich unmittelbar an dieselben an. Jedes dieser Körperchen besitzt einen Kern, welcher den in der Platte zerstreuten Kernen in allen Stücken gleich ist; die ihn umschliessende Masse entspricht eben so genau, einerseits der feinkörnigen Grundmasse der Platte, andererseits der Substanz des Axencylinders. Alle diese Körperchen scheinen einer eigenen Membran zu entbehren, und nicht durch Fortsätze, sondern durch unmittelbare Anlagerung der Substanz unter einander in Zusammenhang zu stehen.

Nach den gegebenen Thatsachen sehe ich die electrische Platte an:

1. als das wahre Ende der electrischen Nervenfaser, eine flächenhafte Ausbreitung des Axencylinders.

2. als eine peripherische Anhäufung von (ngranerw) Nervensubstanz, als ein - sit venic verbo - 
peripherisches Centralorgan, bestehend aus einer Anhäufung feinkörniger Muttermasse mit darin eingebetteten Kernen, welche Bestandtheile theils amorph gelagert, theils zu zellenartigen Körperchen concentrirt sind.

Diese Anschauung steht mit einer sonst sehr auffallenden Thatsache - : der geringen Masse des electrischen Nerven -, in schönstem Einklange. Da jede Platte, so zu sagen, ein Centralorgan ist, so hat der Nerv weiter nichts zu thun, als den Befehl zu überbringen.

\section{B. Vergleichender 'I'heil.}

Für die richtige Deutung der im obigen beschriebenen Elemente des electrischen Organes des Zitterwelses ist es von erster Wichtigkeit, den Bau der analogen Organe anderer electrischer Fische in vergleichende Betrachtung zu ziehen. Ich beschränke mich hier auf diejenige Zitterfische, deren electrische Fähigkẹit physiologisch festgestellt ist, nämlich: die electrischen Rochen (zunächst Torpedo ocellata, Rud. s. Narke, Risso. und T. marmorata Rud. s. Galvanii Bonap.) und den Zitteraal (Gymnotus electricus L.). Über beide liegen sehr genaue Beschreibungen vor: über die Zitterrochen, ältere von VALentin*) (nach Weingeistexemplaren) und SAVI ${ }^{*}$ ) (an frischen Thieren), neuere von R. WAgner ${ }^{*}$ ***) und Pacini $\dagger$ ) (an frischen Exemplaren); über den Zitteraal ältere von Valentin $+\dagger$ ), neue von PACINI ttt) (beide nach Weingeistexemplaren).

Fassen wir die Hauptresultate dieser Untersuchungen zusammen, so finden wir, dass das electrische Organ beider Fische, abgesehen von der Flüssigkeit, aus zwei heterogenen Bestandtheilen zusammengesetzt ist:

1, einem Systeme faseriger, unter sich im Zusammenhange stehender Membranen, welchem das Organ seine äussere Form und seine innere Eintheilung verdankt, die sein Skelet, sein festes Gerüste bilden. Ich bezeichne dieses System kurz als F a serger üste.

2. Einer eigenthümlichen Substanz, welche sich in den Fächern des Fasergerüstes abgelagert findet. Diese Substanz wird von Valentin, der sie zuerst unterschieden und bei beiden Fischen nachgewiesen hat, als "Epiteliallage " bezeichnet.

*) Handwörterb. d. Physiol. Bd. I. p. 251 ff. (Artikel : Eleetricität der Thiere).

***) Etudes anatomiques sur le système nerveux et sur l'organe électrique de la torpille, in Ma t teucci's: traité des phénomènes electro-physiologiques des animaux. 1S44. p. $283 \mathrm{ff}$.

****) I. Neue Untersuchungen über den Bau und die Endigung der Nerven. 1847.

II. Über den feineren Bau des eleetrisehen Organs im Zitterroehen. 1847.

III. Handwörterbuch der Physiol. Bd. III. Abth. 1. (Artikel: sympathischer Nerv, Ganglienstruktur und Nervenendigungen).

IV. Annales des sc. nat. Zool. 3. série. 1547.

V. Zahlreiehe Mittheilungen in den Göttinger Naehrichten, gesammelt in: Neurologische Untersuchungen. 1854 .

†) Sulla struttura intima dell' organo clettrico del Gimnoto e di altri pesci elettrici. (Gazzetta medica italianu feclerativa T'uscanc - 1552. pag. $305 \mathrm{fH}$.)

+ t) a. a. $\quad$ (t十) a. a. O. 
Von den Organen beider Fischgattungen scheint dasjenige des Zitteraales, welches in neuester Zeit durch PaCrsi mit grosser Genauigkeit und Ausführlichkeit beschrieben wurde, sich durch besonders klare Verhältnisse auszuzeichnen, so dass ich es, als ein gleichsam typisches, in erster Reihe betrachte.

\section{Electrisches Organ des Zitteraales.}

Das Faserger üste des electrischen Organes des Zitteraales besteht: erstens aus einer sehnigen Umhüllungshaut, welche das Organ (wenigstens da, wo es nicht von der äusseren Haut überzogen ist) allerwärts bekleidet, und zweitens aus zahlreichen, von derselben (oder der sie vertretenden Cutis) entspringenden, in das Innere des Organes eindringenden Fortsätzen, welche in Form von Scheidewänden die Masse des Organes in zahlreiche Kammern und Kämmerlein abtheilen. Diese Scheidewände zerfallen nach Ausdehnung und Richtung in zwei Ordnungen: die einen entspringen unmittelbar aus der allgemeinen Umhüllungshaut (resp. Cutis) und theilen das Organ in grosse Hauptabtheilungen, - Scheidewände erster Ordnung, (aponeurotische Scheidewände Valentin, Pacini); - die andern dagegen entspringen aus den vorigen und theilen die durch jene umschriebenen Räume in viele kleine secundäre Hohlräume ab -- Scheidewände zweiter Ordnung (Grundmembran der Septa VAL., lamella

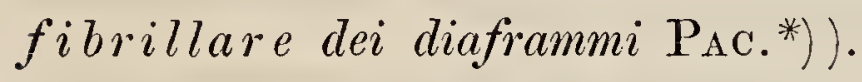

Die Scheidewände erster Ordnung ziehen beim Zitteraale in Form von geraden, unter sich und mit der Axe des Fisches parallel laufenden Bändern, und theilen das electrische Organ der Länge nach in eine Reihe horizontaler, über einander geschichteter, sehr langer, ziemlich breiter, und sehr niedriger K ammern (Bänder VAL.). Diese Kammern werden nun durch die, rechtwinklig aus ihren Wandungen entspringenden, vertical auf die Axe des Fisches gestellten Scheidew ände zweiter Ordnung in unzählige kleine Hohlräume - Fächer - abgetheilt. — Diese Fächer folgen sich in der Richtung von vorn nach hinten, sind schmal, ziemlich hoch und sehr lang; ihr längster Durchmesser schneidet die Axe des Fisches im rechten Winkel. Die vordere und die hintere Wand eines jeden Faches wird durch je eine Scheidewand ziveiter Ordnung gebildet, die schmalen seitlichen Wände dagegen von den Scheidewänden erster Ordnung. -

Im Innern dieser Fächer findet sich nun die eigenthümliche Substanz, welche VALEntro „Epiteliallage ", Pacini "corpo cellulare" nennt.

Valentro ${ }^{*}$ ) berührt das Verhalten dieser Substanz beim Zitteraale nur sehr kurz. Er sagt: „ die Elemente sind durchaus die analogen (wie beim Zitterrochen). In jedem Septum haben wir ein Grundmembran, die Fortsetzung der aponeurotischen Scheidewand, mit der zu beiden Seiden befindlichen Epiteliallage." Die "Epiteliallage» bekleidet aber nach ilım sowol die vordere, als die hintere Fläche jeder Scheidewand zweiter Ordnung, sowol die hintere, als die vordere Wand jedes Faches. - In Bezug auf die Histologie dieser Epiteliallage bemerkt VALENTrN, dass sie mit der des Zitterrochen, die er näher beschrieben hat, übereinstimme. (Siehe unten).

\footnotetext{
*) Septum VAr. ist = Grundmembran + Epiteliallage; diaframma Pac. = lamella fibrillare + corpo cellulare. **) a. a. O. pag. 269.
} 
PACINI*) hat diese von ihm als "corpo cellulare dei diaframmi " bezeichnete Substanz sehr genau und ausführlich beschrieben. Ich gebe einen möglichst kurzen und möglichst vollständigen Auszug davon (hierzu beistehender Holzschnitt, Pacini's Fig. IV.).

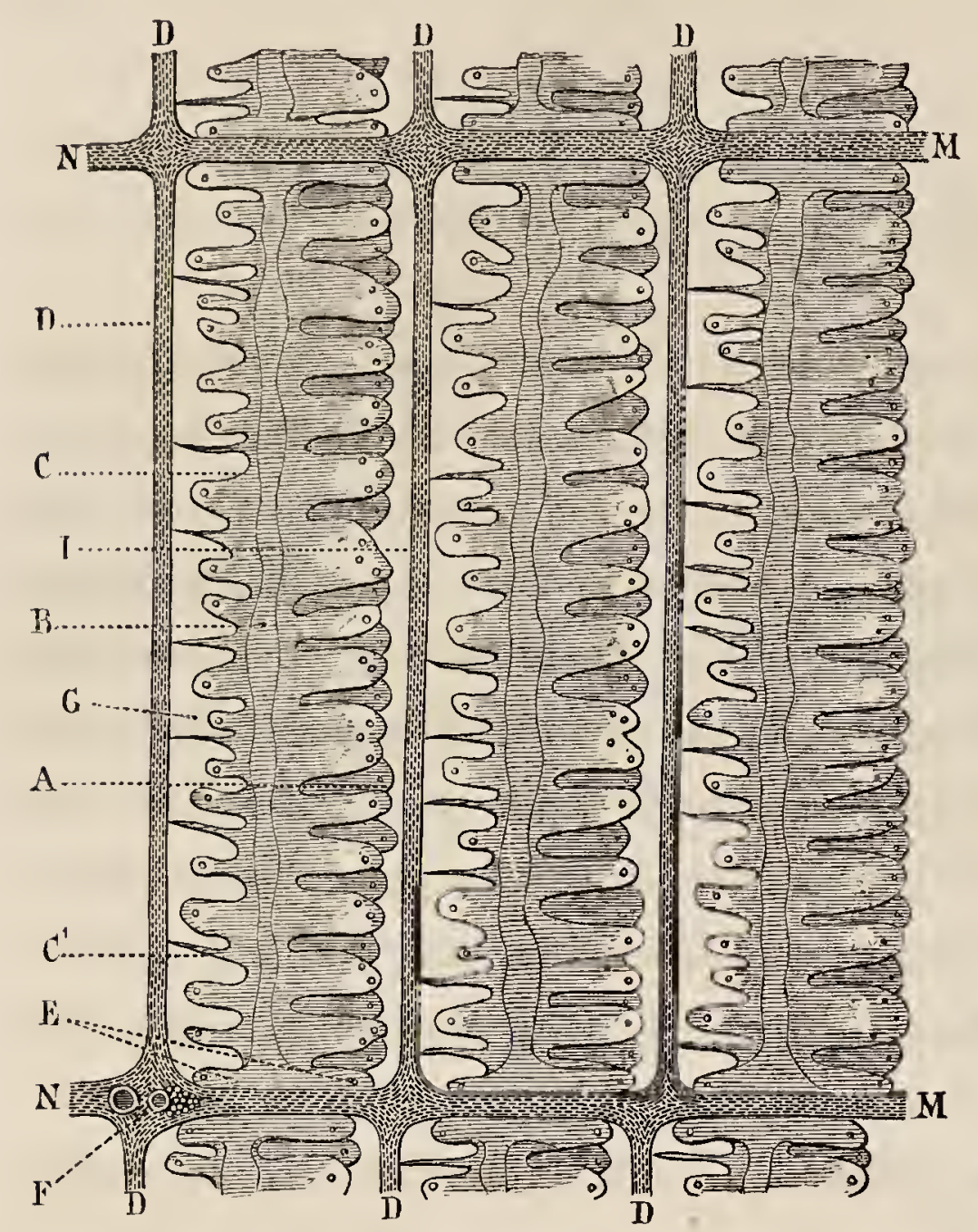

An der vorderen Seite einer jeden Scheidewand zweiter Ordnung (lamella fibrillare) $(D)$ findet sich eine membranöse Ausbreitung (corpo cellulare) (A.B. $C$.$) , welche von der genannten Scheidewand durch einen$ schmalen Zwischenraum $(G)$ getrennt ist, aber durch fadenförmige Verbindungsstränge $\left(C^{\prime}\right)$ mit derselben organisch zusammenhängt. Diese membranöse Ausbreitung ist an den Rändern $(\boldsymbol{E})$ mit den Scheidewänden erster Ordnung (M.N) verwachsen. Ihre vordere, freie Fläche sieht gegen die Hinterfläche der zunächst nach vorn liegenden Scheidewand zweiter Ordnung, ihre hin tere gegen die Vorderfläche der zunächst folgenden. Die membranöse Ausbreitung ist an Flächenraum und Gestalt den Scheidewänden zweiter Ordnung gleich und bildet selbst eine Scheidewand, welche jedes Fach in zwei Abtheilungen scheidet: eine vordere (spazio sopracellulare) $(I)$ zwischen der membranösen Ausbreitung und der vorhergehenden Scheidewand und eine hintere (spazio-sottocellulare) $(G)$ zwischen ersterer und der nachfolgenden Scheidewand. Die erstere Abtheilung ist frei, die letztere von den Verbindungssträngen durchzogen; beide von Flüssigkeit erfüllt.

Ihrer Beschaffenheit nach erscheint diese membranöse Ausbreitung als eine dicke, wellige Membran von etwa 0,010 mm Durchmesser, mit zahlreichen Hervorragungen auf beiden Flächen, besonders aber auf der vorderen, freien. Diese Hervorragungen (appendici cellulari) (A. C.) sitzen mit schmaler und langer, gewöhnlich halbkreisförmig oder S-förmig geschlungener Basis auf der membranösen Ausbreitung, in deren Gewebe sie unmittelbar und ohne Abgrenzung übergehen. Sie haben die Form von Hahnenkämmen, manchmal von Warzen und Keulen.

Histologisch besteht die membranöse Ausbreitung sammt ihren Hervorragungen aus einer äusserst feinen Umhüllungsmembran von etwa $0,0017 \mathrm{~mm}$ Dicke, und einem ganz durchsichtigen, homogenen Inhalte, ohne Spur von Körnchen und von hellgelber Farbe. Dieser Inhalt ist (wenigstens an Weingeistpräparaten) fest, und gleicht einem durchsichtigen weichen und brüchigen Leime. Man erkennt dies deutlich, wenn man einen, dem abgebildeten ähnlichen Durchschnitt zerzupft, wo es oft gelingt, die membranöse Ausbreitung horizontal in zwei Blätter zu spalten. An der Rissfäche sieht man dann die Bruchstücke der hyalinen Substanz, welche die ganze membranöse Ausbreitung mit ihren Hervorragungen erfüllt. - Das Ansehen dieser Substanz erinnert Pacinı an diejenige, welche die Ganglienzellen erfüllt, abgesehen von deren Körnchen, oder an die Substanz, welche KöLliken im peripherischen Ende des electrischen Nerven von Mormyrus longipinnis beschrieben hat. Die hahnenkammförmigen Hervorragungen entlaalten ausserdem in ihrem oberen Theile viele Kerne von ungefälı 0,005 mm im Durchmesser. Es

*) a. a. O. parg. 14 ff. des Separatabdruekes. 
entsprechen ihnen gewöhnlich kleine warzenförmige Anschwellungen am freien Rande der hahnenkammförmigen Hervorragungen, welche sich zu diesen gerade so verhalten wie letztere zur membranösen A usbreitung.

Pacini konnte die Nerven und Gefässe bis in die Scheidewand zweiter Ordnung (lamella fibrillare) verfolgen. Dort sind, seiner Ansicht nach, deren Endigungen. Die Nerven verlaufen zuerst in den Scheidewänden erster Ordnung und schicken kleine Ästchen in die Scheidewände zweiter Ordnung. Dieselben bestehen aus kleinen Bündeln von 2-3 Primitivfasern von 0,006-0,008 mm Durchmesser, deren Axencylinder meist sehr deutlich sind. Sie dringen in querer Richtung in die Scheidewände ein, theilen und zerstreuen sich bald, und durchlaufen einzeln, 0,004-006 mm stark, lange Strecken. Ihre Theilungen geschehen unter mehr oder weniger rechtem Winkel. PAcini beobachtete bis zu 3 aufeinanderfolgenden Theilungen einer und derselben Nervenfaser.

Die Thatsache, dass die Vertheilung der Nerven nur an der "lamella fibrillare ", welche die n egative Fläche des Diaphragma’s darstelle, stattfinde, hält PAcinı für ein Factum von höchster Wichtigkeit und verweist auf ein von ihm entdecktes ähnliches Verhalten beim Zitterrochen. (S. unten).

Pacini glaubt ferner in jedem Fache die drei Elemente einer wahren Volta'schen Säule zu finden. Die in der hinteren Abtheilung (spazio sottocellulare) des Faches enthaltene Flüssigkeit deutet er als negatives, die membranöse Ausbreitung als positives, die in der vorderen Abtheilung (spazio sopracellulare) befindliche Flüssigkeit als leitendes Element. - Die Hervorragungen haben den Zweck, die Ausdehnung der electromotorischen Oberfläche zu vermehren, - die Verbindungsstränge haben zu verhindern, dass die membranöse Ausbreitung sich von der hinter ihr liegenden Scheidewand entferne und die vorhergehende berühre ; - die Scheidewand selbst endlich hat den Zweck, die beiden Flüssigkeiten (nach Art der porösen Scheidewand von Kreide in den Säulen von Bunsen und Grove) zu trennen, und die, in der Berührungsfläche der beiden Flüssigkeiten ansgespannte Ebene für die Ausbreitung der Nerven zu bilden.

Vergleichen wir diese Angaben über die Bestandtheile des electrischen Organes des Zitteraales mit der obigen Beschreibung der analogen Gebilde des Zitterwelses, so ist, trotz bedeutender Abweichungen in untergeordneten Dingen, eine grosse Übereinstimmung in den wesentlichen Punkten unläugbar. Vielleicht würde diese Übereinstimmung noch grösser sein, wenn es einem europäischen Microscopiker jemals vergönnt gewesen wäre, das electrische Organ des Zitterales an frischen, oder in Chromsäure aufbewahrten Präparaten zu untersuchen. Ich verspare eine genauere vergleichende Zusammenstellung auf das Ende dieser Arbeit, und möchte hier nur auf PACINI's „corpo cellulare dei diaframmi aufmerksam machen, welches Gebilde ich als das vollkommene Aequivalent der electrischen Platte beim Zitterwelse betrachte. Es ist, wie die letztere, eine membranöse Ausbreitung, welche in den kleinsten Hohlräumen des Fasergerüstes gelagert ist, eine freie und eine angeheftete Fläche darbietet, aus einer zarten, homogenen Umhüllungshaut und einer durchsichtigen Inhaltsmasse zusammengesetzt ist, welche letztere von Pacisi selbst mit der Substanz, welche die Ganglienzellen erfüllt, verglichen wird, und welche, gleich wie die electrische Platte beim Zitterwelse, zahłreiche eingebettete Kerne enthält.

Dieser Deutung zufolge, an deren Richtigkeit kaum zu zweifeln sein dürfte, muss die Fndigung der electrischen Nerven in diesem Gebilde und nicht, wie $\mathrm{P}_{\text {Acrns }}$ glaubt, in seiner "lamella fibrillare stattfinden. Sehr wahrscheinlich sind Pacrns's "processi spiniformi“ $\left(C^{\prime}\right)$ nichts anderes, als die Endzweighein des electrischen Nerven. 


\section{Electrisches Organ des Zitterrochens.}

Das Fasergerüste des electrischen Organes des Zitterrochens besteht erstens aus einer sehnigen Umh üllungshaut, welche hier das Organ allenthalben (ohne Betheiligung der Cutis) umgibt und zweitens aus aponeurotischen Fortsätzen, welche, aus der Umhüllungshaut entspringend, das Innere des Organes durchziehen und abtheilen. Sie haben aber eine von der der entsprechenden Gebilde des Zitterwelses abweichende Form und Richtung. Die unmittelbar aus der Umhüllungshaut entspringenden Faserhäute - Scheidewände erster Ordıung — ziehen quer auf die Axe des Fisches, von der Rücken-zur Bauchfläche und theilen den Raum des electrischen Organes in eine Anzahl, neben einander stehender, ursprünglich cylindrischer, aber durch wechselseitigen Druck prismatisch gewordener Kammern (Säulen $V_{A L}$., WAG., prismi PAC.). - Diese Kammern sind nun wieder, wie allgemein bekannt ist, durch zahlreiche Querscheidewände (Septa VAL., WAGN., diaframmi PAc.) in (der Axe der Kammer nach) vertical über einander liegende Fächer abgetheilt. Ob aber diese Querscheidewände ihrer Zusammensetzung nach den von VALEntin und PACini mit demselben Namen belegten Gebilden des Zitteraales (Septum $V_{A L}=$ Grundmembran + Epiteliallage ; diaframma PAc. = lamella fibrillare + corpo cellulare) vollkommen entsprechen, geht aus den vorliegenden Beschreibungen nicht mit Sicherheit hervor. Für die Zusammensetzung jeder Querscheidewand aus zwei heterogenen Häuten entscheiden sich VALENTrN und R. WAGNER; SAVI ist dieser Ansicht nur aus theoretischen Gründen günstig; Pacini endlich beschreibt das Gewebe der Diaphragmen als "sehr einfach, aus einer durchsichtigen und homogenen Substanz bestehend. Nach letzterer Anschaung würde das Diaphragma des Zitterrochens nur der electrischen Platte (Epiteliallage VAL., corpo cellulare PAC.) entsprechen, und die faserigen Scheidewände zweiter Ordnung dem Zitterrochen fehlen.

Nach Valentin *) besitzt jede Querscheidewand (Septum) als Grundlage eine Membran, welche als "sehr verdünnte Fortsetzung der aponeurotischen Scheidewand ( (erster Ordnung) anzusehen ist. Dieselbe werscheint an und für sich durchsichtig und bei geeigneter Präparation feinfaserig." Der zwischen je zwei "Septa" befindliche Hohlraum ist allenthalben von einer Epiteliallage ausgekleidet. Jedes Septum enthält demnach drei Membranen : neine mittlere Grundmembran und zwei auf beiden Seiten des letz"teren anliegende Epitelialschichten. “ Die Epiteliallage »bildet einen Körnerüberzug und stellt vielleicht „im ganz frischen Zustande Epitelialzellen mit Kernen (und an den Zellwandungen abgelagerten Körnchen) "dar." - VaLenrrs erkannte in dem Septum sehr gut die Ausbreitung der kleinsten Blutgefässe und Nerven. Beide verlaufen in verschiedenen Höhen. Die Endgeflechte des Nerven scheinen ihm mehr nach der oberen (Rücken-), die feinsten Blutgefässe mehr nach der unteren (Bauch-) Seite jedes Septum's zu liegen.

$\left.S_{A V I}^{* *}\right)$ hält für wahrscheinlich, dass jedes Septum aus zwei Häuten bestehe, glaubt aber, dass die anatomischen Hilfsmittel, es zu beweisen, uns fehlen. Die Diaphragmen sind mit den Rändern an die aponeurotische Scheidewand (erster Ordnung) angeheftet. SAvr sah die Verbreitung der Nerven und Blutgefässe auf den Diaphragmen. Die ersteren bilden nach ilım Maschennetze.

Handw. d. Physiol. Bd I. pag. 254. ff. Fig. 4. *) a. a. O. pag. 284. 
Rud. Wagner stimmt im Ganzen mit der Anschauung Valextin's überein. Er sagt: ${ }^{*}$ ) "Ein Sep"tum hat ungefähr $\frac{1}{300}$ "' und besteht aus drei Lagen: einer mittleren Lage, die vielleicht Fortsetzung der "Membran ist, welche die Säulen überzieht" - (Scheidewand erster Ordnung). "Jedenfalls sind aber in »dieser sehr durchsichtigen, höchst dünnen Lage, die nicht isolirt darstellbar ist, nur sehr wenige discrete "faserige Elemente wahrzunehmen. Einige Male gelang es aber doch, zwischen den Nervenausbreitungen "und Gefässen einzelne, ganz isolirte, wellenförmige, dunkle Fibrillen lie und da wahrzunehmen, welche "mit den gebogenen Fasern der aponeurotischen Scheide sehr übereinstimmten. Sodann erkennt inan ein win bogenförmige Schlingen auslaufendes Gefässnetz, dessen feinste Röhren nur eine Reihe Blutliörperchen "führen. Es ist schwer mit Bestimmtheit zu sagen, scheint aber so, dass das Gefässnetz in dieser mittleren "Membran liegt, denn es ist durchaus nur einfach und wenn man das Septum von der oberen oder unteren "Seite betrachtet, es gehen immer die Ausbreitungen der Nerven, welche eine doppelte Lage formiren, „über dasselbe weg. - Die beiden andern Membranen (Epiteliallagen $V_{A L}$.) sind zwei ebenfalls sehr "dünne, fein granulirte Schichten, eine obere, als Boden des oberen "Kästchens", eine untere als Decke des "zunächst gelegenen unteren. Jede dieser Membranen besteht aus einer äusserst weichen, durchmsichtigen Masse, mit feinen, punktförmigen, zerstreuten Körnchen durchsetzt. "Letztere messen ungefähr $\frac{1}{2000 " . ~ D a z w i s c h e n ~ s i n d ~ a b e r ~ i n ~ g r o ̈ s s e r e n ~ D i s t a n z e n ~ r u n d l i c h e ~ g r a n u l i r t e ~}$ "Kerne eingelagert, von denen die kleineren $\frac{1}{4 \frac{1}{0}}$, die grösseren bis $\frac{1}{20} \overline{0}^{\prime \prime}$ messen. Dadurch erlangt das "Ansehen eine entfernte Ähnlichkeit mit einem Epitelium.

Über die Verbreitung und Endigung der Nervenfasern im electrischen Organe gibt R. WAGner folgendes an $\left.{ }^{*}\right)$ : "Die Primitivfasern, welche zum electrischenn Organe gehen, sind niemals mit Ganglien wund peripherischen Ganglienkörpern versehen, sie gehören zu den eminent breiten Fasern, sie theilen sich „büschelförmig in Äste, diese verzweigen sich weiter dichotomisch und trichotomisch. Diese Äste sind alle"mal eingeschnürt an der Theilungsstelle, sie verlieren hier in der Regel ihre doppelten Conturen, werden „blasser, sind oft nur sehr zart-, oft stärker conturirt, schwellen stets jenseits der Theilungsstelle wieder an wund strahlen dann, blasser und blasser werdend, vielfach getheilt, auf den Blättchen des electrischen Ornganes aus. Thre letzten Zweige breiten sich hirschgeweihartig mit freien Enden aus, werden naber zuletzt so überaus zart, blass, und stimmen in ihrem Ansehen mit der feinkörnigen Subwstanz, aus welcher die Blättchen des electrischen Organes bestehen, so überein, dass es auch mit den stärkwsten und besten Vergrösserungen und unter Anwendung der schiefen Beleuchtung nicht möglich war sich "zu vergewissern, wie die Nerven hier endigen, d. h. man sieht zwar die begrenzende Scheide zuletzt auf(hören, aber der Inhalt, das Ende der Nervenfasersubstanz selbst (man kann wohl sagen der Axencylinder) wscheint in freier Mündung mit der feinen molecularen Masse, aus welcher er besteht, „in die moleculare Masse des Parenchyms des electrischen Organes überzugelien. Wer wjener früheren Annahme, dass die Nervenenden zuletzt mit dem Parenchyme selbst verschmelzen, huldigen "wollte, würde in der That keinen Tadel verdienen."-

PacinI's***) Beschreibung weicht in manchen Punkten von den Angaben der genannten Forscher

*) Über den feineren Bau des electrischen Organes im Zitterrochen. Abh. d. k. Gesellsch. d. Wissensch. zu Göttingen. Bd. III. pag. $18 \mathrm{ff}$.

**) Göttinger Nachr. 20. Octbr. 1851. Nr. 14. (Neurol. Unters. pag. 109). Vergleiche ausserdem: Über den feineren Bau, etc. pag. $15 \mathrm{ff}$ (***) a. a. O. pag. $6 \mathrm{ff}$. 
ab. Für's erste behauptet er, dass die Diaphragmen nicht mit ihrem ganzen Rande mit der Innenfläche der aponeurotischen Scheidewand (erster Ordnung) verwachsen seien, sondern nur an wenigen Stellen, welche den Kanten der Prismen entsprechen. Mit Ausnahme dieser Stellen, an welchen der Eintritt der Gefässe und Nerven erfolge, seien die Diaphragmen durch einen sehr kleinen, mit durchsichtiger Flüssigkeit gefüllten Zwischenraum von der aponeurotischen Scheidewand geschieden. Zerstöre man diese wenigen Anheftungspunkte, so könne man das ganze, aus den übereinander gethürmten Diaphragmen bestehende Prisma aus seiner aponeurotischen Scheide herausziehen. Die Wandungen der, auf diese Weise von der Scheidewand ziemlich unabhängigen Prismen sind nach PAcrNI's Ansicht durch die sie zusammensetzenden Diaphragmen selbst gebildet, die an den Rändern unter einander verwachśen. Er hält es für wahrscheinlich, dass die Fntwicklungsgeschichte zeigen werde, dass die Prismen und Diaphragmen aus übereinandergelegten breitgedrückten Zellen oder Bläschen entstünden, deren sich berührende Wandungen verschmelzen. Die Diaphragmen erscheinen nach PACINi in der That gegen ihre Peripherie hin aus zwei sehr dünnen Blättchen bestehend, welche gegen die Mitte hin verschmolzen sind. - „Das Gewebe der "Diaphragmen ist sehr einfach und besteht aus einer durchsichtigen, homogenen Substanz, in welcher man "hie und da winzige Körnchen (finissime granulazioni) findet, " welche nach PAcrn's Ansicht von geronnenen oder niedergeschlagenen faserstoffigen oder eiweissigen Substanzen herrühren. Ausserdem sehe man noch grosse, sparsame Kerne, welche sich leicht lostrennen und nach seiner Ansicht den Scheiden der Nervenfasern dieser Diaphragmen angehören.

In Bezug auf die Nervenausbreitung und Endigung stimmt Pacrni fast vollkommen mit R. WAGNRR überein. Doch weicht er auch hier in manchen Punkten von seinem Vorgänger ab: "Die Nervenfasern "und Blutgefässe dringen frei in den zwischen je zwei Diaphragmen befindlichen Raum und durchlaufen „darin weite Strecken, umgeben von der Flüssigkeit, welche den Raum erfüllt, und theilen sich gablig in "viele aufeinander folgende Äste. Die feineren Zweige nähern sich immer mehr dem oberen Diaphragma "und setzen sich endlich mit ihren Endzweigen alle an die Unterfläche desselben an, wo sie, in äusserst „feine Fädchen getheilt, verschwinden. Betrachtet man ein solches Diapragma, der Fläche nach aus"gebreitet, so scheint es, als ob die Nervenfasern in seiner Dicke enthalten wären : schlägt man es aber um, "so dass beide Hälften, entweder der oberen oder der unteren Fläche, sich berühren, so überzeugt man sich "leicht, dass alle Nervenfasern sich nur an der untern Fläche des Diaphragma's ansetzen, und dass "die dickern Fasern, welche in ihrer Scheide Kerne haben, welche darin Anschwellungen bilden, durch „diese an derselben anhängen, während die feinsten Nervenendigungen unmittelbar verwachsen sind, indem "sie in die Substanz des Diaphragma's selbst übergehen.

Zur vollkommenen Lösung der in vorstehenden Beschreibungen enthaltenen Widersprüche ist eine erneute Untersuchung dieses, wie es scheint, sehr schwierigen Gegenstandes nothwendig. Indessen möge der Versuch einer Sichtung der vorliegenden Angaben vom vergleichenden Standpunkte aus erlaubt sein.

Aus den Angaben sämmtlicher Schriftsteller, besonders aus R. WAGrer's genauer Beschreibung und Abbildung geht hervor, dass die Diaphragmen des Zitterrochens Bestandtheile enthalten, welche den von Pacixi (beim Zitteraale). "covpo cellulave", von mir (beim Zitterwelse): "Nervenend - Platte oder electrische Platte" genannten Gebilden histologisch entsprechen - membranartige Anhäufungenkörniger Nervenmasse mit eingestreuten Kernen, welche Masse mit den Axen- 
cylindern der Endzweiglein der electrischen Nervenfasern in Continuität steht, und gleichsam nur deren End-Ausbreitung ist. Diese Gebilde sind, wie aus obigen Beschreib ngen hervorgeht, und ihrer Natur nach nicht anders sein kann, gefässlos. Da nun aber in den Diaphragmen des Zitterrochens gleichwol Blutgefässnetze gefunden werden (VALentin, SAvi, R. WAGier), so muss nothwendiger Weise eine zweite Membran als deren Träger vorhanden sein. In der That heben Varextro und R. WAGNER hervor, dass das Blutgefässnetz nicht in derselben Ebene mit der Nervenausbreitung liege, sondern erst bei tieferer oder höherer Einstellung des Microscopes deutlich werde. Diese gefässhaltige Membran muss mit Vatentin als Fortsetzung der das "Prisma« umhüllenden Scheidewand, also als Scheide-wand zweiter Ordnung angesehen werden. Der grossen Dünne dieser Membran wird es zugeschrieben werden müssen, wenn PACiNi derselben nicht erwähnt, SAvi sie nur aus theoretischen Gründen annimmt, Valestin und R. WAGLer nur mit Mühe faserige Elemente darin nachweisen konnten. Die Angabe Pacrni's, dass die Prismen nur durch die eintretenden Gefässe und Nerven an die aponeurotische Scheidewand (erster Ordnung) angeheftet, sonst aber durch einen mit Flüssigkeit gefüllten Zwwischenraum von derselben getrennt seien, scheint mir weder gegen die Existenz genannter Membran, noch gegen deren Natur als Scheidewand zweiter Ordnung zu entscheiden. Bei der grossen Dünne dieser Membran mögen ihre Verwachsungsstellen mit der Scheidervand erster Ordnung, ausgenommen an der Eintrittsstelle der Nerven und Gefässe, bei der Präparation leicht abreissen oder durch Resorption zu Grunde gegangen sein. Es dürfte also anzunehmen sein, dass jedes Diaphragma aus zweierlei Membranen bestehe: 1. der Nervenendplatte, 2. der Scheidewand zweiter Ordnung.

VALentin und WAgner geben an, dass die letztgenannte Membran jederseits, nach oben und nach unten, von einer Nervenmembran ("Epiteliallage () überkleidet sei, ein Verhalten, welches, wenn es in der That vorhanden ist, mit der bei den beiden andern Zitterfischen beobachteten Anordnung in Widerspruch stehen würde. Indessen scheint es, als ob diese Angabe der genannten Forscher mehr in deren Anschauungsweise über den Bau der electrischen "Prismen ", als in zwingender Autopsie wurzle. Jedes „Prisma» ist nach Valentin als eine aus aufeinander gethürmten Kästchen bestehende Säule zu betrachten. Jedes dieser Kästchen ist überall: seitlich, oben und unten, mit der Epiteliallage ausgekleidet*). Solltc nicht die Ansicht von einer allseitigen Auskleidung des Kästchens durch die Epiteliallage gerade darin ihren Grund haben, dass Valestix die Nervenplatte für eine Epiteliallage hielt? Was diesen Verdacht bestärken muss, ist die, mit obiger Anschauungsweise in Widerspruch stehende Bemerkung Valextra's: „Irre ich nicht, so liegen die Endgeflechte der Nerven mehr nach der obern, oder Rücken-, die feinsten "Blutgefüssnetze nach der untern oder Bauchseite jedes Septums hin." Für letzteres Verhalten und gegen das erstgenannte spricht auch Pacinı's Beschreibung; wdie feineren Zwweige ( $s c$. der Nerven [und Gefässe?]) "nähern sich immer mehr dem obern Diaphragma, und setzen sich endlich mit ihren Endzweigen alle an „dessen Unterfläche an etc." So dürften wir also zu dem Schlusse gelangen: 1. dass jedes Diaphragma n ur aus zwei Häuten: einer Nervenplatte und einer Scheidewand zweiter Ordnung bestehe, und ferner 2. dass die erstere nach oben (gegen den Rücken), letztere nach unten (gegen den Bauch) hin gelegen sei.

Damit wäre die Übereinstimmung des Banes des electrischen Organes des /itterrochens mit denen

*) vergl. VAlentix a, a, O, Fig. 1, 13 
der beiden anderen Zitterfische in den wesentlichen Punkten vorhanden. Der letztere Satz (sub Nr. 2.) stünde insbesondere noch mit dem von PACINI ${ }^{*}$ ) aufgestellten physiologischen Gesetze in Einklang, dass nämlich die freie Fläche des Diaphragma's im Augenblicke der Entladung positiv, diejenige dagegen, an welcher die Nerven sich ansetzen, negativ electrisch sei.

Wenden wir das PAcini'sche Gesetz schliesslich auf den Zitterwels an, so haben wir dem anatomischen Befunde nach das Kopfende als positiv, das Schwanzende als negativ zu betrachten. Hoffentlich wird mir noch Gelegenheit werden, die Richtigkeit dieser Folgerung durch das Experiment zu entscheiden.

*) Org. elettr. del Gimnoto pag. 9.27. 


\title{
Erklärung der Tafeln.
}

\author{
T a f e l I.
}

Sämmtliche Figuren dieser Tafel sind in natürlicher Grösse gezeichnet.

Figur 1-5. Diese der Osteologie gewidmeten Figuren haben übereinstimmende Bezeichnung.

$A^{1}$. vorderes Ausfüllungsknöchelchen.

$A^{2}$. hinteres Ausfüllungsknöchelchen.

$D^{1}$. Dornstück des ersten Wirbels.

$D^{2}$. Dornstück des zweiten Wirbels.

$H$. Hammer.

$R^{1}, R^{2}, R^{3}, R^{4}$. erste bis vierte Rippe.

$S$. Steigbügel.

$W^{1}, W^{2}, W^{3}, W^{4}, W^{5}$. erster bis fünfter Wirbel.

$d^{3}, d^{4}, d^{5}, d^{6}, d^{7}$. Dornfortsatz des $3-7$. Wirbels.

$e$. erstes Zwischenwirbelloch, für den Durchtritt der motorischen Wurzeln der beiden ersten Rückenmarksnerven, sowie des electrischen Nerven.

$f$. Federtheil des Springfederfortsatzes.

$g^{\prime 2}$. vorderer Gelenkfortsatz des zweiten Wirbels.

gr. Grube im Bogentheile des zweiten Wirbels zur Aufnahme der Spitze des Stemmfortsatzes.

h. Wirbelloch.

$K$. Wirbelkörper.

$K n$. Knorren des Springfederfortsatzes.

$n^{3}, n^{6}$. Austrittsstelle des dritten, sechsten Rückenmarksnerven.

$0^{2}$. obere Bogenschenkel des zweiten Wirbels.

p. Platte des Springfederfortsatzes.

st. Stemmfortsatz des Springfederfortsatzes.

$u^{2}, u^{3}, u^{4}, u^{5}, u^{6}, u^{7}$. untere Bogenschenkel des zweiten bis siebenten Wirbels.

$v$. Vereinigung der oberen Bogenschenkel des zweiten Wirbels.

$w$. warzige Erhabenheiten auf der, dem Rückenmarkskanale zugewendeten Fläche des ersten Wirbels.

z. Knochenzapfen der Rindensubstanz der vorderen Wirbel, welche in entsprechende Vertiefungen der ihnen zunächst folgenden eingreifen.

V. l. Austrittsstelle des $R$. lateralis $N$. trigemini.

$I X$. Austrittsstelle des N. glossopharyngeus.

X. Austrittsstelle des N. vagus.

$\mathrm{XI}$. Austrittsstelle des $N$. hypoglossus. 
Figur 1. Darstellung des Schädels und der sieben vorderen Wirbel von oben.

Die zur Bezeichnung der Schädelknochen gewählten Zahlen entsprechen den von Cuvier und $V_{A^{-}}$ LENCIENnes in ihrem grossen Werke angewendeten.

Figur 2. Der hintere Theil des Schädels und die fünf ersten Wirbel, von der linken Seite gesehen.

Die unteren Bogenschenkel (falschen Querfortsätze) $\left(u^{2}-u^{5}\right)$ sind nahe über der Ursprungsstelle abgebrochen. Zugleich mit dem untern Bogenschenkel des zweiten Wirbels ist auch der Springfederfortsatz entfernt.

Figur 3. Der zweite Wirbel, von vorn gesehen.

Figur 4. Der erste Wirbel, sein Dornstück und das erste Ausfüllungsknöchelchen, in natürlicher Lage, von vorn dargestellt.

Figur 5. Der erste Wirbel, dessen Dornstück, beide Ausfüllungsknöchelchen und der Steigbügel, in natürlicher Lage, von der linken Seite gesehen.

Figur 6. Uebersichtliche Darstellung der Lage des electrischen Organes, seines Nerven und seiner Gefässe.

Die Hautschwarte ist durch einen, im Bauchtheile in der Mittellinie, im Schwanztheile rechts von dieser von vorn nach hinten geführten Schnitt getheilt und nach beiden Seiten zurückgeschlagen.

A. Arterie des electrischen Organes.

$H$. Hautschwarte.

M. l. grosser Seitenmuskel.

M. r. gerader Bauchmuskel.

$N$. electrischer Nerv.

$V$. Vene des electrischen Organes.

c. äussere Haut.

$f$. innere Sehnenhaut.

i. indifferente Ausfüllungsmasse des Kopf- und Schwanztheiles der Hautschwarte.

o. Substanz des electrischen Organes.

$r . r^{\prime}$. Aeste und Zweige des electrischen Nerven vor seinem Eintritt in das electr. Organ.

$x$. vordere Querscheidewand der Hautschwarte.

$y$. hintere Querscheidewand der Hautschwarte. 


\section{Tafel II.}

Sämmtliche Figuren dieser Tafel sind in natürlicher Grösse gezeichnet.

Figur 1. Verlauf des electrischen Nerven.

Am vorderen Theile des Rumpfes, linkerseits, ist ein grosses Stück Hautschwarte entfernt, desgleichen die darunter liegende Schicht lockeren Bindegewebes und die Fettlage. Ferner ist der am Hinterhaupte befestigte Theil des grossen Seitenmuskels, sowie der unter ihm liegende Springfedermuskel weggenommen. Dadurch werden die Austrittstellen der vordersten Rückenmarksnerven sichtbar, besonders der dicke, durch den electrischen Nerven und die beiden ersten Rückenmarksnerven gebildete Strang. - Der an den Schultergürtel sich ansetzende Kopf des grossen Seitenmuskels ist durchschnitten. Man sieht den unter demselben durchschlüpfenden electrischen Nerven mit der Arterie des electrischen Organes. - Fndlich ist die zwischen der Platte des Springfederfortsatzes und den Muskeln der Brustflosse eindringende Nebenkammer der Bauchhöhle („vordere Abtheilung der cavitas hyperoesophagea «) geöffnet und der sie erfüllende Seitenlappen der Leber herausgenommen. Man sieht den in die Bauchhöhle hineinragenden. in einer Falte der tiefen Fascie eingeschlossenen Theil des electrischen Nerven.

$A$. Arterie des electrischen Organes.

B. Bauchhöhle.

$H$. Hautschwarte.

M. l. grosser Seitenmuskel.

$M$. $l^{\prime}$. Kopf des Seitenmuskels zum Schultergürtel.

$M . r$ gerader Bauchmuskel.

$N$. electrischer Nerv.

S. Schwimmblase.

T. tiefe Sehnenhaut, zwischen den Muskeln und der Bauchhölle.

$V$. Vene des electrischen Organes.

c. äussere Haut.

d. Nervenstämmchen, entstanden aus der Vereinigung des medianen Hautastes (Nro. 5) des zweiten Rückenmarksnerven mit einem Aste $(k)$ des $N$. lateralis trigemini (vergl. Tab. III. Fig. 6. $d$ ).

$f$. innere Sehnenhaut der Hautschwarte.

g. Strang, welcher das Zwillingsganglion des ersten und zweiten Rückenmarksnerreu. und die ron ihm herkommenden Nerven: Nro. 6. 7. 8. 9. enthält.

l. N. lateralis trigemini.

$n^{3}, n^{4}, n^{5}$. Dorsaläste des 3ten bis 5ten Rückenmarksnerven.

o. Substanz des electrischen Organes.

p. Platte des Springfederfortsatzes.

st. Stemmfortsatz des Springfederfortsatzes.

w. dorsale Lüngsscheidewand des electrischen Organes.

1. Dorsalast des ersten Rückenmarksnerven. (Nro. 1.)

2. Dorsalast des zweiten Rückenmarksnerven. (Nro. 2.)

7. rentraler Ast des zweiten Rückenmarksnerven, Hautnerv der Brustflosse. (Nro. 7.)

8. ventraler Ast des zweiten Rückenmarksnerven, Muskelnerv der Rückzieher der Brustflosse. 
ঠ. Grosse Falte der tiefen Sehnenhaut $T$, welche in den vorderen Raum der "cavitas hyperoesophagea" hereinragt und den electrischen Nerven, die Arterie des electrischen Organes, und den ventralen Muskelast des zweiten Rückenmarksnerven (Nro. 8.) in sich schliesst.

£. äusseres Blatt der Falte $\delta$, dessen Fortsetzung nach oben hin den von dem Seitenlappen der Leber erfüllten vorderen Raum der „cavitas hyperoesophagea überzieht.

Bei $\zeta$. ist das Blatt $\varepsilon$. entfernt und dadurch die erwähnte Nebenkammer der Bauchhöhle eröffnet. Der Seitenlappen der Leber ist daraus entfernt. Nach rechts sieht man die Mündung der Nebenkammer in die Bauchhöhle $(\boldsymbol{B})$.

Figur 2. Darstellung der Bauchhöhle von unten.

Die Hautschwarte ist der Länge nach durchschnitten und nach beiden Seiten gelegt; der nach unten gelegene Theil der Muskulatur und der tiefen Sehnenhaut entfernt. Man sieht den unter der Speiseröhre gelegenen Theil der Bauchhöhle (cavitas hypoesophagea). Die Leber ist entfernt.

H. Hautschwarte.

M. l. grosser Seitenmuskel.

M. r. gerader Bauchmuskel.

$N$. electrischer Nerv.

P. Magen.

Q. Milz.

T. tiefe Sehnenhaut.

$x$. vordere Querscheidewand der Hautschwarte.

$\alpha$. Flügelband der Speiseröhre.

ק. Sehnenscheide der Speiseröhre.

$\gamma$. Oeffnung zwischen dem Flügelbande der Speiseröhre und dem Zwerchfelle, durch welche die ncavitas hypoesophagea" mit dem vorderen Raume der "cavit. hyperoesophagea communicirt.

$\delta$. Falte der tiefen Sehnenhaut, welche den electrischen Nerven enthält.

Figur 3. Darstellung der Bauchhöhle von unten.

Das Flügelband der Speiseröhre ist durchschnitten, der Magen nach vorn umgelegt. Man sieht den über der Speiseröhre gelegenen Raum der Bauchhöhle (ncavitas hyperoesophageau), dessen hintere Abtheilung von der Schwimmblase erfüllt wird. Die Lage der vorderen, durch den Seitenlappen der Leber erfüllten Abtheilung dieses Raumes ist links $\left(u^{\prime}\right)$ punktirt angedeutet.

M. $l$. grosser Seitenmuskel.

$N$. electrischer Nerv.

$P$. Magen.

R. Nieren.

S. Schwimmblase.

T. tiefe Sehnenhaut.

$U$. Seitenlappen der Leber.

u. $u^{\prime}$. der in dem vorderen Raume der cavitas hyperoesophagea gelegene 'Theil des Seitenlappens der Leber.

$x$ vordere Querscheidewand der Hautschwarte.

«. «'. Flügelband der Speisröhre, durchschnitten.

$\delta$. Falte der tiefen Sehnenhaut, welche den electrischen Nerven enthält. 


\section{Tafel III.}

Figur 1-5. Gehirn und Anfangstheil des Rückenmarkes in ca. 3-maliger Vergrösserung gezeichnet. Die Bezeichnungen dieser fünf sind unter sich übereinstimmend, und grösstentheils auch mit den von KLAaTsch (de cerebris piscium ostacanthorum aquas nostras incolentium. Halle 1850) bei den Abbildungen des Gehirnes von Silurus Glanis (Fig. 46-50) gebrauchten.
A. Hemisphaerae s. Lobi olfactorii.
B. Lobi optici.
C. Eminentia quadrigemina.
D. Cerebellum.
F. Trigonum fissum.
H. Hypophysis.
L. Lobi inferiores posteriores.
O. Medulla oblongata.
S. Medulla spinalis.

a. infundibulum.

e. electrische Nervenfaser.

g. tubercula intermedia.

h. commissura anterior.

i. commissura interlobularis.

l. lobi inferiores anteriores.

$m$. gemeinschaftliches Bündel der motorischen Wurzel der beiden ersten Rückenmarksnerven nebst der electrischen Nervenfaser.

$m^{\prime}$. motorische Wurzel des ersten Rückenmarksnerven.

$m^{2}$. motorische Wurzel des zweiten Rückenmarksnerven.

$n$. electrisches Centralorgan.

p. corpus callosum.

$r$ ventriculus quartus.

$s^{1}$. sensitive Wurzel des ersten Rückenmarksnerven.

$s^{2}$. sensitive Wurzel des zweiten Rückenmarksnerven.

$v$. commissura spinalis.

$x$. isolirtes motorisches Nervenfädchen.

y.
$z$. lobi posteriores.

I. N. olfactorius.

II. N. opticus.

V. N. trigeminus.
VIII. N. acusticus.

X. N. vagus.

XII. N. hypoglossus. (N spin. I. nach Stari.) 
Figur 1. Gehirn von oben.

Figur 2. Gehirn von unten. Hypophysis weggenommen.

Figur 3. Gehirn von der Seite gesehen. geführt.

Figur 4. Längsdurchschnitt, in der Mittellinie des Gehirnes und Rückenmarkes

Figur 5. Lobi olfactorii und optici, von oben.

Figur 6. Schematische Darstellung des plexus brachialis.

$N$. electrischer Nerv.

V. N. trigeminus.

XII. N. hypoglossus (N. spin. I. Stannius).

a. vorderer Ventralast des $N$. hypoglossus.

$b$. Nerv, entstanden aus der Verbindung des hinteren Astes des $N$. hypoglossus mit dem Ventralaste des $N$. spin. $I$.

c. Hautnerv der Brustflosse, entstanden aus dem Ventralaste (Nro. 7.) des N. spin. II., dem medianen Aste (Nro. 5.) desselben und einem Aste des $N$. lateralis trigemini $(k$.

d. Nerv, entstanden aus der Vereinigung des medianen Astes des N. spin. II. (Nro. 5.) und einem Aste des $N$. lateralis.

e. Wurzelportion des electrischen Nerven.

g. Zwillingsganglion des ersten und zweiten Rückenmarksnerven.

$i$. Hauptast des N. trigeminus.

$k$. Ast des N. lateralis trigemini zur Brustflosse.

l. N. lateralis trigemini.

$m^{1}$. motorische Wurzel des ersten Rückenmarksnerven.

$m^{2}$. motorische Wurzel des zweiten Rückenmarksnerven.

$s^{1}$. sensitive Wurzel des ersten Rückenmarksnerven.

$s^{2}$. sensitive Wurzel des zweiten Rückenmarksnerven.

$x$. isolirtes motorisches Nervenfädchen.

1. Dorsalast des N. spin. I., gemischt.

2. Dorsalast des N. spin. II., gemischt.

3. Medianast des N. spin. I., Muskelnerv.

4. Medianast des $N$. spin. II., Muskelnerv.

5. Medianast des N. spin. II., Hautnerv.

6. Ventralast des N. spin. I., gemischt.

7. Ventralast des N. spin. II., Hautnerv.

8. Ventralast des $N$. spin. II., Muskelnerv.

Figur 7. Intervertebralganglion des ersten Rückenmarksnerven, von der inneren (freien) Seite gesehen. Ziemlich stark vergrössert.

m. motorische Wurzel.

$s$. $\quad$ sensitive Wurzel.

1. Dorsalast.

3. Medianast.

6. Ventralast.

«. Ursprungsstränge des sensitiven Theiles des Ventralastes. 
Figur 8. Intervertebralganglion des zweiten Rückenmarksnerven, von der äusseren (freien) Seite gesehen. Ziemlich stark vergrössert.

$N$. electrischer Nerv.

e. Wurzelportion des electrischen Nerven.

m. motorische Wurzel des N. spin. II.

s. sensitive Wurzel des $N$. spin. II.

2. Dorsalast.

4. Medianast, Muskelnerv.

5. Medianast, Hautnerv.

7. Ventralast, Hautnerv.

8. Ventralast, Muskelnerv.

«. Ursprungsstränge des ventralen Hautnerven.

Figar 9. Stück der electrischen Nervenfaser vor ihrer ersten Theilung, umhüllt von der gefässlosen Scheide. Stark vergrössert.

$e$. electrische Nervenfaser.

$s$. gefässlose Scheide.

Figar 10. Dasselbe Object, mit Essigsäure behándelt. Die Scheide wird blass und zeigt längliche Kerne $(\boldsymbol{K})$.

Figur 11. Längsschnitt aus der rechten Hälfte des Rückenmarkes in der Gegend des Ursprunges des electrischen Nerven, zur Darstellung des electrischen Centralorganes. Stark vergrössert.

A. Unterer (vorderer) Strang des Rückenmarkes.

B. Parenchym des Rückenmarkes in der Umgebung des Centralcanales.

$e$. electrischer Nerv der rechten Seite.

$f$. Axenfaser des electrischen Nerven, ein Fortsatz des electrischen Centralorganes.

$f^{\prime}$. ein anderer Fortsatz des electrischen Centralorganes.

g. Markschicht der electrischen Nervenfaser, durch Chromsäure verändert.

$m^{1}$. motorische Wurzel des $N$. spin. $I$.

$m^{2}$. motorische Wurzel des $N$. spin. $I I$.

$n$. electrisches Centralorgan.

$s$. gefässlose Scheide der electrischen Nervenfaser.

$x$. abirrendes motorisches Nervenfädchen. 


\section{Tafel IV.}

Figur 1. Längsdurchschnitt der Hautschwarte in der Gegend der Fettflosse. Natürliche Grösse.
c. äussere Haut.
$f$. innere Sehnenhaut.
i. indifferente Ausfüllungsmasse.
o. Substanz des electrischen Organes.
$y$. hintere Querscheidewand der Hautschwarte.

Figur 2. Längsdurchschnitt des electrischen Organes. Stark vergrössert.
a. äussere Haut.
b. Papillen der Haut.
c. Membranen des Tächernetzes.
d. $d^{\prime}$. electrische oder Nerven - Endplatten.
n. Endzweiglein des electrischen Nerven.

Figur 3. Eine Nerven-Endplatte, isolirt, von vorn gesehen. Stark vergrössert.

a. Verbindungsstelle mit dem Endzweiglein des Nerven, abgerissen.

Figur 4-6. Verbindung des Endganglions des electrischen Nerven mit der electrischen Platte.

Folgende Bezeichnungen sind diesen Figuren gemeinsam:

$e$. centrale Hervorragung der Vorderfläche der electrischen Platte.

$f$. strahlenförmige Falten, welche von der centralen Hervorragung ausgehen.

$h$. centrale Höhlung der Hinterfläche der electrischen Platte.

$k$. kolbenförmiges Ende des Nervenzweigleins.

$m$. $m^{\prime}$. Umhüllungsmembran der Nerven-Endplatte.

$n$. Endzweiglein des electrischen Nerven.

$r$. Mündung der centralen Höhlung der Hinterfläche der electrischen Platte.

t. trichterförmiges Grübchen in der Mitte der centralen Hervorragung.

w. warzige Erhabenheiten auf der centralen Hervorragung.

$x$. Stelle, wo das Endzweiglein des electrischen Nerven die Membran des Faches durchbohrt und die äussere Scheide verliert.

Figur 4. Durchschnitt des centralen Theiles der Nerven-Endplatte. Stark vergrössert.

Figur 5. Centraler Theil der Nerven-Endplatte, von vorn gesehen. Stark vergrössert.

Figur 6. Dasselbe, hintere Fläche.

Figur 7. Ein Stück des peripherischen 'Lheiles der electrischen Platte. Sehr stark rergrö̈ssert.

Figur 8. Verzweigung der electrischen Nervenfaser im Innern des electrischen ()rganes. Das Fïchernet\% ist weggelassen.

d. electrische Platte.

n. Kweig der electrischen Nervenfaser mit ihren Sicheiden.

$s$. Stelle, wo die Markschicht der Nervenfaser aufhört.

t. Theilungsstellen der Nervenfaser. 
Tab. I.

Fio. 1.

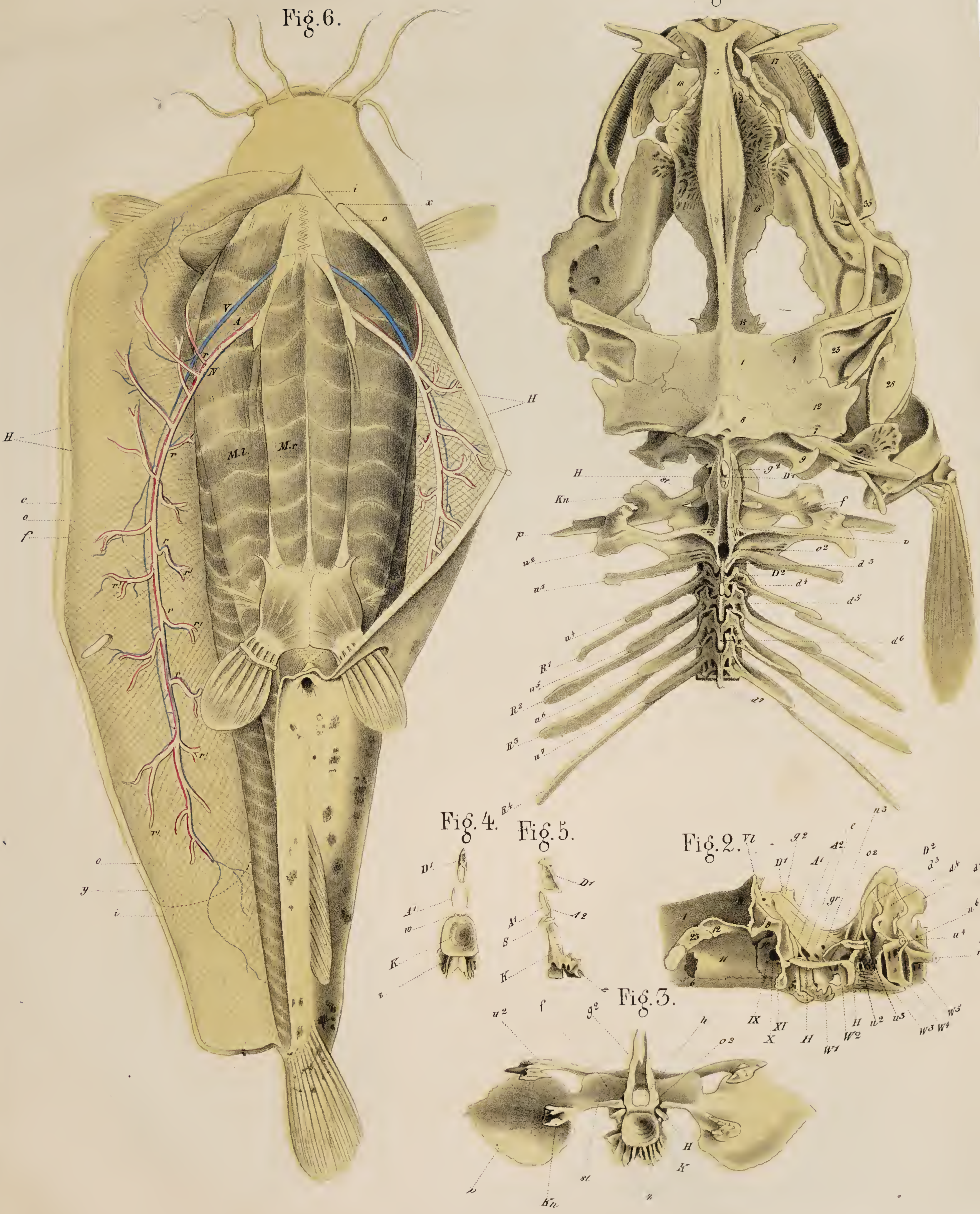



Tab. II.

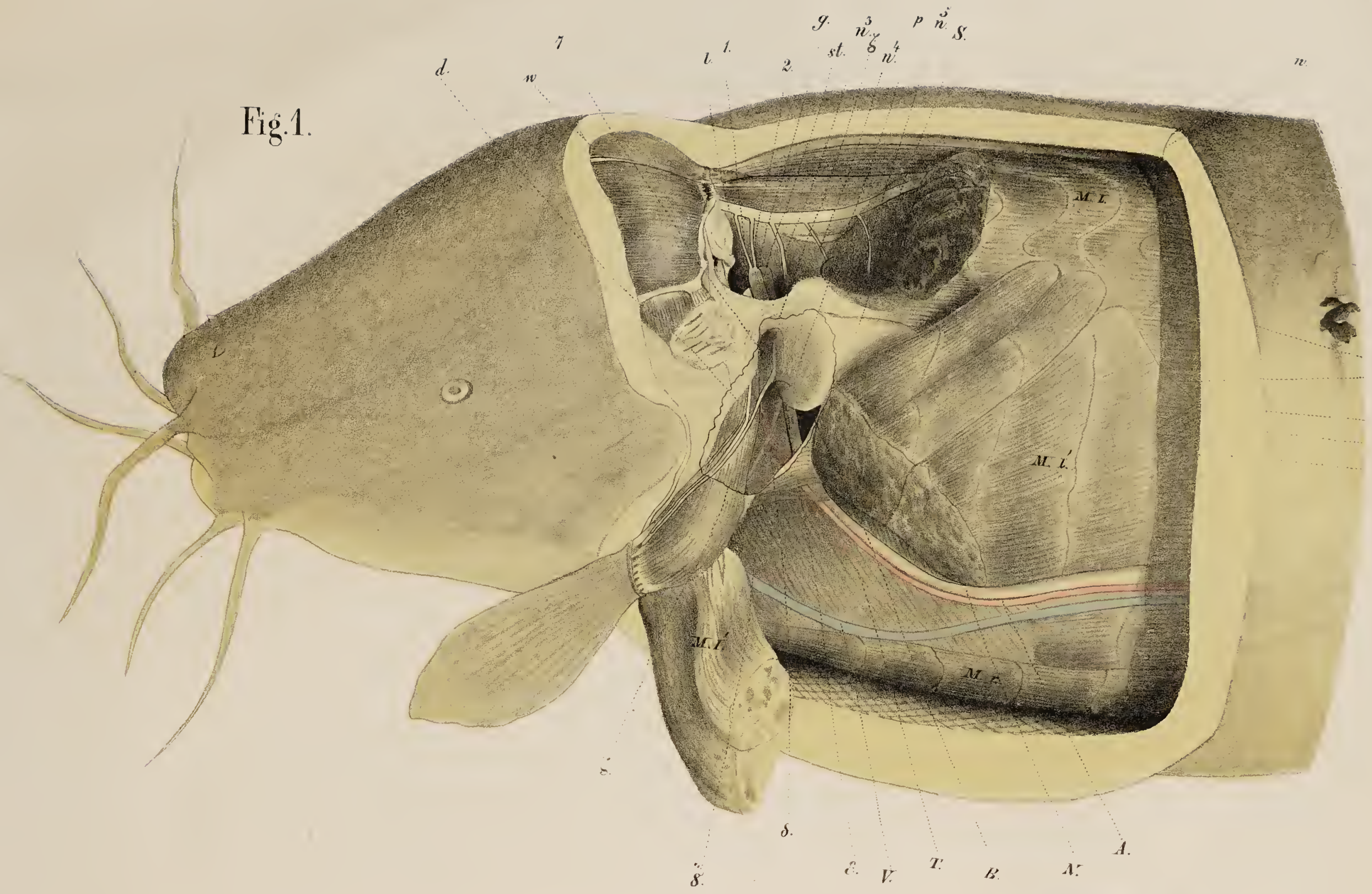

Fig. 2.
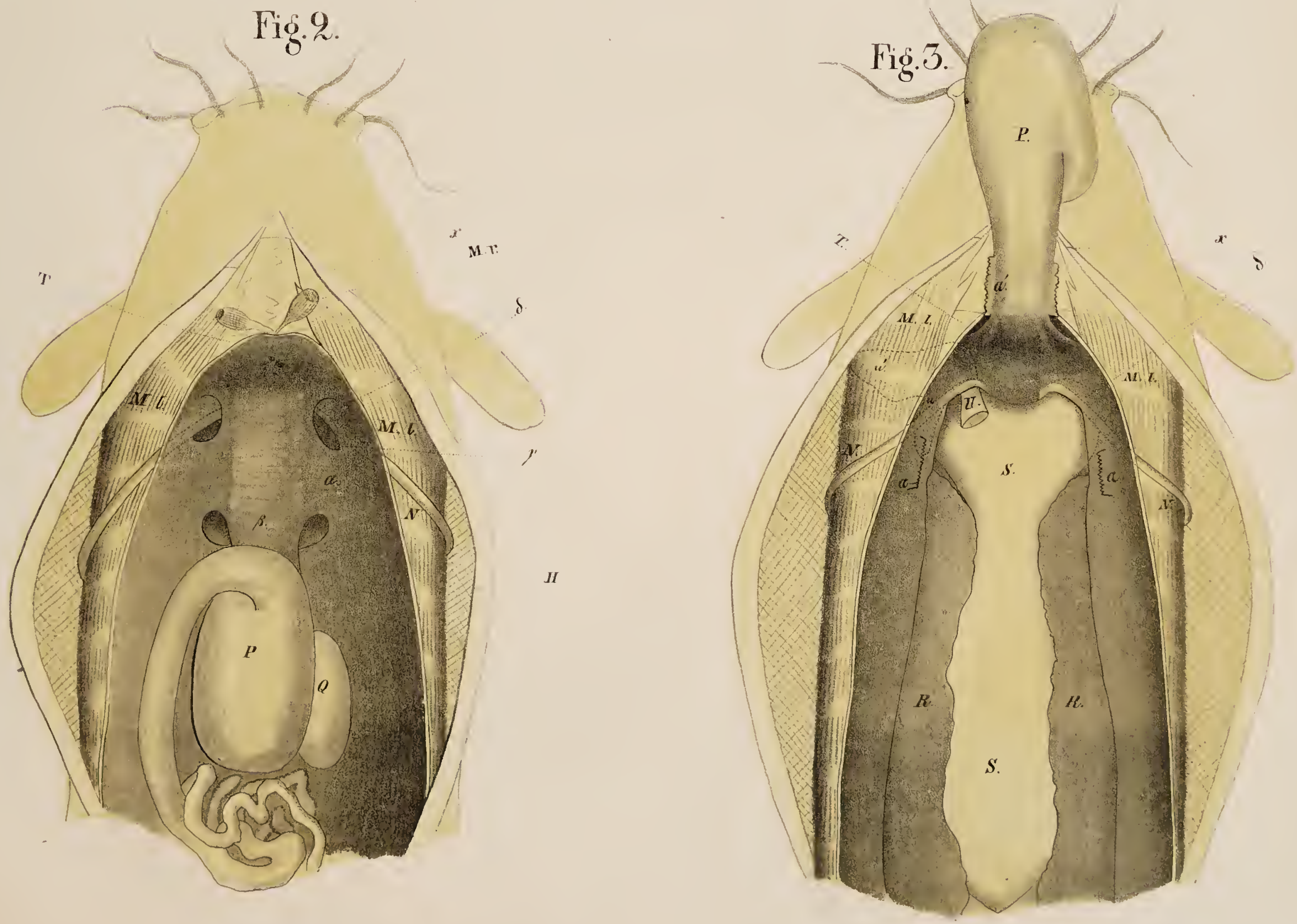

Tab.III.

$\mathrm{Fig.3}$

Fig. 4 .

Fig̉. 8.
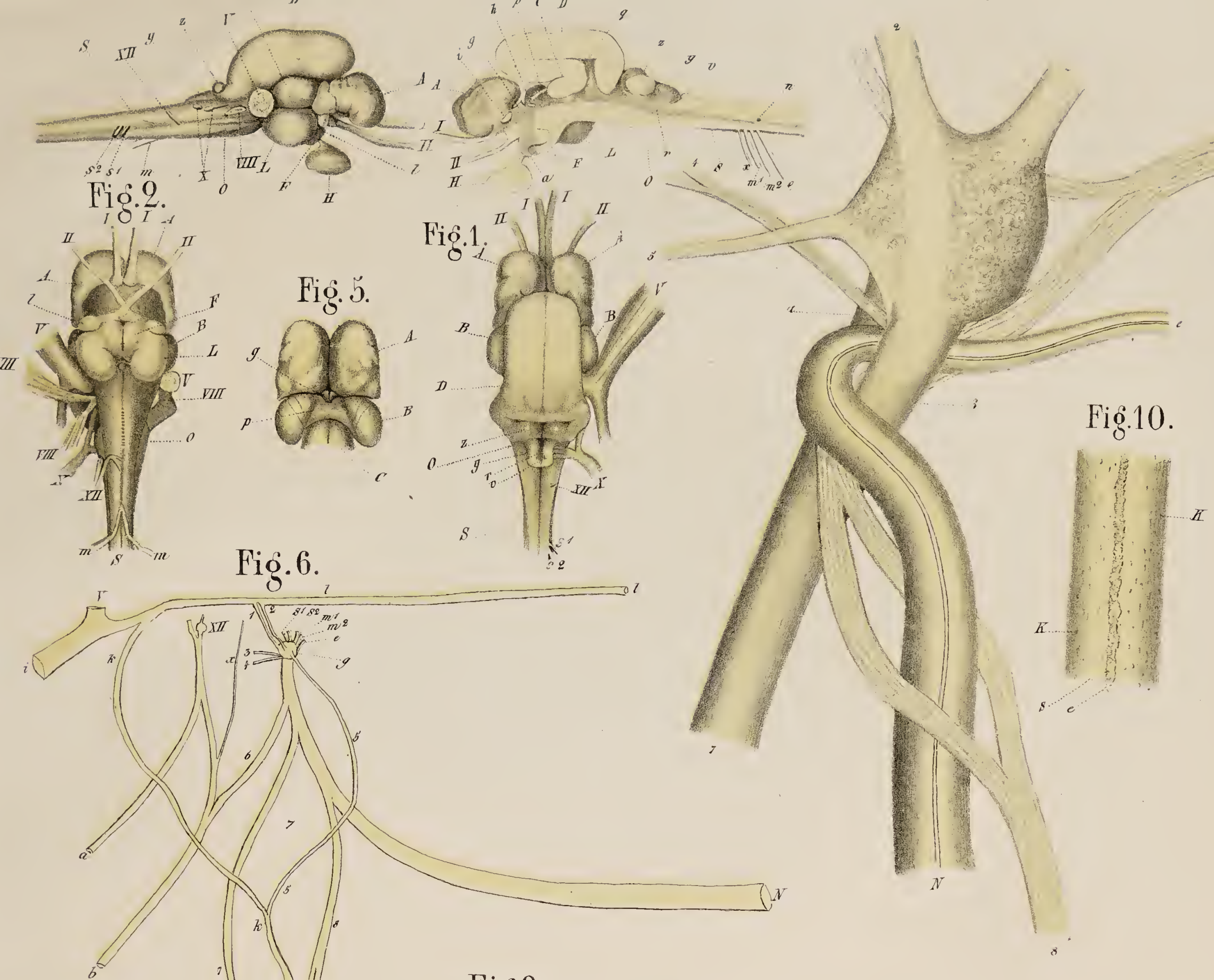

Fig.9.
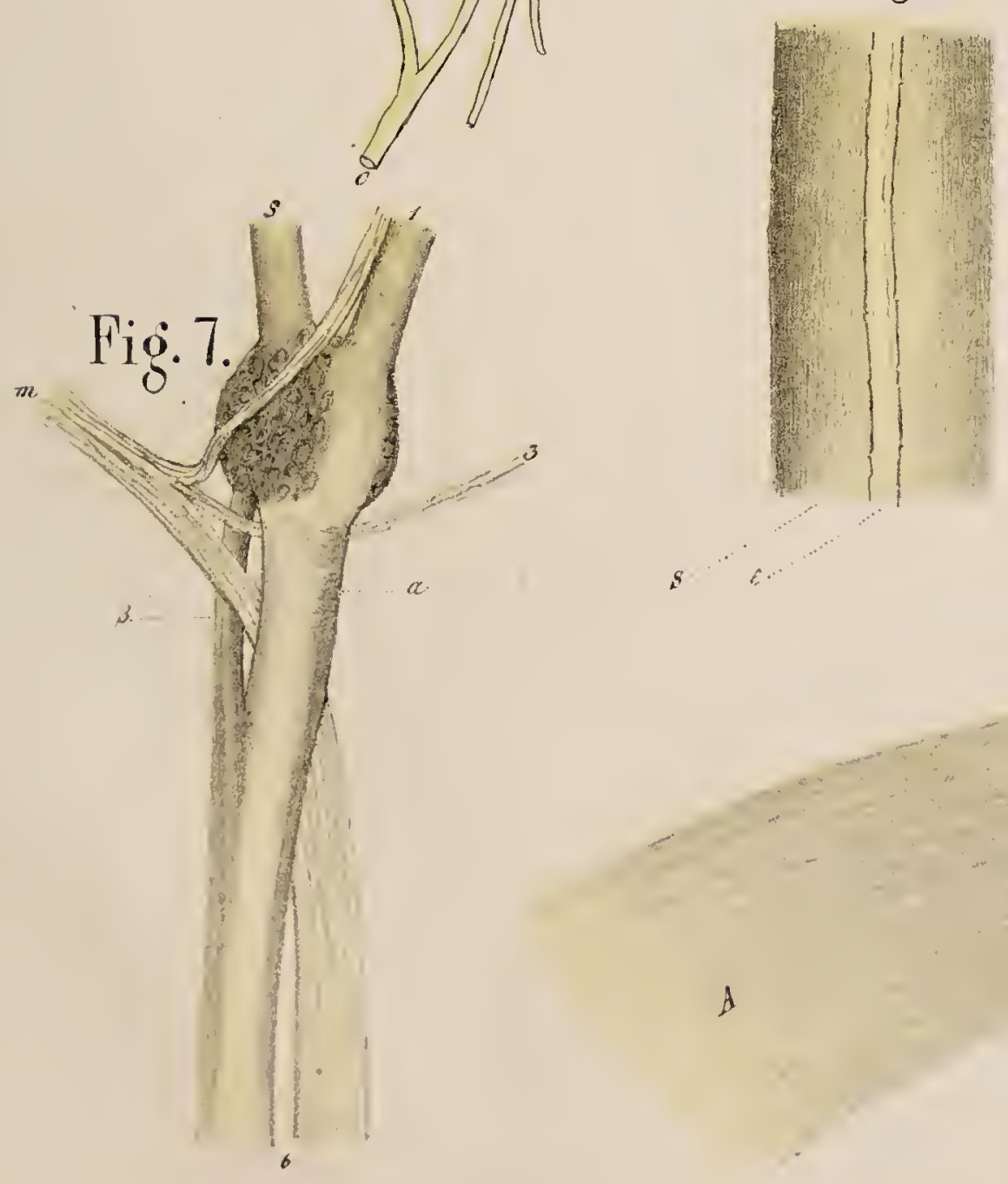

Fig.11.

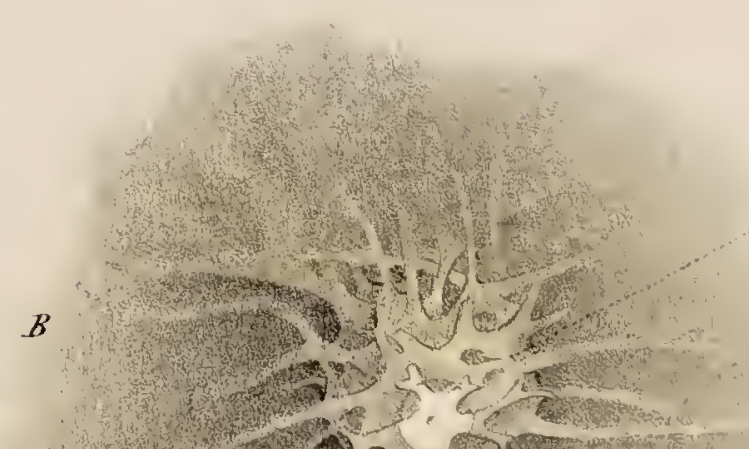

Fig. 10.

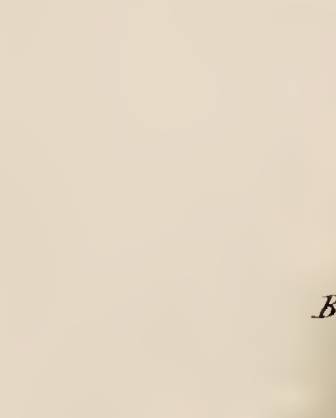



'Trill. II
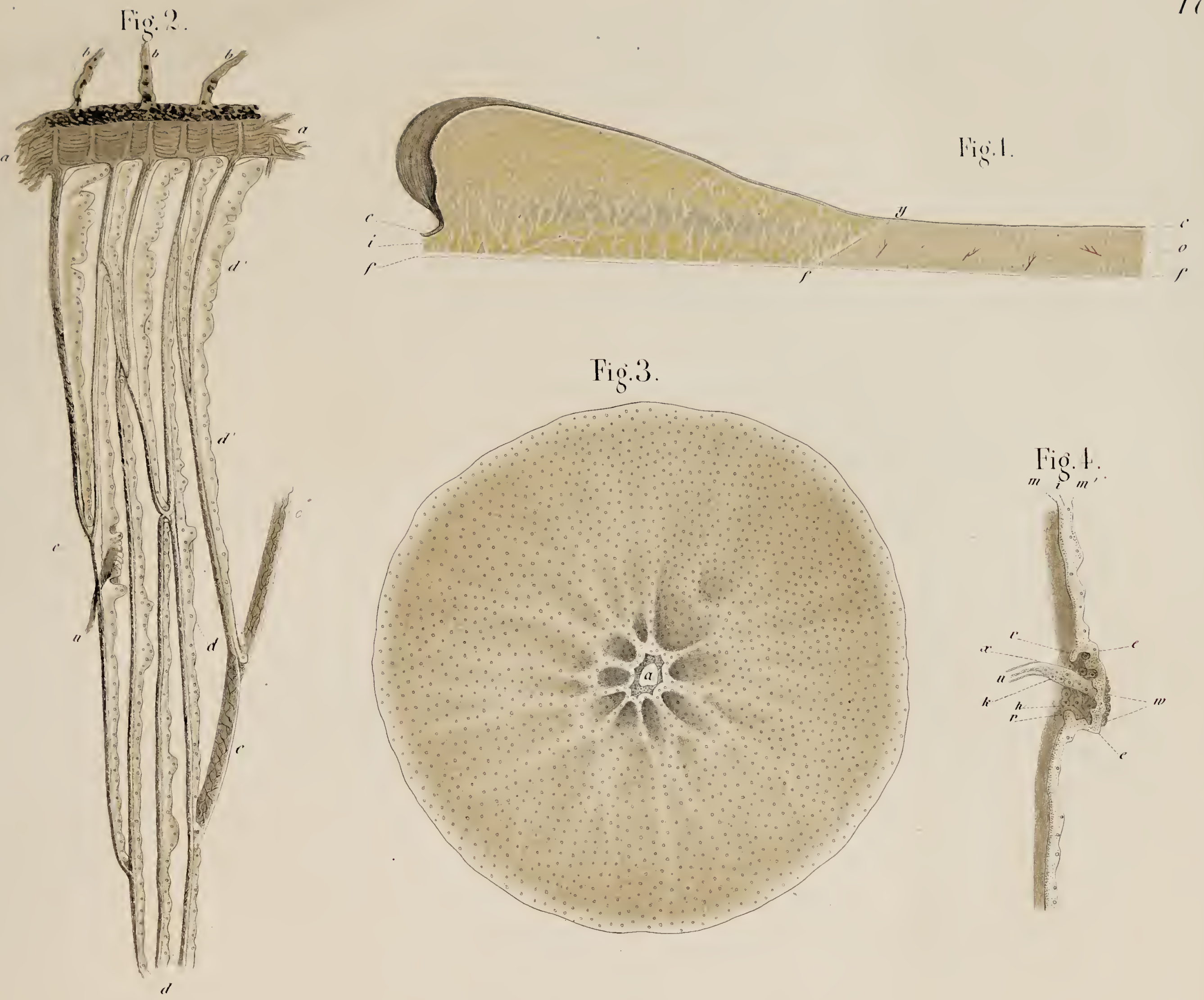

Fig. 3.
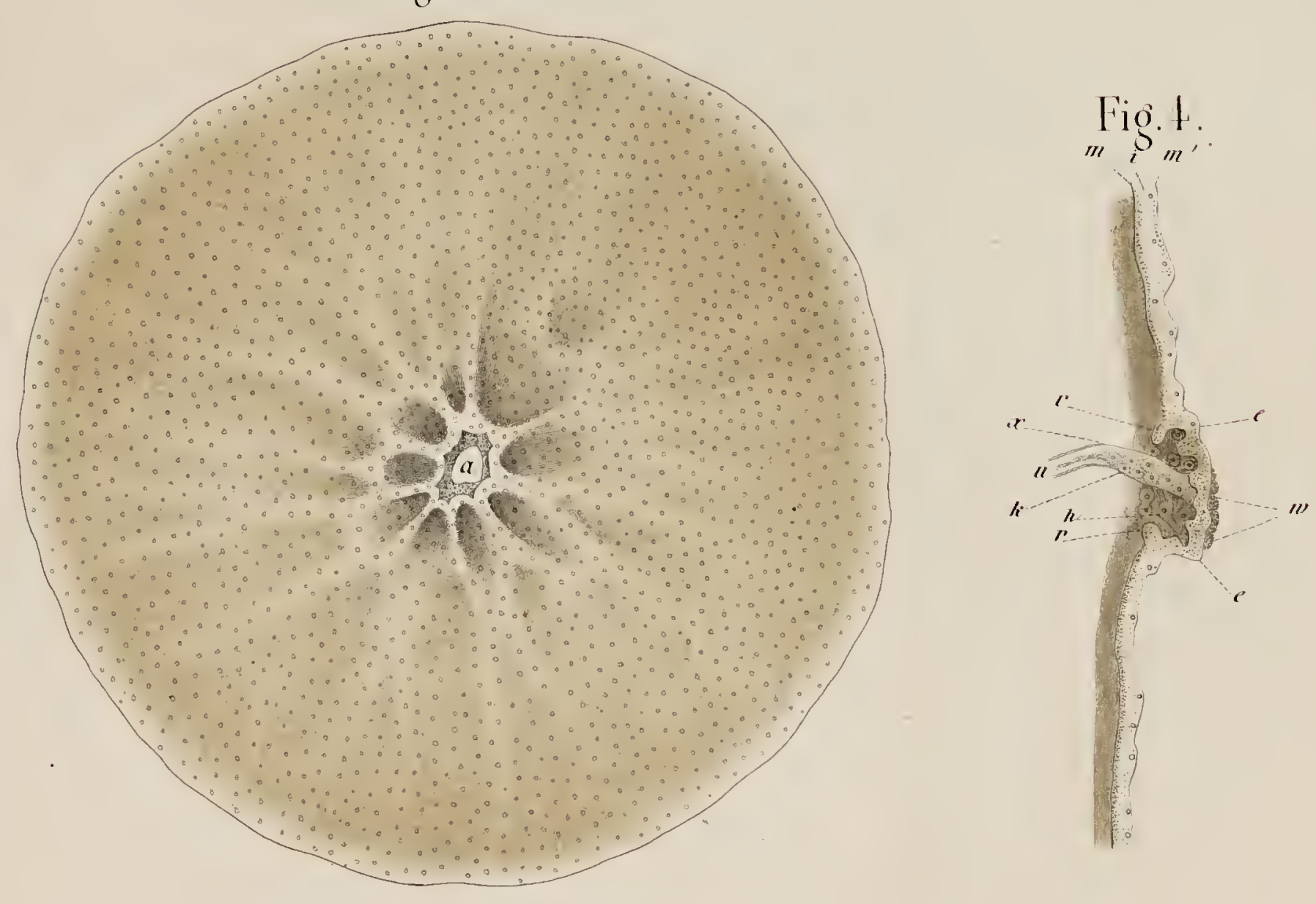

Fig. 8.

Fig. 6.

Fig. '.

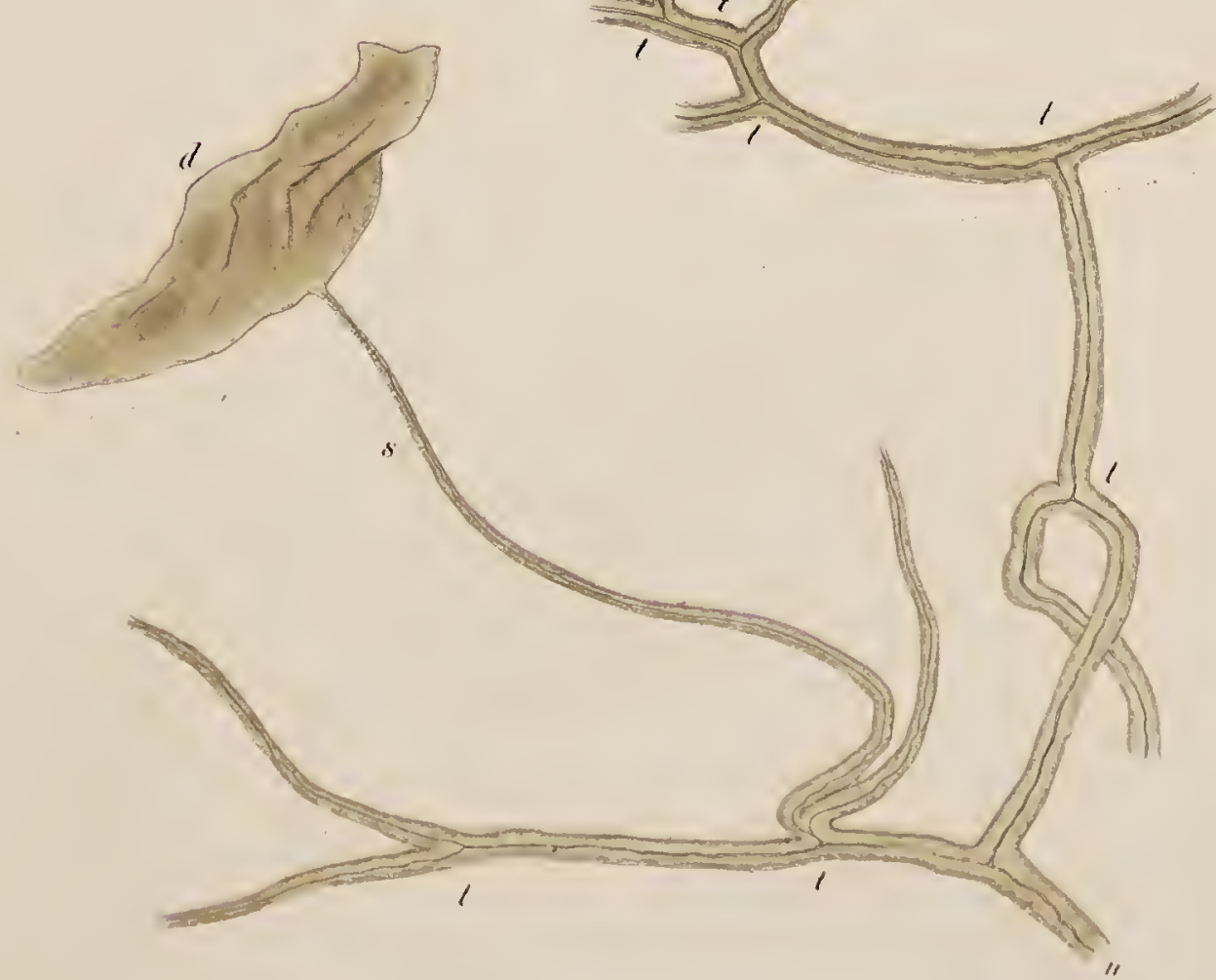

m.

Fig. 



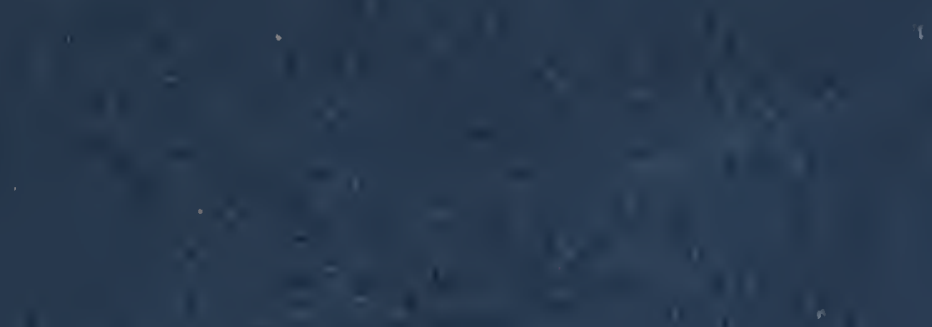

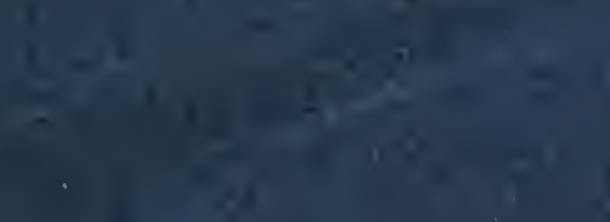

$x^{2}$

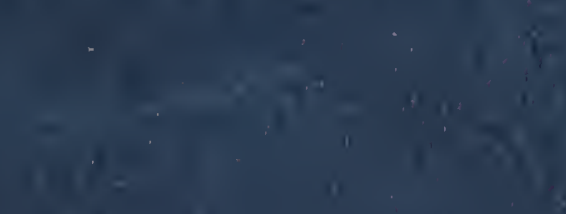

3

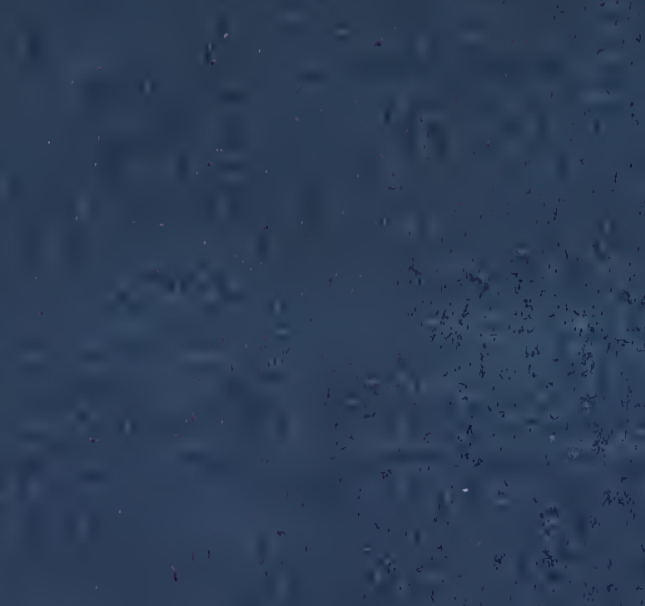

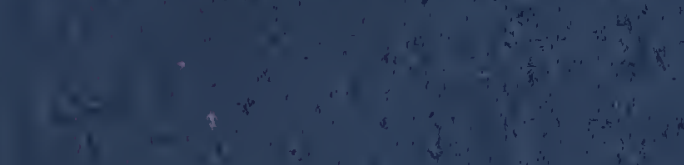




\section{Im Verlag von Wilhelm Eugelmann in LeIPzIG ist ferner erschienen:}

Apelt, Prof. E. F., Die Theorie der Induction. Mit 2 Figuren und einer Zahlentafel. gr. 8. 1854. br. Thlr. 1.10 Ngr.

Braun, Prof. Dr. Alexander, Betrachtungen über die Erscheinung der Verjüngung in der Natur, insbcsondere in der Lcbens - und Bildungsgeschichte der Pflanze. Mit 3 illuminirten Tafeln. gr. 4. 1851. brosch.

Thlr. 3.

Algarum unicellularium genera nova et minus cognita, praemissis observationibus de Algis unicellularibus in genere. Cum tabulis VI. 4 maj. 1855. br. Thlr. 3.

Carus, Prof. J. V., System der thierischen Morphologie. Mit 97 Holzschnitten. gr. 8. 1853. br. Thlr. 3.

- Zur nähern Kenntniss des Generationswechsels. Beobachtungen und Schlüsse. Mit zwei lithographirten Tafeln. gr. 8. 1849. brosch. $15 \mathrm{Ngr}$.

— Jahresbericht über die im Gebiete der Zootomio erschienenen Arbeiten. I. Bericht über die Jahre 1849-52. gr. 8. 1856 . br.

Thlr. 1. $15 \mathrm{Ngr}$.

Fischer, Dr. L. H., Orthoptera Europaea. Accedunt tabulae lap. inc. XVIII. quarum ultima color. gr. 4. 1854. cart.

Thlr. 15. Orthopterorum Europae conspectus systematicus. 8. 1854 . broch.

$10 \mathrm{Ngr}$.

Gegenbaur, Dr. Carl, Beiträge zur näheren Kenntniss der Schwimmpolypen (Siphonophoren). Mit 3 lithographirten Tafeln. gr. 4. 1854. br.

Thlr. 1. $10 \mathrm{Ngr}$.

- Untersuchungen über Pteropoden und Heteropoden. Ein Beitrag zur Anatomie und Entwicklungsgeschichte dieser Thiere. Mit 8 lithograph. Tafeln. gr. 4. 1855. 'Thlr. 8.

Geinitz, Prof. H. B., Die Versteinerungen der Steinkohlenformation in Sachsen. Mit 36 in Farb. gedruckten Steindrucktafeln. gr. Fol. 1855. In Mappe Thlr. 20.

- Geognostische Darstellung der Steinkohlenformation in Sachsen. Mit besonderer Berücksichtigung des Rothliegenden. - A. u. d. T. : Die Steinkohlen des Königreichs Sachsen in ihrem geognostischen und technischen Verhalten geschildert auf Veranlassung des Königl. Sächs. Ministerii des Innern. I. Abtheil. 23 Bog. Text in Folio und 12 in Farben gedruckten lithogr. Tafeln. gr. Folio. In Mappe

Thlr. 12.

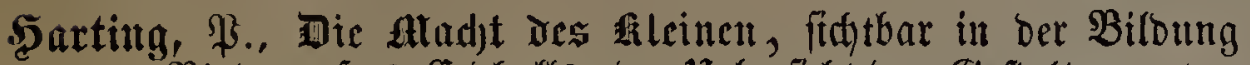

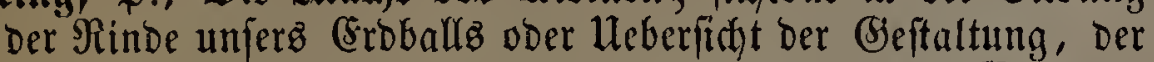

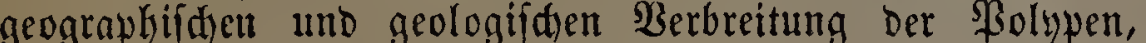

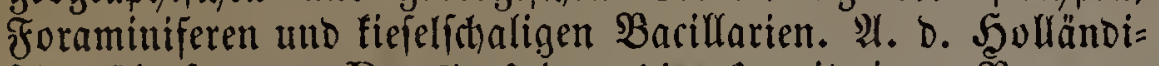
fden überiebt von Dr. A. sdjwarbkopf, mit einem Bortworte von 2 ll. 3. Schlcionen, Dr., Srof. in Sena. Mit 1 Titelfupfer

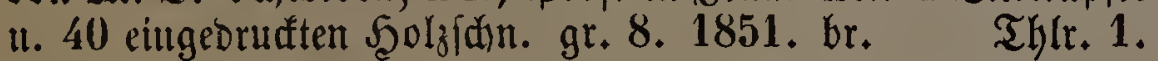

Hasse, Prof. Dr. K. E., Die Menschenblattern und die Kuhpockeneinimpfung, eine geschichtliche Skizze. Akademischer öffentlicher Vortrag gehalten im Grossrathssaale zu Zürich am 11. März 1852. Abgedruckt zum Besten eines in London beabsichtigten Monumentes für Jenner. gr. 8. 1852 . br.

$8 \mathrm{Ngr}$.

IIohl, Prof. Dr. Ant. Friedr., Lehrbuch der Geburtshülfe. Mit Einschluss der geburtshülfl. Operationen und der gerichtl. Geburtshülfe. Mit 76 Original-Holzschn. gr. 8. 1855. br.

Thlr. 5. $20 \mathrm{Ngr}$.

Kölliker, Prof. Dr. A., Mikroskopische Anatomio oder Gewebelehre des Menschen. Specielle Gewebelehre. Mit 4 lithographirten Tafeln und 435 Holzschnitten. gr. 8. 1850-1854. brosch.

Thlr. 9. $10 \mathrm{Ngr}$.

_- Haudbuch der Gewebelehre des Menschen. Für Aerzte und Studirende. Zweite Aufl. Mit 334 Holzschnitten. gr. 8. 1855. br.

Thlr. 3. $20 \mathrm{Ngr}$.
Kölliker, Prof. Dr. A., Die Siphonophoren oder die Schwimm polypen von Messina. Mit 12 lithøgraph. Tafeln. Fol 1853. geb.

Thlr. 8.

Lehmann, Prof. C. G., Handbuch der physiologischen Chemie. gr. 8. 1854 .

Lehrbuch der physiologischen Chemie. 3 Bände. 2. Aufl. 2. Umarbeitung. gr. 8. 1853. br.

Thlr. 8.

Leydig, Dr. Frz., Beiträge zur mikroskopischen Anatomie und Entwickelungsgeschichte der Rochen und Haie. Mit 4 Steindruck tafelñ. gr. 8. 1852. br. Thlr. 1. $10 \mathrm{Ngr}$.

Meyer, Prof. Herm., Lehrbuch der physiologischen Anatomio. Mit 235 Holzschnitten. gr. 8. 1856. br. Thlr. 3. $20 \mathrm{Ngr}$.

Mïller, Prof. Heinr., Anatomisch-physiolog. Untersuchungen über die Retina bei Menschen und Wirbelthieren. (Besonderer Abdruck aus der Zeitschrift für wiss. Zoologie. Bd. V.III.) Mit 2 Kupfertafeln. 8. 1856. br. Thlr. 1.

Naumann, Prof. C. F., Lehrbuch der Geognosie. 2 Bände. Mit einem paläontologischen Atlas von 70 Tafeln. gr. 8 . 1850-54. cart. $\quad$ Thlr. 23. Elemente der Mineralogie. Vierte vermelírte und verbesserte Auflage Mit 398 Figuren in Holzschnitt. gr. 8 . 1855. br.

Thlr. 3 Elemente der theoretischen Krystallographio.' Mit 36 Holzschnitten.

Thlr. 3 .

Radlkofer, Dr. Ludw., Die Befruchtung der Phanerogamen. Ein Beitrag zưr Entscheidung dès darüber bestehenden Streites. Mit 3 lithographirten Tafeln. gr. 4. 1856.

Thlr. 1. $10 \mathrm{Ngr}$. Der Befruchtungsprozess im Pflanzenreich -und sein Verhältniss zu dem im Thierreich. 8. 1856. br. $22 \frac{1}{2} \mathrm{Ngr}$.

Reichel, C. F., Ueber China-Rinden und deren chemische Bestand theile. 8. 1856. geh.

$7 \frac{1}{2} \mathrm{Ngr}$.

Rochleder, Prof. Fr., Phytochemie. gr. 8. 1854. br.

Thlr. 2. $71 / 2 \mathrm{Ngr}$.

Rose, G., Das krystallo-chemische Mineralsystem. Mit 10 Holzschnittẹn. gr. 8\% 1852 . br. Thlr. 1. $15 \mathrm{Ngr}$.

Schleiden, Prof. Dr. M. J., Handbuch der medicinisch. pharmaceutischen Botanik und botanischen Pharmacognosie. Erster Theil. Medicinisch - pharmaceutische Botanik. Mit 236 eingedruckten Figuren in Holzschnitt. gr. 8. 1852. br.

Thlr. 2. $20 \mathrm{Ngr}$. Die pflanze unt ihr Reben. Bopuläre Borträge. Bierte Auflage. Mit $14 \mathfrak{B l}$. in $\mathfrak{5}$ olzidin., ein in Farben geor. Titel= bild u. 5 Supfert. gr. 8. 1855. br.

Siebold, Brof. 6. Th. v., Ueber bie Band- und Blaftumürmer nebft einer Einleitung liber bie Entftehung Der Eingeweide= würme $\mathfrak{M i t} 36$ Scolzidjnitten. 8, 1854. br. $\quad 22^{1 / 2} \mathfrak{R g r}$.

- Wahre Parthenogenesis bei Schmetterlingen und Bienen. Ein Be trag zur Fortpflanzungsgeschichte dieser Thiere. Mit einer Kupfert. 8. 1856. br.

Stein, Prof. Friedr., Die Infusionsthiere auf ihre Entwickelungsgeschichte untersucht. Mit 6 Kupfertafeln. gr. 4. 1854. bi Thlr. 8 .

Stein, Prof. W., Chemische und chemisch-technische Untersuchung der Steinkohlen Sachsens. - A. u. d. T.: Die Steinkohlen des Königr. Sachsens etc. 2. Abtheil. gr. 4. 1857 .

Thlr. 1. $15 \mathrm{Ngr}$.

Zeitschrift für wissenschaftliche Zoologie, herausgegeben von Carl Th. von Siebold und Albert Kölliker. I.-VII. Bd. à 4 . Hefte ù. 1 Suppl.-Heft. VIII. Bd. 1-3. Heft. Mit 159 theils lithogr., theils in Kupfer gest. Tafeln. gr. 8 . 1848 - 56 . br.
Thlr. 43. $15 \mathrm{Ngr}$. 